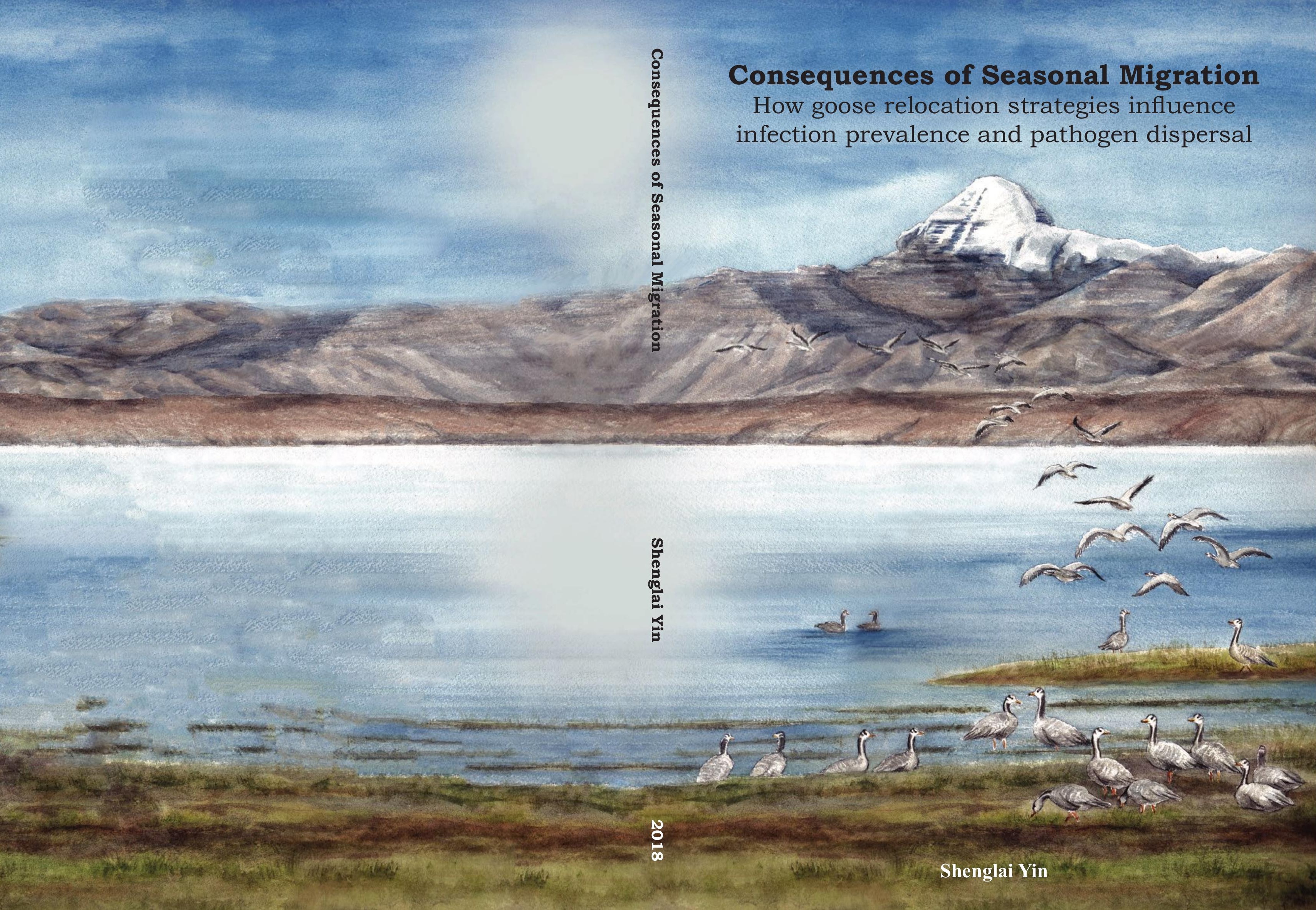




\section{Propositions}

1. Environmental transmission causes avian influenza outbreaks. (this thesis)

2. Migratory birds cannot lose avian influenza viruses via migratory escape.

(this thesis)

3. Applying what we know to explore unknowns, does not ensure truthful knowledge.

4. Invasive species are not disrupting the ecosystem.

5. Data ownership limits research.

6. Given the assumptions underlying models, the amount of time for the presentation of modelling work should be doubled for effective communication.

Propositions belonging to the thesis, entitled "Consequences of Seasonal Migration: How goose relocation strategies influence infection prevalence and pathogen dispersal"

Shenglai Yin

Wageningen, $4^{\text {th }}$ December 2018 


\section{Consequences of Seasonal Migration How goose relocation strategies influence infection prevalence and pathogen dispersal}

Shenglai Yin 


\section{Thesis committee}

\section{Promotors}

Dr W.F. de Boer

Associate professor, Resource Ecology Group

Wageningen University \& Research

Prof. Dr H.H.T. Prins

Professor of Resource Ecology

Wageningen University \& Research

\section{Other members}

Prof. Dr M.E. Visser, Wageningen University \& Research / Netherlands Institute of Ecology, Wageningen Prof. Dr A. Stegeman, Utrecht University

Dr H. van der Jeugd, Netherlands Institute of Ecology, Wageningen

Dr M. van Boven, National Institute for Public Health and the Environment, Bilthoven

This research was conducted under the auspices of the C. T. de Wit Graduate School for Production Ecology and Resource Conservation (PE\&RC). 


\title{
Consequences of Seasonal Migration How goose relocation strategies influence infection prevalence and pathogen dispersal
}

\author{
Shenglai Yin
}

Thesis

submitted in fulfilment of the requirements for the degree of doctor at Wageningen University

by the authority of the Rector Magnificus

Prof. Dr A. P. J. Mol,

in the presence of the

Thesis Committee appointed by the Academic Board

to be defended in public

on Tuesday $4^{\text {th }}$ December 2018

at 4 p.m. in the Aula. 
Shenglai Yin

Consequences of Seasonal Migration: How goose relocation strategies influence infection prevalence and pathogen dispersal,

148 pages.

$\mathrm{PhD}$ thesis, Wageningen University, Wageningen, the Netherlands (2018)

With references, with summaries in English, Chinese and Dutch

ISBN: 978-94-6343-504-8

DOI: https://doi.org/10.18174/457989 


\section{Contents}

Chapter $1 \quad$ General introduction

Chapter 2 No evidence that migratory geese disperse avian influenza viruses from breeding to wintering ground

Chapter 3 Effects of migration network configuration and migration synchrony on infection prevalence in geese

Chapter 4 Habitat loss facilitates infection outbreak and pathogen dispersal: An agent-based model of infected migratory waterfowl

Chapter 5 Comparing outbreak patterns of highly pathogenic avian influenza viruses between bar-headed goose and swan goose

Chapter 6 Synthesis

References

Summary

Samenvatting

摘 要

Affiliations of co-authors

Acknowledgments

Short biography

Publications

PE\&RC training and education statement

Colophon 


\section{Chapter 1}

General introduction 


\section{Short introduction of migration}

Many animals, including birds, mammals, insects and fishes, undertake seasonal movements between their breeding and wintering sites (Dingle and Drake 2007). Although the fundamental causes for migration are still debated, the most plausible hypotheses suggest adaption to spatially and temporally fluctuating resources or climate, or avoiding predation (McKinnon et al. 2010). Biologists have been fascinated by bird migration for decades (Alerstam and Lindström 1990; Moreau 1972). For example, Bengt Berg (1885-1967) followed migrtaory common crane Grus grus from Europe to find out their southmost wintering site in Africa in the 1920s.

Some bird species can undertake an incredibly long distance migration, and have excellent navigation skills, which allow them to re-find habitats at more or less the same time from year to year. For example, arctic terns Sterna paradisaea migrate 80,000 km each year from pole to pole despite their small size of only 100g (Egevang et al. 2010). Bar-tailed godwit Limosa lapponica migrate $11,000 \mathrm{~km}$ from Alaska to New zealand, which is the longest nonstop migration we known so far (Battley et al. 2012). Another particular fascinating case is the bar-headed goose Anser indicus, a medium-sized goose species (Takekawa et al. 2017), with an estimated global population size of 52,000-60,000 birds (Mundkur et al. 2017). Most bar-headed geese breed in specific wetlands in northern Mongolia (Takekawa et al. 2009), and seasonally cross the Qinghai-Tibet plateau to winter in the Lhasa region, some of them even fly over the Himalayas to winter in southern India (Takekawa et al. 2017). This singleseason migration is approximately $3000-5000 \mathrm{~km}$ long at an average height of about $5-8 \mathrm{~km}$ (Takekawa et al. 2017).

Bird migration has ecological, evolutionary and social consequences (Altizer et al. 2011; Newton 2007). It has direct trophic effects, such as changing trohpic relationships by providing consumers and competitors, and indirect vector effects such as transporting diseases, nutrients, seeds and energy (Thomas et al. 2003). For example, the seasonal visit of migratory waders in Plymouth (USA) significantly decrease local prey density (Schneider and Harrington 1981). Eleanora's Falcon Falco eleonorae can disperse seeds over hundreds kilometres, transporting seeds from mainland to islands (Viana et al. 2016). Moreover, seasonal migration can cause physiological and phenotypical evolution and adaption in migratory birds (Owen and Moore 2006; Thomas et al. 2003). For example, bar-headed geese have relatively larger lungs compared to other migratory waterfowl species and can increase 
their breathing rate up to 7 times the normoxic resting rate when exposed to severe hypoxia (Scott and Milsom 2007; Black and Tenney 1980; Scott et al. 2011). These adaptions can help them efficiently take in and transport $\mathrm{O}_{2}$ while flying at extremely high altitude, and may contribute to their rapid elevation climbing (Hawkes et al. 2011). Finally, the seasonal visit of migratory bird species may cause human-animal conflicts. For example, visiting of migratory geese and swans in Europe and America caused conflicts with farmers by foraging on agriculture land (Fox et al. 2016; Silke Bauer et al. 2018).

\section{Migration affects pathogen dynamic}

Among these various consequences of bird migration (Seebacher and Post 2015), pathogen dispersal and host-pathogen interaction have attracted a lot of attention because they affect both wildlife and human health (Khatchikian et al. 2015; Boulinier et al. 2016; Reed et al. 2003). For example, a new strain of West Nile Virus was first isolated at Romania in 1996, and it was successively isolated in the Middle East and other European countries including Morocco, Tunisia, Israel and Italy in 1997 (Sejvar 2003). In 1996, it emerged in New York, and was subsequently dispersed across the United States, reaching California and Florida within 4 years. West Nile Virus has caused more than 45,000 confirmed human infection cases in United States in 1999-2016 (https://www.cdc.gov/westnile/statsmaps/cumMapsData. html\#one), and their rapid dispersal was correlated strongly with bird migration (Di Giallonardo et al. 2016).

For a better understanding of how bird migration affects pathogen dispersal and infection prevalence dynamics, empirical studies such as tracking bird migration (Rappole et al. 2000; Prosser et al. 2009, 2016), analysing spatial and temporal correlation between bird movement and infection outbreak (Si et al. 2009; Verhagen et al. 2014), phylogenetic relationships among infection outbreaks (Tian et al. 2015; Chen et al. 2005) and theoretical modelling (Breban et al. 2009; Rohani et al. 2009) have been carried out.

On the one hand, the West Nile Virus example illustrated that bird migration can facilitate pathogen dispersal and infection prevalence. Another well-known example is the dispersal of Avian Influenza Viruses (AIVs). For example, the global dispersal of H5 subtype is spatially and temporally correlated with bird migration (Verhagen et al. 2015; Si et al. 2009; Xu et al. 2016). Furthermore, previous studies have also shown that the arrival of migratory waterfowl species such as mallard Anas platyrhynchos, greater white-fronted goose Anser albifrons, and whooper swan Cygnus cygnus on their overwintering site can amplify AIVs infection 
prevalence (Verhagen et al. 2014; Yin et al. 2017; Newman et al. 2009).

On the other hand, bird migration, especially long-distance migration, can reduce pathogen dispersal and infection prevalence by so-called migratory escape or migratory culling (Altizer et al. 2011). The migratory escape means that, if a pathogen can persist in the environment and be infectious (e.g., helminths, ectoparasites, and microbial pathogens), migration allows the host to escape from infectious sites and relocate to sites with lower infection risk (Loehle 1995). For example, lesser black-backed gulls Larus fuscus with a long-distance migration have a lower seroprevalence of AIVs compared to those with shorter migration distances (Arriero et al. 2015).

Migratory culling means that, if a pathogen can cause negative impacts on host conditions (e.g., reducing intake rate, and thereby reduce body mass, increasing mortality and/or reducing migration capacity), the infected hosts can be separated from the population, and thereby, reducing the infection prevalence (Loehle 1995; Altizer et al. 2011). For example, bewick's swans Cygnus columbianus bewickii infected with low pathogenic AIVs (LPAIVs) delayed their migration and showed a reduced migration distance compared with healthy individuals (van Gils et al. 2007). Migratory escape and culling have been observed not only in migratory birds, but also in other migratory animals such as reindeer Rangifer tarandus (Folstad et al. 1991) and monarch butterflies Danaus plexippus (Bradley and Altizer 2005).

Overall, previous efforts showed that bird migration affects pathogen dispersal and infection dynamics in migratory populations, but its effects may vary from one host-pathogen interaction to another (Altizer et al. 2011; McKay and Hoye 2016). Due to the huge potential threats for wildlife and human health, better understanding of how bird migration affects pathogen dispersal and pathogen infection dynamic in a migratory population is urgently needed, especially of generalist pathogens that infect multiple species.

\section{Spatio-temporal migration patterns}

Resting on stopover sites is a crucial feature for most migratory birds to complete their seasonal migration (Bowlin et al. 2010; Zhao et al. 2017; Yamaguchi et al. 2008), because these stopover sites are the places where they can refuel and prepare for the next bout of migration (Navedo et al. 2010). It is especially true for migratory goose species, which commonly have a long-distance migration and follow a capital breeding strategy, i.e., migratory birds store their body mass along migration for maximizing their breeding success 
(Stephens et al. 2009; Si et al. 2018).

Stopover sites, together with breeding site and overwintering sites, are connected in a migration network by bird movement among the sites. Birds migration show a spatial pattern, selecting some stopover sites over others, and thereby influence the network configuration. For example, migratory birds tend to use the same stopover sites successively during their autumn migration to minimize migration duration and arrive at their overwintering sites on time, but they tend to use different stopover sites in a parallel network configuration during their spring migration to track food availability along their migration route and reduce competition (Kölzsch et al. 2016; Si et al. 2009).

Apart from the various network configurations, migratory birds from one population vary in their timing of departure as well (i.e. synchrony of departure) due to e.g., differences in body condition, competition for limited resources, and optimization of mating opportunities (Morbey and Ydenberg 2001; Muraoka et al. 2009). Field observations revealed that departure synchrony for spring migration varies from weeks to months among waterfowl species such as common teal Anas crecca, bar-headed goose, greylag goose Anser anser and mallard (Gupta et al. 2010; Hornman et al. 2015).

These spatial configurations and the levels of temporal synchrony in departure may influence pathogen dispersal and infection prevalence in migratory populations by affecting contact probabilities among birds, aggregation size and resting periods at stopover sites. For example, synchronized migration (i.e., birds migrate together in large flocks) might be associated with higher infection prevalence, because these birds have more frequent contacts with each other (Buehler and Piersma 2008; Gaidet et al. 2012; Altizer et al. 2011). However, the influences of different spatial and temporal migration strategies on pathogen dispersal and infection prevalence in migratory populations have not been examined yet.

Furthermore, spatial and temporal patterns of goose migration depend on external variables. The spatial configuration largely depends on habitat availability along migration routes, however, habitat availability is declining in some areas. For example, $30 \%$ of habitat of migratory waterfowl has been lost in 1990-2000 in areas of southeast China (Gong et al. 2010; Zhang et al. 2015; Navedo et al. 2010). Moreover, the departure synchrony is influenced by, e.g., ambient temperature (Seebacher and Post 2015; Fox and Walsh 2012). It has been observed that greylag goose, eurasian wigeon Anas penelope and pale-bellied brent goose Branta bernicla hrota have either advanced their spring migration timing or delayed 
their autumn migration timing due to warming ground temperatures (Clausen and Clausen 2013; Lehikoinen and Jaatinen 2012).

The effects of spatial configuration and temporal migration synchrony have rarely been examined. Therefore, I used various modelling techniques to examine their effects on pathogen dispersal and infection prevalence in a migratory population.

\section{From a network perspective}

In the last decade, network analysis has been become a new approach to study the mechanisms of dispersal, such as human transport over the world airport network and goods transportation in the global cargo network (Guimerà and Amaral 2004; Kaluza et al. 2010), because network characteristics affect the likelihood of dispersal (Banks et al. 2015).

Network approaches have been used to study pathogen dispersal as well. For example, contact networks were used to simulate the dispersal of severe acute respiratory syndrome (Meyers et al. 2005), networks of cattle and sheep farms were used to analyse foot-andmouth disease outbreaks, and transportation networks of poultry animals were used to analyse dispersal of HPAI H5N1 (van Kerkhove et al. 2009).

The most discussed network characteristics that have huge impacts on pathogen dispersal are scale-free and small-world networks (Banks et al. 2015). Scale-free networks are heterogeneous since most sites possess few links and a few sites possess many links (Barabási and Albert 1999). A network is classified as a scale-free network when its logtransformed degree distribution (i.e., number of links a site has) follows a power law distribution (Silk et al. 2017). Small-world networks are homogeneous since sites have approximately the same number of links, but a small-world network possesses characteristic shortcuts and high clustering, so that any site can be reached from any other site in just a few steps (Barabási and Albert 1999; Banks et al. 2015).

In a scale-free network, pathogens can be quickly dispersed over the whole network when a hub site (i.e., site with a relatively high degree) is infected. In a small-world network, pathogens can be quickly dispersed over the whole network because the pathogen can easily infect other sites in just a few steps. These two network types allow a pathogen to be dispersed efficiently, even if it is not highly infectious or well adapted for long-distance dispersal (Banks et al. 2015). 
Most real life networks possess both scale-free and small-world characteristics, e.g., world airport network (Guimerà and Amaral 2004) and trade network (Kaluza et al. 2010; Caton et al. 2006). These characteristics of real life networks may be the result of how links were generated, namely by preferential attachments to a well-connected site, or by preferential attachments to nearby sites (Barthélemy 2011; Li et al. 2012). For example, a company that wants to expand its business prefers to join such an organization of other companies and preferably cooperates with one company that already has well-established business partnerships (Li et al. 2012).

Bird migration networks may also possess these scale-free and small-world characteristics. However, the characteristics of bird migration networks have rarely been examined in empirical studies or in theoretical work, although it can provide a better understanding of the pathogen dispersal mechanism.

\section{Short introduction of avian influenza virus}

AIVs is a type of influenza virus that is adapted to infect birds, especially waterfowl, i.e., ducks, geese and swans. AIVs infect mainly birds, but in some cases, it can also infect mammals such as swine, horses, whales, bats and humans (Tong et al. 2013; Webster et al. 1992; Olsen et al. 2006). AIVs have many subtypes due to the antigenic properties of two glycoproteins (i.e., haemagglutinin and neuraminidase) on the surface of the viral particle (Webster et al. 1992; Ellis et al. 2004). To date, 16 HA subtypes (H1 to H16) and 9 NA subtypes (N1 to N9) were isolated from wild birds, and the combinations of one HA and one NA result in various subtypes of AIVs (Olsen et al. 2006). Furthermore, AIVs can be classified into two groups: low pathogenic AIVs (LPAIVs) and highly pathogenic AIVs (HPAIVs) based on the illness that they cause in chickens. In most cases, LPAIVs infection in wild birds only causes mild symptoms. However, LPAIV subtypes H5 and H7 can mutate to HPAIVs when multiple LPAIV subtypes co-infect one host, especially in poultry farms with low bio-security and high density of domestic birds (Alexander 2007; Takekawa et al. 2010).

AIVs outbreaks, especially HPAIVs outbreaks, attract public concerns for animal and human health (Zhou et al. 2017; Ligon 2005). A well-know example is the outbreak of HPAI H5N1 at Qinghai Lake region in 2005, during which more than 6000 wild birds, such as barheaded goose, great black-headed gull Larus ichthyaetus and brown-headed gull Larus brunnicephalus, were found dead (Chen et al. 2005). Moreover, HPAI H5N1 has caused 
more than 850 confirmed human cases since 2013 , with a nearly $50 \%$ fatality rate (WHO 2018). Another subtype HPAI H7N9 has caused more than 1500 confirmed humans cases with a $40 \%$ fatality rate (WHO 2018; Kile et al. 2017). Furthermore, HPAIV outbreaks in poultry farms can cause substantial economic losses. For example, at least 150 million poultry birds were culled for preventing HPAI H5N1 spreading during 2015-2017 (www.oie.int).

Since the risks for HPAIVs outbreaking are high when the HPAIVs are dispersed into a new location, a better understanding of their dispersal mechanisms is urgently needed for planning better field surveillance programs (van Dijk 2014; Verhagen et al. 2015; Xu et al. 2013) and predicting HPAIV outbreaks (van Dijk 2014; Prosser et al. 2013). Meanwhile, since LPAIVs are predecessors for HPAIVs, understanding of their dispersal mechanisms is urgently necessary as well (Cappelle et al. 2014; Verhagen et al. 2014; Yin et al. 2017).

\section{AIVs travel the world}

Bird migration, poultry production practices, legal and illegal wildlife and domestic bird trade, and human travel have all been suggested being responsible for AIVs dispersal (Choi et al. 2016; Takekawa et al. 2010). Among these factors, migration of waterfowl species is one of the most discussed. First of all, waterfowl species are the main hosts for AIVs in the wild (van Dijk 2014; Kleijn et al. 2010; Munster et al. 2007). Moreover, migratory waterfowl species travel over vast areas regularly twice a year (Rappole 2013), and some of them, such as several duck species, can be asymptomatic carriers of AIVs (van Dijk et al. 2015; Kida et al. 1980). Therefore, migration of waterfowl species provides good opportunities for a rapid dispersal of AIVs. However, the following questions are not fully understanded yet: Are migratory waterfowl able to migrate while infecting with AIVs? Are the migratory waterfowl responsible for AIVs dispersal? Can a migratory population sustain AIVs infection during migration?

AIVs can be transmitted between infected and susceptible birds via airborne secretions by direct contact, but faecal-oral transmission is more common and efficient, especially for dabbling ducks such as mallard that shed AIVs contaminated faeces into the water (Kleijn et al. 2010; Hoye et al. 2011; van Dijk 2014). A susceptible bird can be infected by ingesting water that was contaminated with AIVs (Webster et al. 1992). Seasonal dynamics of AIVs infection prevalence in mallard is relatively well studied: it increases immediately after the breeding season when there are a lot of immunological naïve juvenile birds in the population, 
and gradually decreases during autumn migration, reaching its lowest level during spring migration (Latorre-Margalef et al. 2014). This pattern suggests that migratory duck species are infected with AIVs at their northern breeding sites, and they can disperse these AIVs during their southward autumn migration (Galsworthy et al. 2011; Gunnarsson et al. 2012; Gilbert et al. 2006; Hulse-Post et al. 2005). However, the seasonal dynamics of AIVs infection prevalence in other waterfowl species, such as in several geese species, is relatively less studied (Kleijn et al. 2010). Thereby, tt is not clearly known what role migratory geese play in dispersing AIVs.

Furthermore, few studies have compared HPAIV outbreak patterns that occurred in different waterfowl species. For example, swan goose Anser cygnoides and bar-headed goose are two congeneric species with large overlapping breeding areas, and they can produce fertile offspring (Ottenburghs et al. 2016). However, HPAIVs outbreaks were rarely reported in swan goose, but frequently reported in bar-headed goose (Chen et al. 2005; Takekawa et al. 2010). This may relate to different contact with HPAIVs outbreaks areas along their migration routes, or with different contacts with domestic birds which are possibly a source of HPAIVs (Fearnley 2015; Takekawa et al. 2010). A better understanding about why these congeneric species have distinctive outbreak patterns may provide more insights into the interaction between HPAIVs and migratory waterfowl species, and thereby the mechanism of HPAIVs dispersal.

\section{Thesis outline}

Year-round surveillance of migratory duck species suggested that they are infected with AIVs at their breeding sites, and that they can disperse these AIVs along their autumn migration. However, similar year-round surveillance in migratory goose species is rare. It has been suggested that migratory goose species are rarely infected with AIVs at their breeding sites, but are infected with AIVs at their overwintering sites (Kleijn et al. 2010). This may indicate that migratory goose species have less opportunity to be exposed to AIVs in the north and that they play less of a role in dispersing AIVs during their autumn migration. However, migratory goose species may still get infected on their overwintering sites, and disperse the AIVs from there.

In Chapter 2, I analyse LPAIVs infection data that were collected from three migratory goose species (i.e., bean goose Anser fabalis, barnacle goose Branta leucopsis and greater white-fronted goose) from their breeding sites, stopover sites and overwintering sites. I 
examine LPAIVs spatial-temporal dynamic of infection prevalence in these migratory goose species and discuss their role in dispersing AIVs. I aim to answer:

1) whether LPAIVs infection in migratory goose species is absent on their breeding sites?

2) whether the infection prevalence increases over time on wintering sites?

3) whether the prevalence of infection reduces to intermediate levels on spring stopover sites?

In Chapter 3, I examine the effects of spatial and temporal migration patterns on dynamic of LPAIVs infection prevalence in a migratory population. I apply a discrete-time SIR (Susceptible-Infected-Recovered) model (de Jong et al. 1995), with environmental transmission and migration, to various migration strategies, including networks with serial, and/or parallel stopover sites, and with various levels of migration synchrony. I aim to answer:

1) how does the configuration of a migration network affect infection prevalence?

2) does high synchrony in timing of migration increase infection prevalence?

3 ) is there a specific migration pattern, regarding the number of stopover sites and migration synchrony that minimizes pathogen infection?

As previously mentioned, characteristics of migration networks, especially scale-free and small-world networks, are efficient in dispersing pathogen. Habitat loss, however, may change the network characteristics and consequently affect the pathogen dispersal and infection prevalence in migratory populations by confining migratory birds to fewer remaining sites. In Chapter 4, I generate migration networks of greater white-fronted goose in the East Asian- Australasian Flyway with various habitat loss scenarios. I use Agent-based models, with SIR-type infection dynamics, to examine infection prevalence and pathogen dispersal among sites in various migration networks. I aimed to answer:

1) whether sites loss facilitates infection prevalence in migratory birds?

2) whether sites loss increases the probability of pathogen infecting in remaining sites?

In Chapter 5, I summarize the historical HPAIV outbreaks in swan goose and bar-headed goose and compared their contact opportunities with HPAIV outbreaks sites and domestic 
birds in their migration corridors. I also discuss the possible influences of historical exposure to domestic birds and migration strategy on their HPAIV outbreak patterns. Their migration corridors were estimated from GPS tracking data by using a dynamic Brownian Bridge Movement Model (dBBMM).

Finally, in Chapter 6, I discuss my main findings from each chapter, and generalize the findings to a broader context that related to the general understanding on pathogen dispersal and host-pathogen interaction. 


\section{Chapter 2}

No evidence that migratory geese disperse avian influenza viruses from breeding to wintering ground

S. Yin, D. Kleijn, G.J.D. M. Müskens, R.A.M. Fouchier, J.H. Verhagen, P.M. Glazov, Y. Si, H.H.T. Prins, W.F. de Boer (2017). No evidence that migratory geese disperse avian influenza viruses from breeding to wintering ground. Plos ONE 12(5): e0177790. 


\begin{abstract}
Low pathogenic avian influenza virus can mutate to a highly pathogenic strain that causes severe clinical signs in birds and humans. Migratory waterfowl, especially ducks, are considered the main hosts of low pathogenic avian influenza virus, but the role of geese in dispersing the virus over long-dsusceptistances is still unclear. We collected throat and cloaca samples from three goose species, bean goose Anser fabalis, barnacle goose Branta leucopsis and greater white-fronted goose Anser albifrons, from their breeding grounds, spring stopover sites, and wintering grounds. We tested if the geese were infected with low pathogenic avian influenza virus outside of their wintering grounds, and analysed the spatial and temporal patterns of infection prevalence on their wintering grounds. Our results show that geese were not infected before their arrival on wintering grounds. barnacle geese and greater white-fronted geese had low prevalence of infection just after their arrival on wintering grounds in the Netherlands, but the prevalence increased in successive months, and peaked after December. This suggests that migratory geese are exposed to the virus after their arrival on wintering grounds, indicating that migratory geese might not disperse low pathogenic avian influenza virus during autumn migration.
\end{abstract}




\section{Introduction}

Pathogens can strongly influence host populations by reducing activity, reproduction or survival (De Crespigny and Wedell 2006; Burthe et al. 2008; Bradley and Altizer 2005). Many pathogens are capable of infecting more than one host species. The avian influenza viruses (AIVs), for example, are highly infectious to a wide range of wildlife, domestic animals, and humans (van Dijk et al. 2015; WHO 2018; Chen et al. 2005; Claas et al. 1998). In 2016, a highly pathogenic AIV (HPAIV) H5N8 was isolated from water birds in Russia, rapidly followed by isolations in India and Europe (World Organization for Animal Health 2017). The highly infectious and fast spread of AIV has boosted research into the presence and dynamics of this pathogen in wild birds.

Based on their ability to cause disease in chickens, AIVs are characterized by two types: HPAIV, such as the one isolated in 2016, and low pathogenic AIV (LPAIV). The latter occurs more frequently in wild birds. When they are infected with LPAIV, wild birds do not show any clinical signs. Therefore, the migration of wild birds might contribute to the dispersal of LPAIV. Insights into the dynamics of LPAIV infection in migratory wild birds can help us to better understand and predict the spatial and temporal distribution of LPAIV outbreaks.

Most of what is known about the ecology of LPAIV prevalence is based on information from duck species such as mallard Anas platyrhynchos. Ducks are considered the main hosts of LPAIV, because their aquatic habits facilitate transmission, spread, and persistence of LPAIV (Webster et al. 1992; Garamszegi and Møller 2007). Previous studies from Northern Hemisphere have shown that LPAIV circulates year-round in ducks, and the infection peaks just after the breeding season when the population comprises many immunologically naive juveniles (Krauss et al. 2004; Wallensten et al. 2007). LPAIV prevalence typically declines after the breeding season, from as high as $60 \%$ during the post-breeding migration to as low as $0.25 \%$ during spring migration (Olsen et al. 2006). Many ducks are long-distance migrants. They encounter migratory birds from other flyways and aggregate in large numbers at stopover sites during migration. Aggregation may facilitate outbreaks of LPAIV infection because the virus can be more rapidly transmitted between individuals that occur in high density (Krauss et al. 2004; Gaidet et al. 2012). Long-distance migrations, encounters with other birds, and aggregation of many duck species such as mallard could provide an 
explanation for why AIV disperse over long distances so fast (Keawcharoen et al. 2008; Gilbert et al. 2006).

However, it is unlikely that all migratory waterfowl have a similar role in the dispersal of LPAIV. Other waterfowl, such as geese, might only be secondary hosts (Kleijn et al. 2010). Geese may become infected after exposure to LPAIV from a primary host, but lose the LPAIV rapidly (Kleijn et al. 2010). Furthermore, some species, such as greater white-fronted goose, breed at higher latitudes than mallard. These more northerly distributed geese may be less unlikely to be exposed to LPAIV. Therefore, it has been proposed that geese are not infected with LPAIV during their breeding phase (Kleijn et al. 2010), which means that they might have no LPAIV infection when they start their autumn migration, and thereby, play a limited role in dispersing LPAIV from their breeding grounds along the migratory flyways. However, year-round studies of LPAIV prevalence in goose species are rare and we still lack robust evidence that LPAIV is absent in geese during part of their annual cycle.

Here, we examined prevalence of LPAIV infection in three arctic-breeding goose species, bean goose Anser fabalis, barnacle goose Branta leucopsis and greater white-fronted goose Anser albifrons. These species have been identified as hosts of AIV (Munster et al. 2007), and they are abundant wintering goose species in central-western Europe where they aggregate in large numbers and share stopover sites and wintering grounds with high densities of a wide variety of ducks. We studied these three goose species that breed in tundra and high-latitude boreal forest wetlands from approximately June to September. After the breeding season, a large part of the population migrates to the Netherlands for overwintering. Bean geese and greater white-fronted geese also winter in large numbers in Hungary (Underhill et al. 2001). Bean geese and greater white-fronted geese arrive in large numbers at the Netherlands in November-December, and leave in February-March, while barnacle geese arrive in October and leave in March (Underhill et al. 2001). During the winter of 2012-2013, there were more than 190,000 bean geese, 750,000 barnacle geese and 760,000 greater whitefronted geese overwintering in the Netherlands (Hornman et al. 2015).

We compared the prevalence of LPAIV infection in these three species on their breeding grounds, wintering grounds, and spring stopover sites. As these goose species might be merely secondary hosts of LPAIV, we expect them to be largely free of LPAIV on the breeding grounds, and we expect high prevalence of LPAIV on the wintering grounds, and then especially to the middle or later part of their wintering period, as the LPAIV is assumed 
to be transmitted only after arrival at these wintering grounds. In a previous study carried out in Snow geese Chen caerulescens from North America, prevalence of AIV infection declined in 4 out of 5 spring migrations. Therefore, we also expect an intermediate level of infection in spring migration (Samuel et al. 2015). We specifically tested 1) if LPAIV infection in all three goose species is absent on their breeding grounds; 2) if the prevalence of infection increases over time on wintering grounds; 3 ) and if the prevalence of infection reduces to intermediate level on spring stopover sites. As we know that factors such as age, body condition, and sex may influence prevalence of LPAIV infection in geese (van Dijk et al. 2015; Kleijn et al. 2010), we also included these factors into our analyses to compare their effects with that of temporal patterns.

\section{Methods}

\section{Ethics statement}

The Animal Ethics Committee of the Erasmus Medical Center (Stichting DEC Consult) approved these studies permit number 122-07-09, 122-08-12, 122-09-20, 122-10-20 and 122$11-31$.

\section{Samples}

We used data of LPAIV infection in bean geese, barnacle geese and greater white-fronted geese that were collected between 2002 and 2013 within the framework of AIV surveillance programs (Verhagen et al. 2014). Geese were caught and tested for AIV infection on their breeding grounds, spring stopover sites, and wintering grounds. All sampled geese were also weighed, aged and sexed, and wing length and head length were measured. All individuals were ringed before release. Samples from wintering grounds were mainly taken in the Netherlands, one of the most important wintering grounds for migratory waterfowl in centralwestern Europe (Madsen and Cracknell 1999). Dutch samples $(n=8,196)$ were from geese caught in November-February between late 2006 and early 2013. Other samples $(n=764)$ were obtained from their breeding grounds, wintering grounds outside the Netherlands and spring stopover sites between 2002 and 2013. Samples from the wintering grounds outside the Netherlands were mainly from Hungary, another important wintering ground for migratory birds (Madsen and Cracknell 1999). Samples from breeding grounds were mainly from the Kolguev Island, Russia, where the largest Russian breeding population of greater white-fronted geese and a significant proportion of the barnacle geese can be found. Samples 
from spring stopover sites were mainly from Kologriv, Russia, an important spring stopover site of migratory geese. The breeding grounds and the spring stopover sites are located on the flyway of the greater white-fronted geese population that winters in the Netherlands (Kölzsch et al. 2016). The sampled geese were caught by means of live decoys, mechanical clap-nets, cannon nets, or standing nets. A small part of our data had been analysed in previous studies (Lewis et al. 2013; Kleijn et al. 2010).

\section{Virus detection}

Sterile cotton swabs were used to collect cloaca, throat or combined cloaca-throat samples from each individual goose. Samples were stored in transport medium at $4{ }^{\circ} \mathrm{C}$ for maximally two weeks until transported to the laboratory, where samples were stored at $-80{ }^{\circ} \mathrm{C}$ until testing (Kleijn et al. 2010). RNA was isolated by the Magna-Pure LC system with the Magna-Pure LC total nucleic acid isolation kit (Roche Diagnostics, Almere, the Netherlands), and the AIVs were detected by a generic real-time reverse transcriptase PCR (RRT-PCR) assay targeting the matrix (M) gene (M RRT-PCR). Amplification and detection were performed on an ABI 7700 machine with a TaqMan EZ RT-PCR core reagents kit (Applied Biosystems, Nieuwerkerk aan den IJssel, the Netherlands) and $20 \mu 1$ of RNA eluate in an end volume of $50 \mu \mathrm{l}$. A more detailed method description can be found in previous studies (Munster et al. 2009; Kleijn et al. 2010).

\section{Data analysis}

The prevalence of infection was expressed as the percentage of positive samples in each group of interest (e.g., species or season). As the sample sizes from outside the Netherlands were low, we used straight-forward proportion tests on the total number of samples from each location to examine if prevalence of infection differed among breeding grounds, spring stopover sites, wintering grounds in Hungary, and wintering grounds in the Netherlands.

To determine if the prevalence of infection on the wintering grounds was significantly lower directly after the arrival of migratory geese compared to later months, we only used the dataset from the Netherlands. Because sample size varied dramatically among years, we furthermore restricted our analysis to the years with more than 200 samples. Sample size in each year is shown in Table S2.1.

We constructed Generalized Linear Models (GLMs) for each species, assuming a binomial 
error distribution, and using a logit link function. The response variable was infection status (binomial), and the predictor variables included year (categorical), month (categorical), sex, age, body condition, interaction between year and age, and interaction between year and body condition. Body condition index was calculated as described in a previous study (SchulteHostedde et al. 2005). We used the first principle component (PC1) of a PCA analysis of wing length and head length as an index of body size. Next, the index of body size and logtransformed body weight were included in an ordinary least squares (OLS) regression to calculate the residuals. The residuals were used as an index of body condition, and the individual with a greater and positive residual was considered to have a better body condition than those with a lower residual (Schulte-Hostedde et al. 2001).

We used a multi-model inference approach to determine the best set of models to describe the variation in prevalence of infection. In total, 52 models were ranked with ascending AICc (Akaike information criterion corrected for small sample size) scores for each species. The top model sets were selected, using the criterion AICc $<2$ (Grueber et al. 2011). To account for model selection uncertainty, model averaging was carried out using the full-model method (Scheper et al. 2014). For barnacle geese and greater white-fronted geese, we chose the top model to predict the prevalence of infection and examine the effect of month. For bean geese, we chose the second model form the rank because it includes the variable month. Tukey's post hoc test was used to test for differences in prevalence among years and months. Effect of age on prevalence of LPAIV infection in greater white-fronted goose was examined in each year separately. All statistical and modelling analyses were carried out in R 2.11.0 (R Development Core Team 2016).

\section{Results}

\section{LPAIV infection in different parts of the flyway}

Out of the 268 samples collected on breeding grounds and 297 on spring stopover sites, none tested positive for LPAIV. LPAIV infection, however, was detected in samples from wintering grounds in both the Netherlands and Hungary (Table 2.1). Proportion test confirmed that prevalence of infection on the wintering grounds (both in Hungary and the Netherlands) was significantly higher than that on the breeding grounds or spring stopover sites $(\mathrm{df}=3, \mathrm{Z}$ score $=8.69, \mathrm{P}<0.001)$. 
Table 2.1 Prevalence of LPAIV infection and sample sizes ( $\mathrm{N}$ positive/ $\mathbf{N}$ total) of bean goose Anser fabalis, barnacle goose Branta leucopsis and greater white-fronted goose Anser albifrons at breeding grounds, spring stopover sites and wintering grounds in Hungary and the Netherlands.

\begin{tabular}{lcccc}
\hline Locations & bean goose & barnacle goose & $\begin{array}{c}\text { greater white- } \\
\text { fronted goose }\end{array}$ & Total \\
\hline Breeding grounds & $0(0 / 22)$ & $0(0 / 9)$ & $0(0 / 237)$ & $0(0 / 268)^{\mathrm{a}}$ \\
Spring stopovers & $0(0 / 10)$ & $0(0 / 2)$ & $0(0 / 285)$ & $0(0 / 297)^{\mathrm{a}}$ \\
$\begin{array}{c}\text { Wintering grounds } \\
\text { (Hungary) }\end{array}$ & $27 \%(6 / 22)$ & $0(0 / 7)$ & $11 \%(18 / 170)$ & $12 \%(24 / 199)^{\mathrm{b}}$ \\
$\begin{array}{c}\text { Wintering grounds } \\
\text { (Netherlands) }\end{array}$ & $2 \%(12 / 508)$ & $12 \%(173 / 1404)$ & $13 \%(798 / 6374)$ & $12 \%(983 / 8286)^{\mathrm{b}}$ \\
\hline $\begin{array}{l}\text { a and b refer to the statistical differences at } \alpha=0.05 \text { (proportion test, } \mathrm{df}=3, \mathrm{Z} \text { score }=8.69, \mathrm{P}<0.001) \\
\text { Infection variation on the wintering grounds }\end{array}$
\end{tabular}

The multi-model inference approach revealed that prevalence of LPAIV infection was associated with different variables for different species. For bean geese, only year was included in the top model set (Table 2.2). 
Table 2.2 Summarized results of the multi-model inference approach.

\begin{tabular}{|c|c|c|c|c|c|c|c|c|c|c|}
\hline Species & Model & Year & Month & Sex & Age & BC & Year $\times$ BC & Year $\times$ Age & $\omega_{\mathrm{m}}$ & $\Delta \mathrm{AICc}$ \\
\hline \multirow{6}{*}{ bean goose } & 1 & -1.29 & & & & & & & 0.44 & 0.00 \\
\hline & 2 & -1.33 & + & & & & & & 0.22 & 1.41 \\
\hline & 3 & -1.28 & & 0.27 & & & & & 0.18 & 1.81 \\
\hline & 4 & -1.25 & & & 0.29 & & & & 0.17 & 1.83 \\
\hline & $\beta$ & -1.29 & + & -1.29 & 0.05 & & & & & \\
\hline & $\omega_{\mathrm{p}}$ & 1.00 & 0.21 & 0.18 & 0.17 & & & & & \\
\hline \multirow{5}{*}{ barnacle goose } & 1 & + & + & & 0.29 & 0.64 & + & & 0.44 & 0.00 \\
\hline & 2 & + & + & & & 0.62 & + & & 0.37 & 0.32 \\
\hline & 3 & + & + & & -0.33 & 0.61 & + & + & 0.19 & 1.71 \\
\hline & $\beta$ & $+* *$ & $+* *$ & & 0.07 & 0.63 & + & + & & \\
\hline & $\omega_{\mathrm{p}}$ & 1.00 & 1.00 & & 0.63 & 1.00 & 1.00 & 0.19 & & \\
\hline \multirow{4}{*}{$\begin{array}{l}\text { greater white- } \\
\text { fronted goose }\end{array}$} & 1 & + & + & & -2.32 & 0.71 & + & + & 0.73 & 0.00 \\
\hline & 2 & + & + & -0.01 & -2.32 & 0.71 & + & + & 0.27 & 1.98 \\
\hline & $\beta$ & $+* * *$ & $+* * *$ & -0.01 & $-2.32 * * *$ & 0.71 & + & $+*$ & & \\
\hline & $\omega_{\mathrm{p}}$ & 1.00 & 1.00 & 0.27 & 1.00 & 1.00 & 1.00 & 1.00 & & \\
\hline
\end{tabular}

The candidate models were ranked in order of increasing difference of AICc $(\triangle \mathrm{AICc}<2)$; The parameter estimates for males as compared to zero for females. The parameter estimates for adults as compared to zero for juveniles. The parameter estimates in each candidate model are given in columns. $\beta$ indicates the averaged estimates. $\omega_{\mathrm{p}}$ indicates the relative importance. $\omega_{\mathrm{m}}$ indicate the probability that the model is the best approximating model in the set. $\mathrm{BC}$ refers to body condition. + indicates this factor variable was included in the model. asterisks refer to the statistical difference $(*, \mathrm{P}<0.05 ; * *, \mathrm{P}<0.01 ; * * *, \mathrm{P}<0.001)$. 
We included the variable month in the model to examine the variation of prevalence over months. The subsequent tests showed that the prevalence of LPAIV infection was slightly higher in 2008-2009 compared to 2009-2010 (Figure 2.1A; $\mathrm{Z}$ value=-1.94, $\mathrm{P}=0.052$ ), and the prevalence slightly increased over the months (Figure $2.2 \mathrm{~A} ; \mathrm{Z}$ value $>0.77, \mathrm{P}>0.267$ ), but the differences were not statistically significant at the $\alpha=0.05$ level. For barnacle geese, year, month, age, body condition and the interaction between year and body condition were included in the top model (Table 2.2). The prevalence in the last two years was higher than in the previous years, and peaked in 2012-2013 (Figure 2.1B; $\mathrm{Z}$ value $>3.12, \mathrm{P}<0.01$ ).

Prevalence of LPAIV infection increased dramatically over the months with the highest values in January and February (Figure 2.2B; $\mathrm{Z}$ value $>2.92, \mathrm{P}<0.016$ ). For greater whitefronted geese, year, month, age, body condition, the interaction between year and body condition, and the interaction between year and age were included in the top model. Similar to barnacle goose, greater white-fronted geese had a higher prevalence in the last two years (Figure 2.1C; $\mathrm{Z}$ value $>3.44, \mathrm{P}<0.01$ ). Prevalence of LPAIV infection in December-February was higher than in November (Figure 2.2C; $\mathrm{Z}$ value $>7.37, \mathrm{P}<0.001$ ).

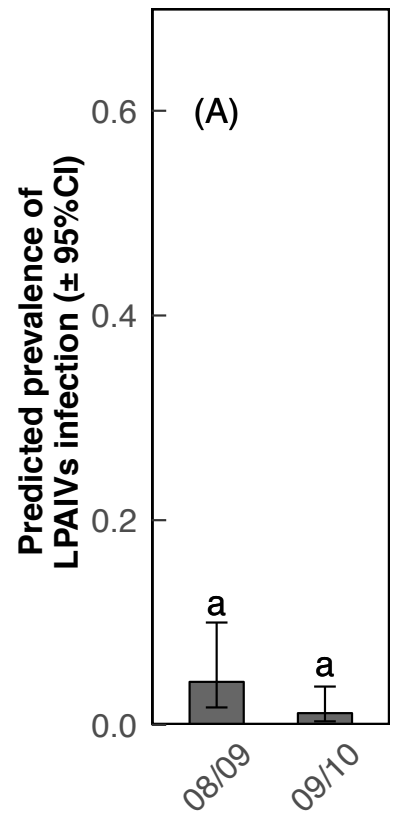

Sampling Years

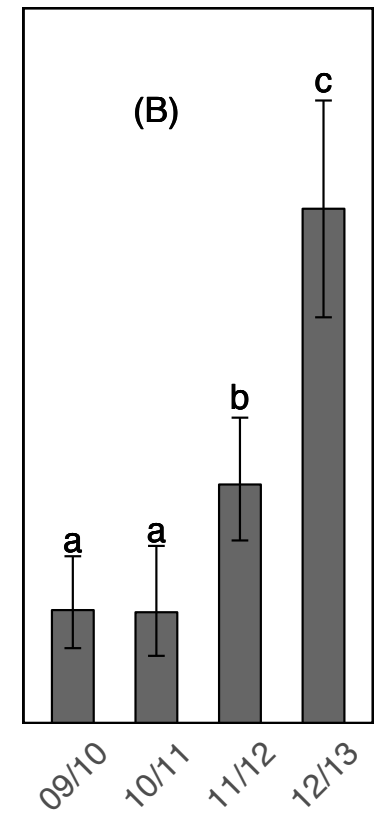

Sampling Years

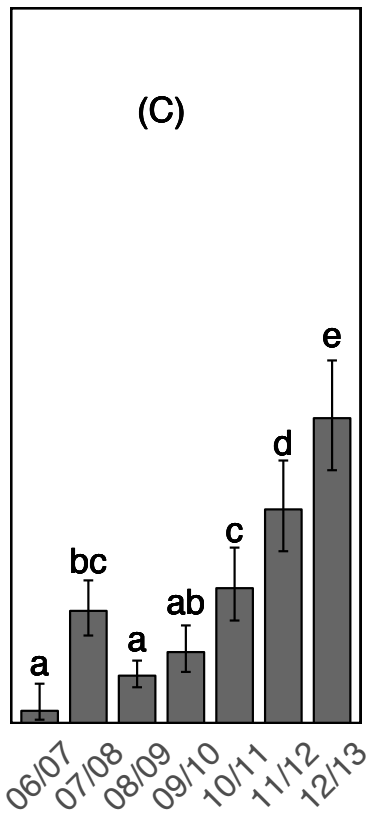

Sampling Years

Figure 2.1 Predicted prevalence of LPAIV infection ( $\pm 95 \%$ confidence interval) in each year for three species, separately. (A) bean geese; (B) barnacle geese; (C) greater white-fronted geese. a, b and $\mathrm{c}$ refer to the statistical difference at $\alpha=0.05$. 

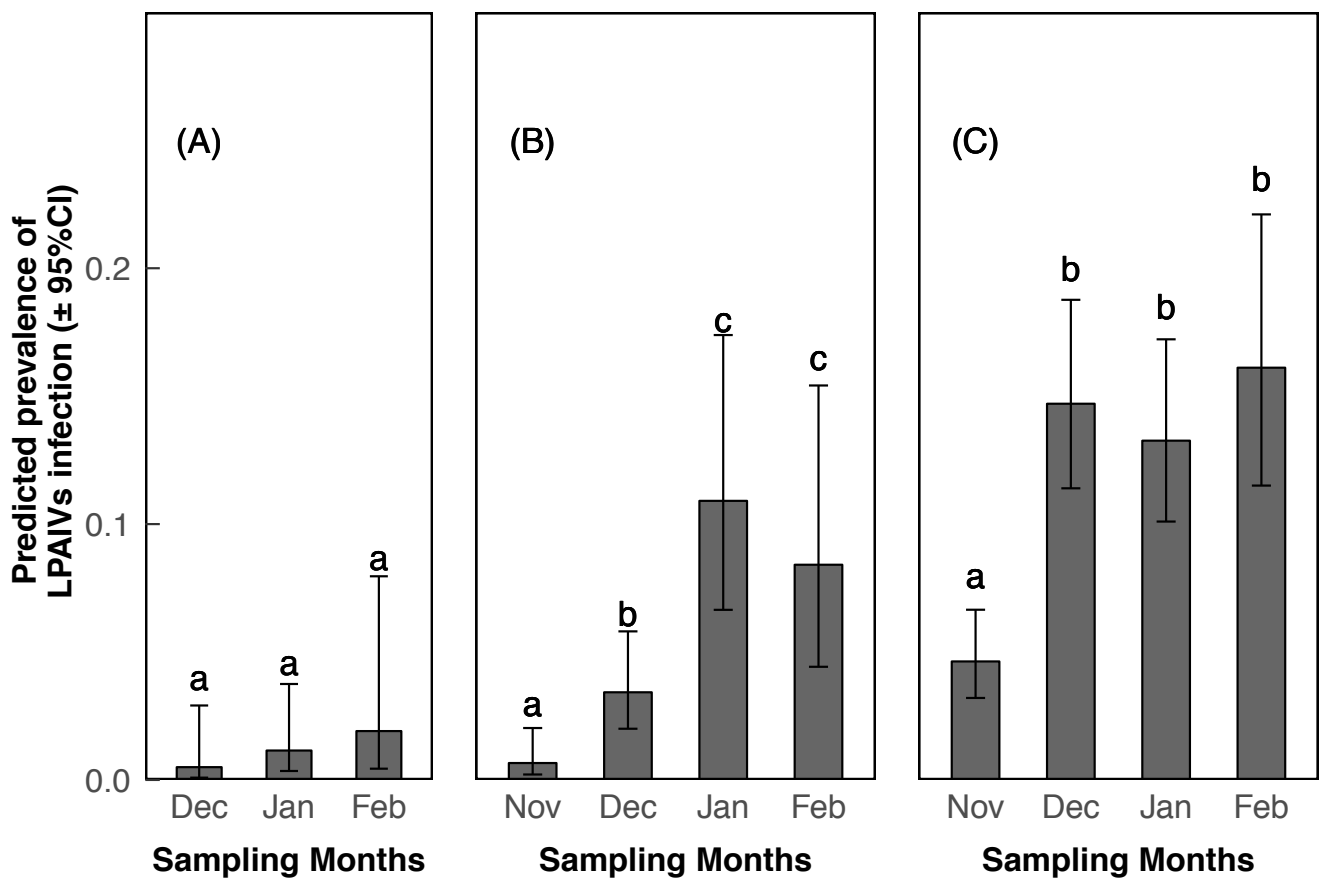

Figure 2.2 Predicted prevalence of LPAIV infection ( $\pm 95 \%$ confidence interval) in each month for three species, separately. (A) bean geese; (B) barnacle geese; (C) greater white-fronted geese. a, $\mathrm{b}$ and $\mathrm{c}$ refer to the statistical difference at $\alpha=0.05$.

The differences in prevalence of LPAIV infection between juvenile and adult greater white-fronted geese differed among sampling years, as juvenile birds had higher prevalence than adults in 2006-2007 (Figure 2.3; $\mathrm{Z}=-3.47, \mathrm{P}=0.005), 2008-2009(\mathrm{Z}=-2.87, \mathrm{P}=0.004)$ and 2009-2010 $(Z=-3.13, P=0.002)$, but not in others $(Z$ value $>-1.95, P>0.05)$.

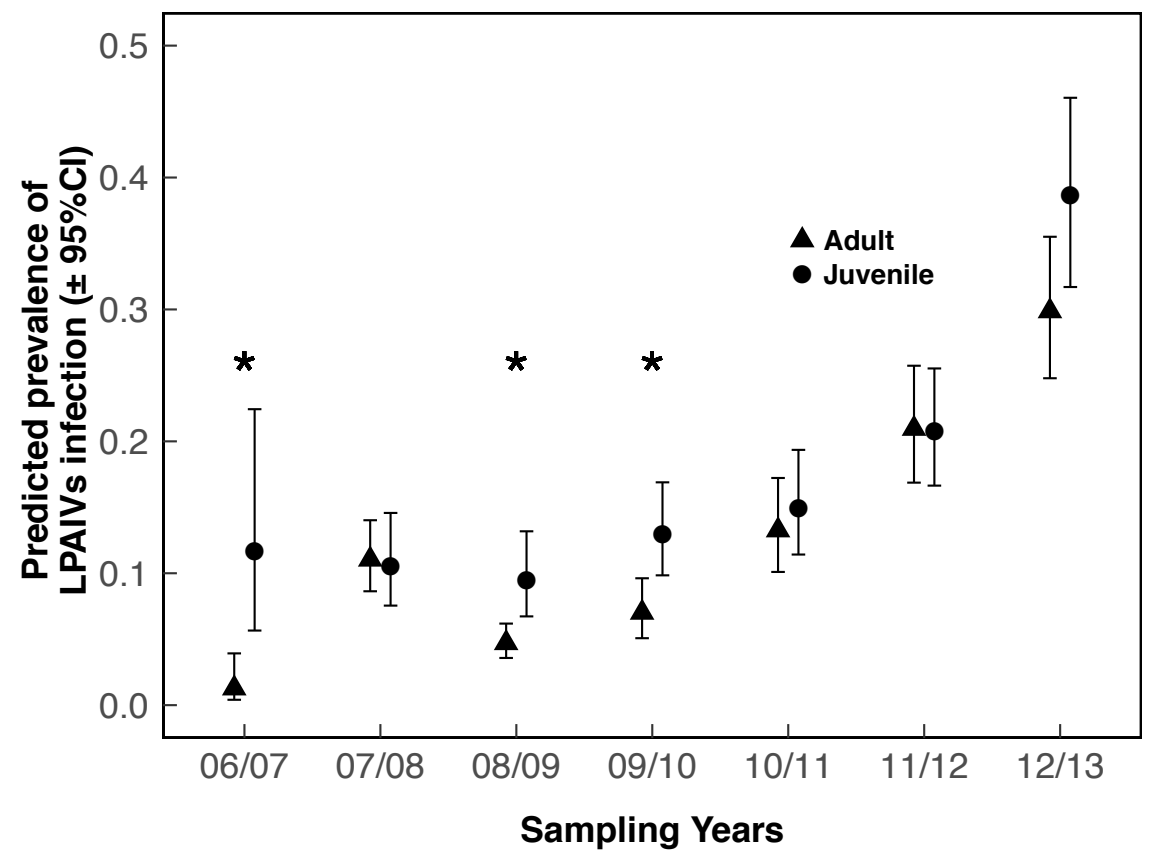

Figure 2.3 Predicted prevalence of LPAIV infection ( $\pm 95 \%$ confidence interval) over years in adult and juvenile greater white-fronted geese. 


\section{Discussion}

The large distances covered by migratory geese and the mixing of different flyway populations during parts of their annual cycle cause concerns about the dispersion of AIV across continents. We found no LPAIV infection in three goose species on their breeding grounds or spring stopover sites. The prevalence of LPAIV infection was low just after their arrival on wintering grounds in the Netherlands but increased during successive months to peak after December. These results suggest that the studied migratory goose species are free of LPAIV infection on their high-latitude breeding grounds, and only become infected after exposure to LPAIV on their wintering grounds.

The lack of any LPAIV infection in the three goose species on their breeding grounds (Table 2.1) is in line with a previous study that found geese might have no LPAIV infection during autumn migration (Samuel et al. 2015; Jonassen and Handeland 2007). Furthermore, a study on LPAIV infection of pink-footed geese Anser bachyrhynchus over their flyway gave a similar result, namely infection was only found on their wintering grounds (Hoye et al. 2011). These findings indicate that migratory geese can lose LPAIV in some phases of their annual cycle, and strongly suggest that migratory geese do not carry LPAIV from their breeding grounds to their wintering grounds. This contrasts with ducks such as mallards, which can preserve LPAIV in the population over their entire annual cycle (van Dijk et al. 2015). Compared to ducks, geese are less restricted to wetland habitat, and they mainly forage on land and defecate in compact droppings. These different traits reduce the chance for faecal-oral transmission (Kleijn et al. 2010), and reduce environmental transmission, which is important for LPAIV to persist in a waterfowl population (Breban et al. 2009; Wang et al. 2012; Rohani et al. 2009). This could be one factor explaining why geese, but not ducks, are free of LPAIV during part of their annual cycle.

Migratory waterfowl are generally considered asymptomatic carriers of LPAIV because they do not show serious disease signs when infected. Consequently, they are potentially important in dispersing LPAIV over long distances (Kida et al. 1980). If migratory waterfowl carry LPAIV during autumn migration, prevalence of LPAIV infection should have been stable or decreased after their arrival on the wintering grounds. However, LPAIV prevalence in the examined geese was low upon their arrival in October-November (Figure 2.2). Only after November, did prevalence of infection increase in wintering geese. This suggests that migratory geese were exposed to LPAIV that circulated on wintering grounds. This is 
consistent with the idea that migratory birds more likely amplify local LPAIV infection, because they may not be immune to a locally circulating virus and may have reduced immunocompetence because of physiological costs of migration (Latorre-Margalef et al. 2009; Altizer et al. 2011).

Although barnacle and greater white-fronted geese had a relatively high prevalence of infection in February (Figure 2.2B and C), they did not show any infection on spring stopover sites in Russia (Table 2.1). This refutes our supposition that the prevalence of LPAIV infection is intermediate on spring stopover sites. In Canada geese Branta canadensis, virus shedding after infection with HPAIV takes up to 6 days (Pasick et al. 2007). Assuming barnacle and greater white-fronted geese have a similar shedding period to that of Canada geese, they had plenty of time to recover from the infection during the spring migration. The absence of LPAIV infection, especially in greater white-fronted geese, on spring stopover sites suggests that these geese do not maintain the virus within their own population and that they are not being exposed to new LPAIV during spring migration. However, sample sizes from spring stopover sites were low, and analyses based on larger sample sizes are required to confirm this tentative conclusion.

Variations of LPAIV infection among years are commonly reported in wild birds (LatorreMargalef et al. 2009; Wallensten et al. 2007; Kleijn et al. 2010). In our study, prevalence of LPAIV infection significantly increased in the last two years in barnacle geese and greater white-fronted geese (Figure 2.1B and C). High prevalence of LPAIV infection is frequently associated with a large proportion and number of juveniles in the population, because they are immunological naïve (Scott Krauss et al. 2004). However, the proportions of juvenile barnacle geese and juvenile greater white-fronted geese in the last two years were not consistently higher than those in previous years (Hornman et al. 2013, 2015). Moreover, prevalence of infection in greater white-fronted geese did not differ between juveniles and adults in these last two years (Figure $2.3 ; \mathrm{P}>0.05$ ). Therefore, the proportion of immunological naive juveniles in the population alone cannot explain the variations in the prevalence of LPAIV infection in this study, which also begs for further study.

Our findings, which are largely based on data from greater white-fronted geese, suggest that migratory geese are free of LPAIV infection before their autumn migration, and exposed to LPAIV after their arrival on the wintering grounds. It indicates that migratory geese are secondary hosts of LPAIV, that they are free of LPAIV infection during certain parts of their 
annual cycle. Therefore, there is no evidence that migratory geese disperse AIV over their migration flyways. More likely, migratory geese arriving and aggregating on their wintering grounds amplify the infection of local LPAIV, instead of introducing novel strains from afar. 
Chapter 2 Migratory Geese Do Not Disperse AIV

\section{Appendix to Chapter 2}

Table S2.1 Sample size of each species in successive winters in the Netherlands.

\begin{tabular}{cccc}
\hline Winter & bean goose & barnacle goose & greater white-fronted goose \\
\hline $2006-2007$ & 71 & 43 & 282 \\
$2007-2008$ & 91 & 171 & 1,050 \\
$2008-2009$ & 235 & 61 & 1,522 \\
$2009-2010$ & 274 & 380 & 987 \\
$2010-2011$ & 62 & 372 & 811 \\
$2011-2012$ & 45 & 385 & 1,058 \\
$2012-2013$ & 13 & 267 & 664 \\
total & 508 & 1,404 & 6,284 \\
\hline
\end{tabular}


Table S2.2 Mean estimated goose population size in the Netherlands from July 2006-May 2013.

\begin{tabular}{|c|c|c|c|c|c|c|c|c|c|c|c|c|}
\hline Species & July & Aug. & Sept. & Oct. & Nov. & Dec. & Jan. & Feb & Mar. & Apr. & May & June \\
\hline bean goose & 33 & 1 & 15 & 13,660 & 87,663 & 335,280 & 176,431 & 127,608 & 662 & 24 & 1 & 2 \\
\hline barnacle goose & 15,853 & 14,893 & 30,172 & 118,412 & 314,670 & 420,221 & 503,470 & 549,122 & 458,145 & 262,323 & 102,150 & 8,665 \\
\hline $\begin{array}{l}\text { greater white- } \\
\text { fronted goose }\end{array}$ & 102 & 129 & 1,645 & 223,681 & 616,648 & 655,524 & 764,731 & 667,125 & 366,123 & 3,658 & 102 & 42 \\
\hline Total & 15,988 & 15,023 & 31,832 & 355,753 & $1,018,981$ & $1,411,025$ & $1,444,632$ & $1,343,856$ & 824,930 & 266,005 & 102,253 & 8,708 \\
\hline
\end{tabular}

The numbers of geese are averaged with the actual counting of each month from 2006/2007 to 2012/2013; All the data are from Sovon reports Watervogels in Netherland in 2006/2007, 2007/2008, 2008/2009, 2009/2010, 2010/2011, 2011/2012 and 2012/2013 (https://www.sovon.nl/sovonrapporten).

Table S2.3 Sample collection and virus detection for avian influenza virus from three samples goose species.

https://doi.org/10.1371/journal.pone.0177790.s003 


\section{Chapter 3}

Effects of migration network configuration and migration synchrony on infection prevalence in geese

S. Yin, H.J. de Knegt, M.C.M. de Jong, Y. Si, H.H.T. Prins, W.F. de Boer (2018).

Effects of migration network configuration and migration synchrony on infection prevalence in geese. Plos Computational Biology. In revision. 


\begin{abstract}
Migration can influence dynamics of pathogen-host interactions. However, it is not clearly known how migration pattern, in terms of the configuration of the migration network and the synchrony of migration, affects infection prevalence. We therefore applied a discrete-time SIR model, with environmental transmission and migration, to various migration networks, including networks with serial, parallel, or both serial and parallel stopover sites, and with various levels of migration synchrony. We applied the model to the infection of avian influenza virus in a migratory waterfowl population. In a network with only serial stopover sites, increasing the number of stopover sites reduced infection prevalence, because with every new stopover site, the amount of virus in the environment was lower than that in the previous stopover site, thereby reducing the exposure of the migratory population. In a network with parallel stopover sites, both increasing the number and earlier appearance of the stopover sites led to an earlier peak of infection prevalence in the migratory population, because, with multiple parallel stopover sites, the migratory population is exposed to larger total amount of virus in the environment, speeding-up the accumulation of infections. Furthermore, higher migration synchrony reduced the average number of cumulative infection because the majority of the population can fly to a new stopover site where the amount of virus is still relatively low and has not been increased due to virus shedding of infected birds. Our simulations indicated that if migratory species have a migration pattern with multiple serial stopover sites and with high migration synchrony, they can reduce their infection prevalence.
\end{abstract}




\section{Introduction}

Many species migrate between their wintering and breeding grounds (Dingle and Drake 2007) in response to seasonal changes in resources and habitat conditions, such as due to seasonal changes in food availability (Berthold 1997; Altizer et al. 2011). However, migration can also facilitate pathogen transmission, as migratory animals can disperse pathogens over long distances (Altizer et al. 2011), or trigger infection outbreaks by exposing the population to pathogens in novel habitat (van Dijk et al. 2015; Verhagen et al. 2014). For example, migration of passerine birds has contributed to the spread of the West Nile Virus across North America (Owen et al. 2006; Rappole et al. 2000), and the migration of waterfowl has contributed to the global spread of the highly pathogenic avian influenza virus (HPAIV) H5N1 and H5N8 (Si et al. 2009; Xu et al. 2016).

Migration, however, can also reduce infection in a migratory population by so-called migration escape (Loehle 1995; Satterfield et al. 2015). It describes that, if the amount of pathogen in the environment accumulates during the staying of the hosts, migration allows the hosts to 'escape' from the accumulated pathogen in the habitat. For example, lesser blackbacked gulls Larus fuscus with a long migration distance have a lower seroprevalence of avian influenza virus compared to gulls with a short migration distance (Arriero et al. 2015). Most of the studies, however, focused on spatial-temporal and phylogenetic correlations between animal movements and infection outbreaks (McKay and Hoye 2016; Xu et al. 2016; Tian et al. 2015), whilst other aspects of migration that might affect infection prevalence have not yet been investigated, such as the configuration of the migration network and the synchrony in timing of migration.

Migratory animals, particularly migratory birds, can use stopover sites in serial configuration, in which all individuals use the same stopover sites successively and the number of these stopover sites varies among species. For example, sandpiper Calidris mauri and black turnstone Arenaria melanocephala use stopover sites more frequently and spend less time to refuel on each site than dunlin Calidris alpine, red knot C. canutus or bar-tailed godwit Limosa lapponica (O’Reilly and Wingfield 1995; Iverson et al. 1996; Yamaguchi et al. 2008). On the other hand, migratory birds, such as swan goose Anser cygnoides, bar-tailed godwit, brent goose Branta bernicla and greater white-fronted goose Anser albifrons can use stopover sites in a more parallel configuration (Battley et al. 2012; Kölzsch et al. 2016; Green et al. 2002; Batbayar 2013; Batbayar et al. 2011), in which all individuals split to use multiple stopover 
sites at the same time over a wider front. Hence, there are potentially many distinct network configurations with respect to the use of serial and parallel stopover sites. The configuration of a migration network is expected to influence the aggregation of migratory birds and their exposure to pathogens at these stopover sites (Buehler and Piersma 2008; Rohani et al. 2009).

Apart from different configurations of migration network, migration synchrony (i.e., timing of migration) also varies among migratory individuals, due to e.g., differences in body condition, competition for limited resources, and optimization of mating opportunities (Morbey and Ydenberg 2001; Muraoka et al. 2009). For example, a population of swan geese Anser cygnoides might take weeks to leave a habitat, whereas a population of barnacle geese might take months. This variation in migration synchrony might also influence infection dynamics because it regulates bird abundance at stopover sites. For example, previous studies proposed that high migration synchrony might be associated with high infection prevalence as individuals have increased contact probabilities in these larger migratory flocks (Buehler and Piersma 2008; Gaidet et al. 2012). However, no study has investigated how configuration of migration network and synchrony of migration affects the infection prevalence in a migratory population.

In this study, we applied a time-discrete SIR (Susceptible-Infected-Recovered) model to various scenarios of spring migration to explore how variations in configuration of migration network and synchrony of migration affect the infection prevalence. The model and scenarios were applied to infection of low pathogenic avian influenza virus in migratory waterfowl species, since the outbreaks of avian influenza virus caused concerns but the relationship between waterfowl migration and virus dispersal is not fully understood (Ren et al. 2016; Takekawa et al. 2010; Yin et al. 2017). We aimed at answering the following questions: (1) How does the configuration of a migration network affect infection prevalence? (2) Does high synchrony in timing of migration increase infection prevalence? (3) Is there a specific migration pattern, regarding the number of stopover sites and migration synchrony that minimizes pathogen infection?

\section{Methods}

We first designed a simulation model that represents a migratory waterfowl population (10,000 birds). Furthermore, we applied an SIR model to simulate the virus transmission during migration (Figure 3.1). Since the wild waterfowl usually keep a certain distance between each other, the densities of the waterfowl on stopover sites might be constant. 
Therefore, we assumed that the transmission of avian influenza virus is independent to bird density (Yin et al. 2017). Furthermore, we included environmental transmission process into the SIR model (Figure 3.1) because, if a pathogen can persist in environment for an extended period of time, it significantly contributes to infection prevalence (De Rueda et al. 2015), and determines the persistence of the pathogen in a migratory population (Rohani et al. 2009; Breban et al. 2009; Stallknecht et al. 2015).

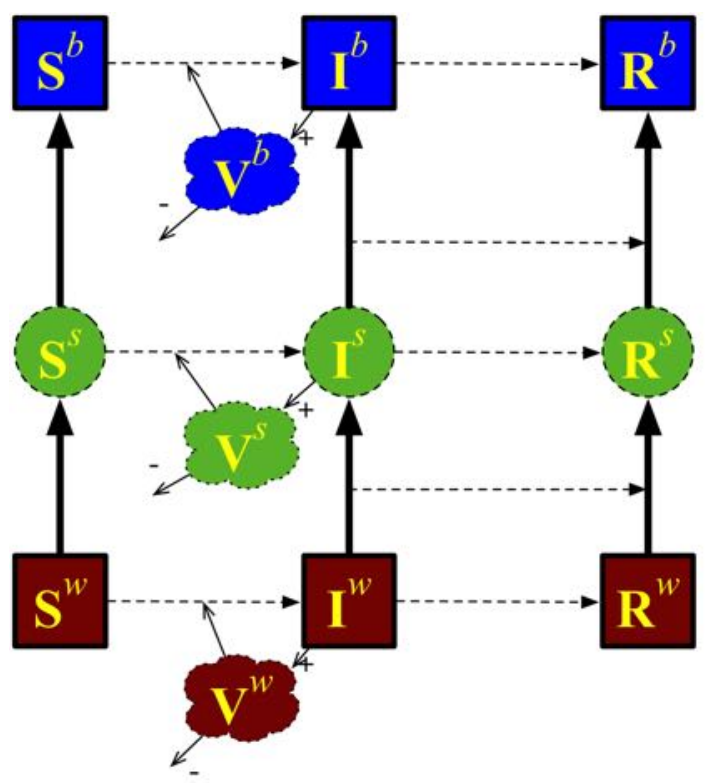

Figure 3.1 Illustration of the SIR model. S, I, R are the susceptible, infected, recovered birds, and $V$ is the virus in the environment. The dashed circles mean that the number of stopover sites varies in different scenarios. The superscript letters $\mathrm{w}, \mathrm{s}$, and $\mathrm{b}$ denote wintering ground, stopover sites, and breeding ground, respectively. The dashed lines denote the transition of the infectious status. The thick solid lines denote the movement of birds. The thin solid lines denote the dynamics of the virus in the environment.

We only simulated the spring migration to exclude the influence from other factors, such as breeding. The simulation started with a virus-free population exposed to virus in their wintering grounds, and the simulation ended when all birds completed their migration. To avoid the complex dynamics of infection and cross-immune responses to multiple virus strains, we assumed that the migratory birds were exposed to single strain of avian influenza virus. We further assumed that migratory birds had no severe responses to the infection, and that they obtained permanent immunity after their recovery. The model variables are summarized in Table 3.1. The model parameters are mainly obtained from migratory goose species, and they are summarized in Table 3.2. 
Table 3.1 The variables of the model, with their abbreviation, definition, and units.

\begin{tabular}{|c|c|c|}
\hline Variable & Definition & Unit \\
\hline$S_{t}^{i}$ & number of susceptible birds & bird \\
\hline$I_{t}^{i}$ & number of infected birds & bird \\
\hline$R_{t}^{i}$ & number of recovered birds & bird \\
\hline$N_{t}^{i}$ & number of birds & bird \\
\hline$S^{i j}{ }_{t+\tau / \omega}$ & number of susceptible birds after the flying from habitat $i$ to $j$ & bird \\
\hline$I^{i j}{ }_{t+\tau / \omega}$ & number of infected birds after the flying from habitat $i$ to $j$ & bird \\
\hline$R_{t+\tau / \omega}^{i j}$ & number of recovered birds after the flying from habitat $i$ to $j$ & bird \\
\hline$m_{t}^{i}$ & the number of birds that migrate & - \\
\hline$\mu^{i}$ & mean day of the migration departure date & - \\
\hline
\end{tabular}

$i$ denotes the location along the migration network, either wintering ground, stopover site, or breeding ground. $t$ denotes the time step. $\tau$ denotes the total number of flying days from the wintering ground to the breeding ground. $\omega$ denotes the number of stops. 
Table 3.2 The parameters of the model with their abbreviation, definition, value, and units.

\begin{tabular}{|c|c|c|c|c|}
\hline Parameter & Definition & Value & Unit & Reference \\
\hline$N_{0}$ & population size & 10,000 & bird & - \\
\hline$\beta$ & transmission rate parameter & $0.064(0.05-0.27)$ & $d a y^{-1}$ & (Rohani et al. 2009) \\
\hline$\gamma$ & recovery probability & 0.14 & $d a y^{-1}$ & $\begin{array}{c}\text { (Webster et al. 1992; } \\
\text { King et al. 2010) }\end{array}$ \\
\hline $6 \sigma$ & $\begin{array}{l}\text { the length of the migration } \\
\text { synchrony }\end{array}$ & $0-13$ & week & - \\
\hline$\eta$ & $\begin{array}{c}\text { virus decaying rate in the } \\
\text { environment }\end{array}$ & $0.03(0.25-0.01)$ & - & (Rohani et al. 2009) \\
\hline$d$ & migration distance & 3900 & $\mathrm{~km}$ & (Kölzsch et al. 2016) \\
\hline$v$ & flying speed & $1680(864-3888)$ & $\mathrm{km} d a y^{-1}$ & (Kölzsch et al. 2016) \\
\hline$\tau$ & total number of flying days & 2.32 & day & \\
\hline$\omega$ & number of stops & $0-10$ & - & - \\
\hline$\varepsilon$ & virus shedding rate & - & virus bird ${ }^{-1}$ & (Breban et al. 2009) \\
\hline$V_{i}^{0} / \varepsilon$ & $\begin{array}{l}\text { initial amount of virus in } \\
\text { environment per shedding } \\
\text { rate (in scale of bird) }\end{array}$ & 300 & bird & (Breban et al. 2009) \\
\hline$T$ & $\begin{array}{l}\text { total number of refuelling } \\
\text { days }\end{array}$ & 80 & days & (Kölzsch et al. 2016) \\
\hline
\end{tabular}

\section{SIR model}

In our time-discrete SIR model, susceptible birds cannot be infected during flying due to absence of direct transmission or environmental transmission. Infected birds can recover from infection and obtain immunity (Figure 3.1).

The number of susceptible birds (S), the number of infected birds (I), the number of recovered birds $(\mathrm{R})$, and the number of total birds $(\mathrm{N})$ was calculated in each site according to the following difference equations:

$$
\begin{aligned}
& S_{t}^{i}=S_{t-1}^{i}-\frac{\beta S_{t-1}^{i}\left(I_{t-1}^{i}+\frac{V_{t-1}^{i}}{\varepsilon}\right)}{N_{t-1}^{i}}-\frac{m_{t-1}^{i} S_{t-1}^{i}}{N_{t-1}^{i}}+\frac{m_{t-1}^{i-1} S_{t-1}^{i-1}}{N_{t-1}^{i}} \\
& I_{t}^{i}=I_{t-1}^{i}+\frac{\beta S_{t-1}^{i}\left(I_{t-1}^{i}+\frac{V_{t-1}^{i}}{\varepsilon}\right)}{N_{t-1}^{i}}-\gamma I_{t-1}^{i}-\frac{m_{t-1}^{i} I_{t-1}^{i}}{N_{t-1}^{i}}+\frac{m_{t-1}^{i-1} I_{t-1}^{i-1}}{N_{t-1}^{i}}
\end{aligned}
$$




$$
\begin{aligned}
& R_{t}^{i}=R_{t-1}^{i}+\gamma I_{t-1}^{i}-\frac{m_{t-1}^{i} R_{t-1}^{i}}{N_{t-1}^{i}}+\frac{m_{t-1}^{i-1} R_{t-1}^{i-1}}{N_{t-1}^{i}} \\
& N_{t}^{i}=S_{t}^{i}+I_{t}^{i}+R_{t}^{i}
\end{aligned}
$$

where $\beta$ is the transmission rate parameter $\left(d a y^{-1}\right), \gamma$ is the recovery rate parameter $\left(d a y^{-1}\right)$, $m_{t-1}^{i}$ is the number of birds (bird) that migrate, $V_{t}^{i}$ is the amount of virus that is shed by birds per day (virus $d a y^{-1}$, for the difference equation see below), $\varepsilon$ is the virus shedding rate (virus $\left.\operatorname{bird}^{-1}\right), t$ is the discrete day, $i$ is the site.

Equations (3.5 - 3.8) depicted infection dynamics while flying between stopover sites.

$$
\begin{aligned}
& S_{t+\frac{\tau}{\omega}}^{i j}=\frac{m_{t}^{i} S_{t}^{i}}{N_{t-1}^{i}} \\
& I_{t+\frac{\tau}{\omega}}^{i j}=\frac{m_{t}^{i} I_{t}^{i}(1-\gamma)^{\tau / \omega}}{N_{t-1}^{i}} \\
& R_{t+\frac{\tau}{\omega}}^{i j}=\frac{m_{t}^{i} R_{t}^{i}}{N_{t-1}^{i}}+\frac{m_{t}^{i} I_{t}^{i}\left(1-(1-\gamma)^{\tau / \omega}\right)}{N_{t-1}^{i}} \\
& \tau=\frac{d}{v}
\end{aligned}
$$

$\omega$ is the number of stops in the migration network, $\tau$ is the total number of flying days (day) from wintering to breeding ground, $d$ is the total migration distance $(\mathrm{km})$, and $v$ is the averaged flying speed $\left(\mathrm{km} \mathrm{day}^{-1}\right)$.

Since the migratory birds share stopover sites in their migration, and the avian influenza virus can persist in water for an extended period of time (Samuel et al. 2015; Brown et al. 2009), we assumed that the stopover sites were contaminated at a very low level $\left(V_{0}^{i}\right)$ before arrival of the migratory birds. The amount of virus in the environment $\left(V^{i}{ }_{t}\right)$ was calculated by the following difference equation:

$$
V_{t}^{i}=V_{t-1}^{i}-\eta V_{t-1}^{i}+\varepsilon I_{t-1}^{i}-\eta \varepsilon I_{t-1}^{i}
$$

where $\eta$ is the virus decaying rate in the environment. We divided equation (9) by shedding rate $\varepsilon$ (virus bird $^{-1}$ ) to obtain the following equation:

$$
\frac{V_{t}^{i}}{\varepsilon}=\frac{V_{t-1}^{i}}{\varepsilon}-\eta \frac{V_{t-1}^{i}}{\varepsilon}+I_{t-1}^{i}-\eta I_{t-1}^{i}
$$


which allows us to use $\mathrm{v}_{\mathrm{t}}^{\mathrm{i}} / \varepsilon$ (bird), i.e. the amount virus shed per infectious bird, instead of $V^{i}{ }_{t}$ to estimate the amount of virus in the environment (Breban et al. 2009).

\section{Migration networks}

We designed three different configurations of the migration network, networks with serial stopover sites (Figure 3.2, network S), networks with parallel stopover sites (Figure 3.2, network P), and networks with both serial and parallel stopover sites (Figure 3.2, network PSS, SPS and SSP). In the parallel configurations, birds distributed evenly over all stopover sites. 


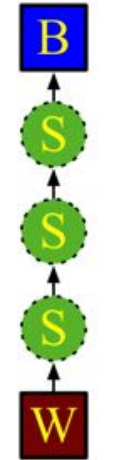

S

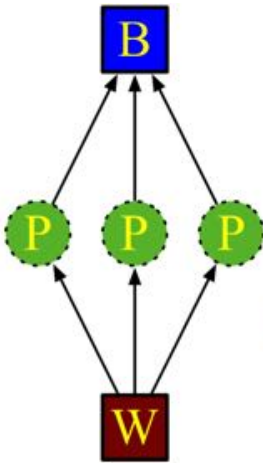

$P$

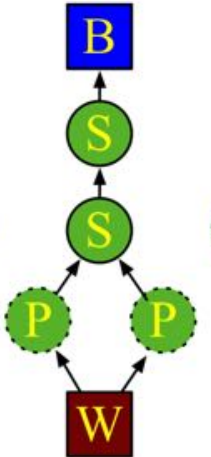

PSS

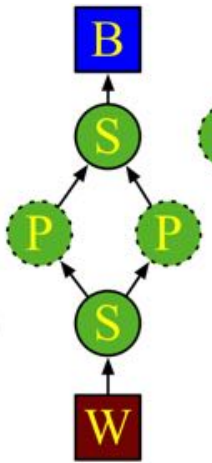

SPS

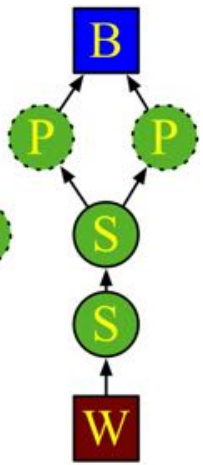

SSP

Figure 3.2 Illustrations of different migration networks with serial stopover sites (S), parallel stopover sites (P), and serial-parallel stopover sites (PSS, SPS, or SSP, the position of P indicates the position of parallel stopover sites in the network). The wintering ground, stopover sites, and breeding ground are depicted in red, green, and blue, respectively. The dashed circles mean that the number of stopover sites varies in different scenarios.

\section{Migration synchrony}

Field observations showed that the arrival and departure of waterfowl generally follow a unimodal patterns (Gupta et al. 2010; van Gils et al. 2007). Therefore, we used a truncated Gaussian distribution to calculate the number of population that migrate at each time step:

$$
m_{t}^{i}=\left\{\begin{array}{c}
\int_{t}^{t+1} N\left(\mu^{i}, \sigma^{2}\right) \times \frac{1}{\int_{\mu^{i}-3 \sigma}^{\mu^{i}+3 \sigma} N\left(\mu^{i}, \sigma^{2}\right)} \times N_{0}, \mu^{i}-3 \sigma \leq t \leq \mu^{i}+3 \sigma \\
0, \text { else }
\end{array}\right.
$$

where $\mu^{i}$ is the mean day of the migration departure date from habitat $i, \sigma$ is the spread of the distribution around the mean. As can be seen from the truncation, we assumed that the whole population departs from (and arrive at) a site within $6 \sigma$ days. Therefore, the migration synchrony can be increased or decreased by changing the parameter $6 \sigma$. A greater $6 \sigma$ represents a lower synchrony of migration, and vice versa.

\section{Migration patterns}

To examine whether there is an optimal migration pattern that minimizes infection prevalence, we combined various migration networks and various levels of migration synchrony $(6 \sigma=0,1,2 \ldots 13)$. Since the migration synchrony influences the abundance of birds on successive stopover sites, we only considered the migration networks with serial stopover sites (number of stopover site $=0,1,2,3 \ldots 10$ ). Totally, we evaluated 154 scenarios to test their impacts on infection prevalence dynamics. 


\section{Results}

\section{Environmental transmission}

Although the environmental transmission contributed more than $70 \%$ to the total infection prevalence (Figure 3.3), its contribution decreased, however, with an increasing number of serial stopover sites, as the migratory birds move to next stopover site where the amount of virus was still relatively low.

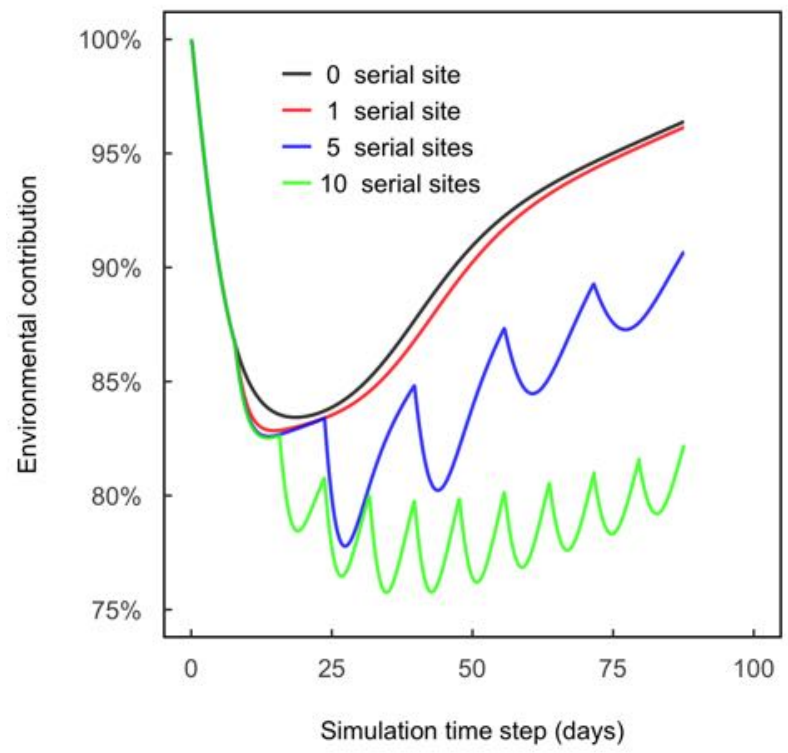

Figure 3.3 Simulated environmental contributions to the total prevalence of infection. The moment of arrival at a stopover site is visible in the graph by a sudden sharp drop in environmental contribution. These results are obtained from migration networks with $0,1,5$, and 10 serial stopover sites. All the birds migrate at the same time $(6 \sigma=0)$.

\section{Network configuration}

In networks with only serial stopover sites, an increasing number of sites reduced both infection prevalence (i.e. number of infected birds) and cumulative prevalence (i.e. sum of recovered birds and infected birds) in the migratory population (Figure 3.4A and B). Whereas, in networks with parallel sites, both an increasing number of parallel sites and earlier use of parallel stopover sites led to a faster accumulation of infections, and therefore, an earlier infection peak in the migratory population (Figure 3.4C and D, and Figure 3.5). Similar patterns were observed when we varied the initial amount of virus in the environment. The infection always peaks earlier in a migration network with 10 parallel stopover sites than that in a migration network with 5 parallel stopover sites. Furthermore, the 
difference in day of infection peak increases along with increasing the initial amount of virus in the environment (Figure S3.1).
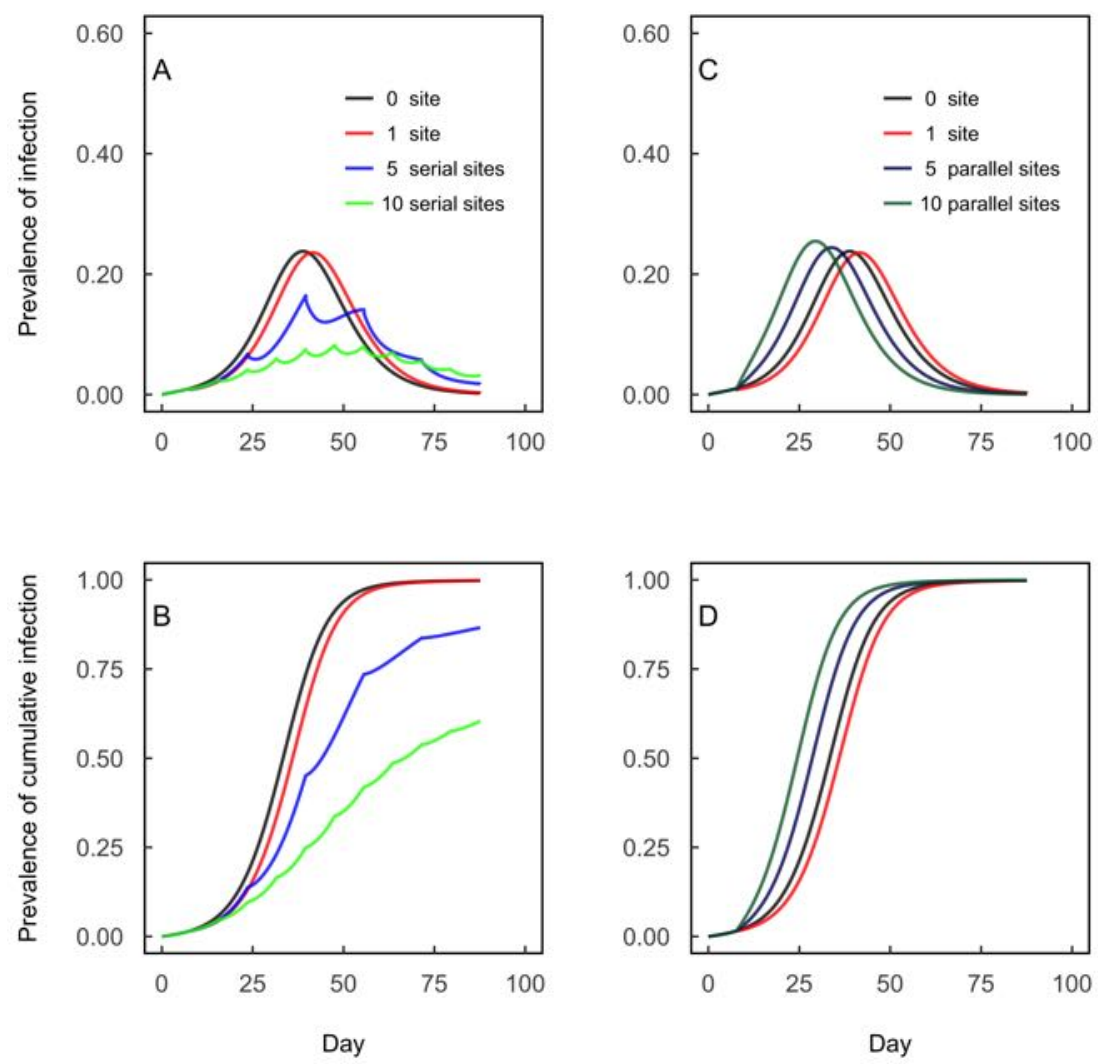

Figure 3.4 Simulated prevalence of infection $(A, C)$ and prevalence of cumulative infection $(B$, D). These results are obtained from migration networks with $0,1,5$ and 10 serial stopover sites (A, B), and with 5, 10 parallel stopover sites (C, D). All birds migrate at the same time $(6 \sigma=0)$.

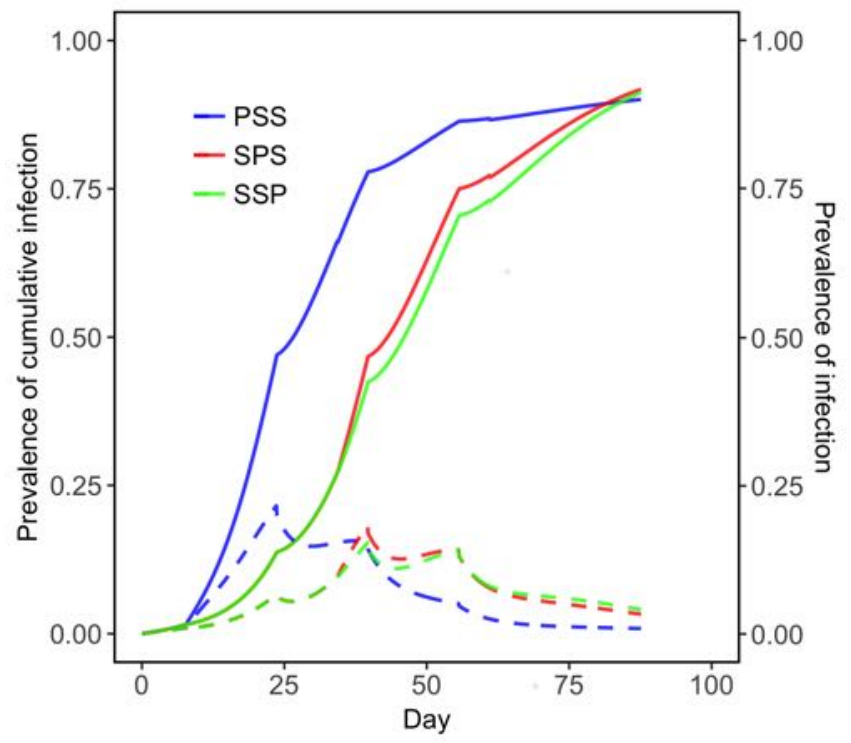

Figure 3.5 Simulated prevalence of infection (dashed lines) and prevalence of cumulative infection (solid lines). These results are obtained from migration networks with 1 pair of parallel stopover sites and 2 serial stopover sites. The position of $\mathrm{P}$ in the legend indicates the positions of the parallel stopover sites in the migration networks. All birds migrate at the same time $(6 \sigma=0)$. 


\section{Migration synchrony and migration pattern}

Unexpectedly, decreasing migration synchrony led to an increasing in the number of cumulative infections (Figure 3.6). Furthermore, we also calculated the average number of cumulative infections over the period of infection development (i.e., from the beginning of infection till new infections are no longer recorded), showing that decreasing migration synchrony generally facilitated cumulative infection (Figure 3.7). A migration strategy with multiple serial stopover sites $(n=10)$ and high migration synchrony $(6 \sigma=0)$ led to the lowest average number of cumulative infections. The effect of migration synchrony on the average number of cumulative infections interacted with the effect of the number of stopover sites, because the number of serial stopover site had the largest effect only when the migration synchrony was highest (Figure 3.7).

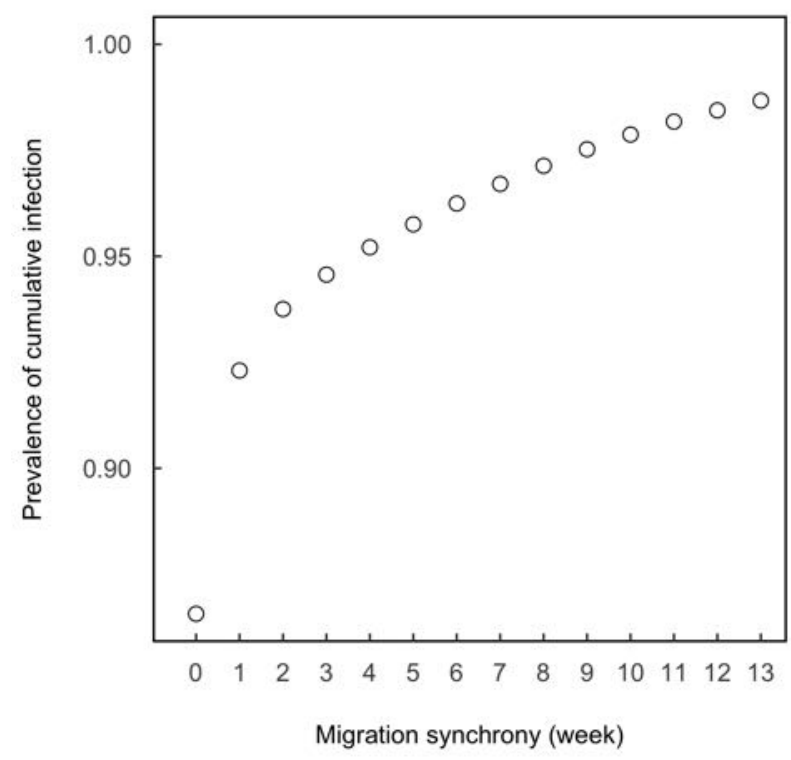

Figure 3.6 Simulated prevalence of cumulative infection at the end of migration. These results are obtained from migration networks with 5 serial stopover sites, and with various levels of migration synchrony $(6 \sigma=1,2,3 \ldots \ldots 13)$. 


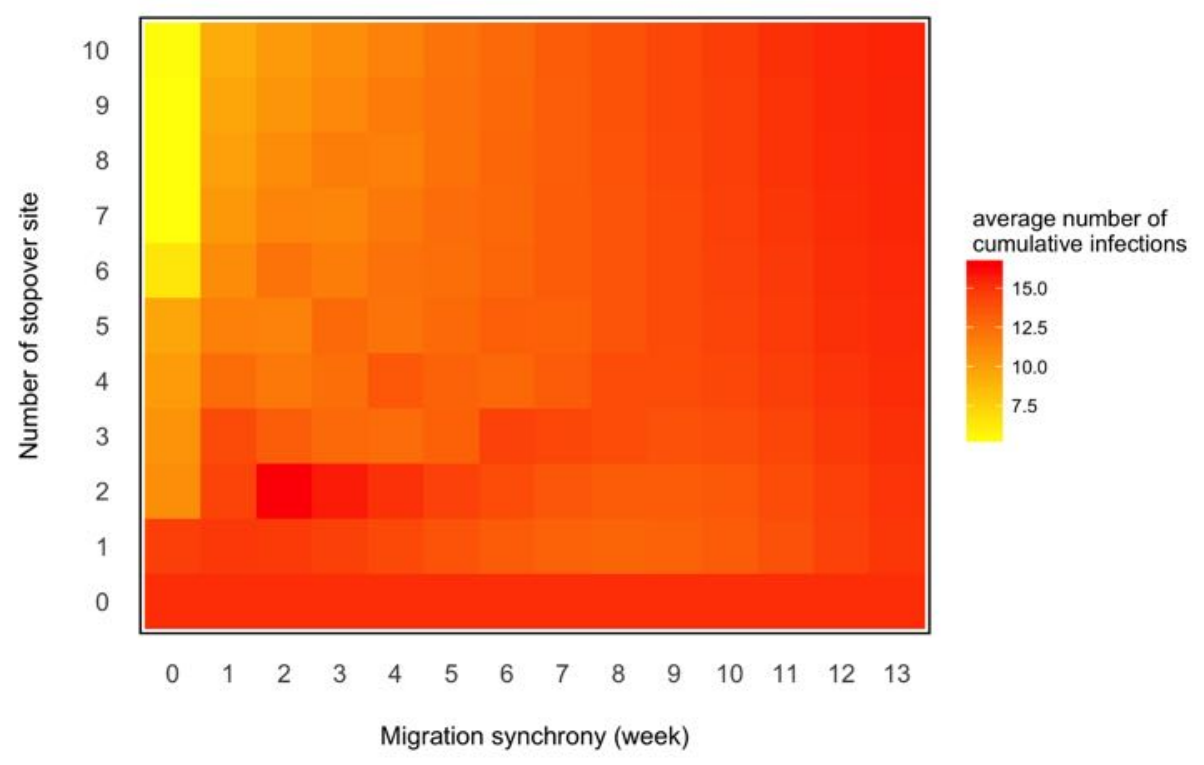

Figure 3.7 Simulated average number of cumulative infections during the development of

infection. These results are obtained from various migration patterns that vary in number of serial stopover sites $(\mathrm{n}=0,1,2,3 \ldots 10)$ and timing of migration synchrony $(6 \sigma=1,2,3 \ldots \ldots 13)$.

\section{Discussion}

In our simulation, we found that the configuration of the migration network and the synchrony in timing of migration affected the infection dynamics in a migratory population. Specifically, we found that migration can reduce the infection prevalence in the population, which is in agreement with migratory escape (Loehle 1995; Satterfield et al. 2015). Furthermore, high migration synchrony did not increase infection prevalence, whereas low migration synchrony led to a larger infection prevalence in a migratory population. This brings us a new insight into the possible relationships between animal movement pattern and pathogen infection.

Avian influenza virus can accumulate in the environment and can persistent for weeks and even month. Thereby, staying in habitats for long period increases risks for exposing to the virus in the environment. This is illustrated by that the infection prevalence in resident waterfowl is year-round (Wilcove 2008), but the infection prevalence in migratory waterfowl can decrease to very low level (Yamaguchi et al. 2008; Yin et al. 2017). According to our simplified model of one-strain and permanent acquired immunity, however, structure of migration network with serial stopover sites can reduce the infection prevalence. This is because, when migratory birds start arriving at a habitat where has very low or even no accumulation of virus in the environment, environmental transmission contribute relatively 
little to the infection. This is in line with the concept of migratory escape (Loehle 1995; Altizer et al. 2011), which has also been supported by empirical studies. For example, in reindeer Rangifer tarandus herds, migration can significantly reduce the abundance of larval Hypoderma tarandi in the population (Folstad et al. 1991).

On the contrary, parallel stopover sites facilitated the number of cumulative infections. Although the use of parallel stopover sites reduced the abundance of migratory birds in each stopover site, it did not influence the direct transmission probability in our densityindependent transmission model. However, when the migratory population used parallel stopover sites, especially at the early stage of the migration, it was exposed to larger total amount of virus that existed in the environment, which sped-up the accumulation of infections. It indicates that the infections accumulate faster when the migratory population encounters more virus in the environment.

The fast accumulation of infections that is associated with earlier parallel sites in the migration network might contribute to the absence of avian influenza virus infection in these migratory waterfowl when they arrive at their breeding ground (Yin et al. 2017). For example, the greater white-fronted goose migrate over a broad front in the early stages of their spring migration (Kölzsch et al. 2016), the infection might develop so fast that the majority of the population have recovered from the infection before arriving at their breeding grounds. Many other migratory species, such as snow geese Anser caerulescens, sandhill cranes Antigone Canadensis and demoiselle cranes Grus virgo, trek over a broad front as well (Samuel et al. 2015; King et al. 2010; Takekawa et al. 2017; Prins and Namgail 2017). We predict that, in these species, infection peaks at an earlier stage of their migration than that of similar species with a relatively unidirectional migration, such as barnacle geese (Eichhorn et al. 2006; Shariatinajafabadi et al. 2014). To test this prediction, more empirical studies, involving outbreak monitoring and GPS tracking of bird migration, are necessary.

Stopover sites are essential for many migratory waterfowl to complete their migration successfully (Dingle and Drake 2007), especially for migratory waterfowl (i.e. ducks, geese and swans) which are the main wild host for avian influenza virus. For example, mallard, greater white-fronted goose and whooper swan Cygnus cygnus take multiple stopover sites along their migration for refuelling. The availability of stopover sites, however, is threatened by human activities (Wilcove 2008). For example, suitable stopover sites in the East AsianAustralian flyway experienced dramatic loss during the past 20 years, especially for the 
stopover sites located in China (Breban et al. 2009; Stallknecht et al. 2015). This may change the configuration of migration network. One of the possible consequences is that the migration distance becomes shorter due to the loss of habitats, which may facilitate the infection prevalence of avian influenza virus in a migratory population. To obtain a better understanding of the effects of habitat loss on the infection dynamics in migratory populations, more studies that take a network perspective are required, studying effects such as those triggered by habitats loss on infection dynamics.

Previous studies have suggested that animal movements in large flocks might facilitate infection prevalence, and cause outbreaks due to more frequent contact among animals in dense aggregations (Altizer et al. 2011). This idea does not hold in our simulation since we assumed that, in migratory waterfowl population, the transmission of avian influenza virus was density-independent. However, our simulation showed that a larger migrating flock with a higher synchrony of migration can negatively affect infection prevalence, because when the migratory birds migrated together (e. g., $6 \sigma=0$ ), they experienced a lower infection risk at new stopover sites due to the lower amounts of viruses present in the environment. However, when the birds migrate with a lower migration synchrony (e.g., $6 \sigma=13$ ), they experienced a higher infection risk because the amount of viruses in the environment has been elevated by infected birds that arrived earlier.

Migratory waterfowl have distinct migration patterns in terms of number of stopover sites and migration synchrony. For example, swan geese take about 13 stopover sites with a relatively high migration synchrony in about 5 weeks (Batbayar et al. 2011), mallard Anas platyrhynchos take about 3 stopover sites with a relatively high migration synchrony in about 5-7 weeks (Yamaguchi et al. 2008), whereas barnacle geese often take a single stopover site (Tombre et al. 2008) with an extremely low migration synchrony in about 4 months (Hornman et al. 2015). Our simulation showed that migration pattern influenced infection dynamics, and that multiple serial stopover sites with high migration synchrony minimized the average number of cumulative infections (Figure 3.7). It indicates that decisions with regard to the migration network and migration synchrony can minimize transmission of avian influenza virus during migration.

In general, our simulations demonstrate that migration patterns can affect infection dynamics in a migratory population. Although our study focused on a system with single avian influenza virus strain and migratory waterfowl, the findings can be extended to other 
migratory host species, and other pathogens that can persist in the environment. We call for more studies on animal migration that analyse the effects of network configuration, timing of migration (e.g., under influence of global climate change), and movement patterns on disease dynamics. Application of mathematical modelling of animal movements over a migration network can be greatly helpful in understanding mechanisms related to pathogen dispersal. 


\section{Appendix to Chapter 3}

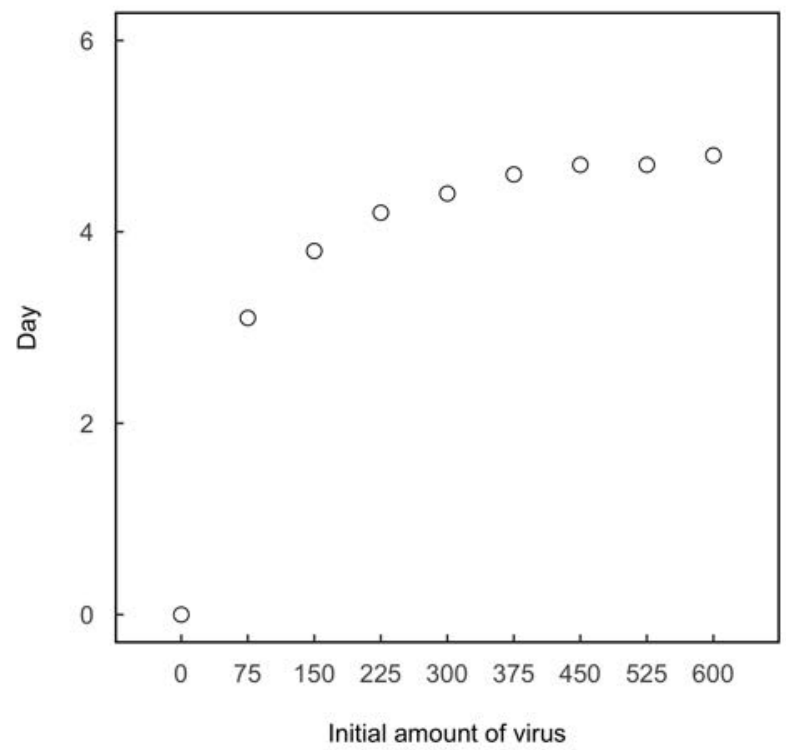

Figure S3.1 Simulated difference in the day of infection peak between networks with 10 parallel stopover sites and 5 parallel stopover sites. All birds migrate at the same time $(6 \sigma=0)$. 


\section{Chapter 4}

Habitat loss facilitates infection outbreak and pathogen dispersal: An agent-based model of infected migratory waterfowl

S. Yin, M.C.M. de Jong, Y. Xu, H.H.T. Prins, W.F. de Boer (2018). Habitat loss facilitates infection outbreak and pathogen dispersal: An agent-based model of infected migratory waterfowl. Submitted. 


\begin{abstract}
Habitat loss can extensively affect migration networks, and thereby influence host-pathogen interactions. For such an intensive impact, we constructed migration networks of a migratory waterfowl population in the East Asian-Australasian Flyway, integrated with an agent-based model, bird migration behaviour, and SIR-type infection dynamics. We studied prevalence dynamics of pathogen infection in a migratory population and pathogen dispersal over the migration network, under three scenarios of site loss. Site loss was mainly observed in the southern part of the East Asian-Australasian Flyway. Migration allowed the birds to escape from contaminated sites and temporally reduce their infection prevalence. In the network with severe site loss, however, birds migrated over a shorter distance and aggregated in a single wintering site, which facilitated pathogen infection. In addition, sites that received more connections from other sites and were visited by more birds were more prone to be infected by the pathogen, and site loss increased this probability. Our findings suggest that habitat loss facilitates disease outbreak in a migratory population and increases the probability for pathogen dispersal.
\end{abstract}




\section{Introduction}

Migration influences the dynamics of pathogen-host interactions (Altizer et al. 2011). For migratory birds, although some migratory species undertake nonstop migration, most migratory species need to refuel on stop-over sites during their migration (Navedo et al. 2010; Kölzsch et al. 2016). Bird migration is a point of attention for emerging zoonotic pathogens such as avian A influenza viruses (AIVs) (Verhagen et al. 2015), West Nile virus (Paz 2015), B. burgdorferi-infected ticks (Khatchikian et al. 2015) and even drug-resistant enteropathogens (Palmgren et al. 1997), since birds can carry pathogens over their longdistance migration. Migration can facilitate infection prevalence in migratory birds by increasing exposure risk to pathogens that persist in stop-over sites (Krauss et al. 2010), or facilitate pathogens dispersal by introducing pathogens from one stop-over site to another (Verhagen et al. 2015). However, migration can also allow host species to escape from infected habitats where infection has built up over time through migration escape (Altizer et al. 2011). However, availability of suitable stop-over sites in the East Asian-Australasian Flyway decreased, especially in China, where $30 \%$ of natural wetlands were lost between 1990 to 2000 (Gong et al. 2010; Zhang et al. 2015; Navedo et al. 2010). Consequently, migratory animals are restricted to fewer remaining stop-over sites. This more intensive use of remaining sites might increase infection prevalence in migratory birds and the probability of stop-over site infection. Stop-over site loss can thus have a large impact on pathogen-host interactions and pathogen dispersal. A better understanding of how stop-over loss influences host-pathogen interaction and pathogen dispersal is urgently needed for monitoring and controlling avian-borne (zoonotic) diseases.

Long-distance migration of birds is often over a network of connected stop-over sites, in which two sites are connected through bird migratory movements, linking site A with site B. The relative importance of sites and links can be weighed on basis of the number of birds that use a particular stop-over site or that move over a link. Migrating birds nearly always carry pathogens, and migration networks can thus be studied by mathematical models to explore the effects of network properties, such as network topology and network metrics, on infection prevalence and spatial dispersal of pathogens. For example, link density, i.e. the fraction of existing links over the total number of possible links, reflects the connectivity of the network, which is commonly used to indicate the capability of the network for pathogens dispersal. Various studies analysed networks of human and animal movements for infection percolation 
(Keeling et al. 2010), such as the global trade networks (Banks et al. 2015), the livestock trade networks (Motta et al. 2017), and social contact networks of animals (Silk et al. 2017).

Networks, such as real-world trade and transport networks, are often found to be scale-free (Banks et al. 2015). The scale-free topology facilitates dispersal of pathogens in the network due to cascading infection patterns from well-linked hubs (Watts and Strogatz 1998). When extensive site disappears in a network, migratory birds become increasingly confined to fewer and fewer remaining stop-over sites, so that the scale-free topology could disappear, which could make the pathogen dispersal less effective. Alternatively, the infection prevalence in migratory birds and the probability of pathogen infection among remaining sites might increase. However, no study so far tested the effects of site loss on infection prevalence and pathogen dispersal in a migration network.

We therefore modelled infection of the avian influenza virus in a migratory waterfowl population that, like most avian influenza viruses in wild birds, causes no or only mild symptoms. We used modelled behaviour of migratory birds over a network of connected sites and virus infection to test whether sites loss 1) facilitates infection prevalence in migratory birds; and 2) increases the probability of pathogen infecting in remaining sites.

\section{Methods}

We selected a widely distributed migratory waterfowl species, the greater white-fronted goose Anser albifrons. Their distribution range in the East Asian-Australian Flyway covers large area form $70^{\circ} \mathrm{N}$ in Russia to $29^{\circ} \mathrm{N}$ in China, including Mongolia, Japan, Korea and Yangtze River Basin. Locations of suitable wetlands were obtained from predicted probabilities from a logistic regression model, testing the relationships between presence/absence (binomial) of greater white-fronted geese and environmental factors, including water body area, elevation, longitude, and foraging area. The foraging area was defined as grassland and cropland within maximum foraging distance of greater whitefronted geese (Johnson et al. 2014). We selected those wetlands where the predicted probability of use exceeded $75 \%$. Additionally, we calculated the percentage of area loss for selected wetlands based on the sum of water body area and surrounding grassland area between 1992 and 2012, in order to generate various networks under different scenarios of habitat loss. 
Each selected wetland was a site in the migration network, and each site was given geographic coordinates, area size, percentage of area loss, and site type (either breeding site, stop-over site or wintering site; Table S4.1). During simulations, we also assigned three state variables to each site, infectious stage (healthy/infectious), the amount of pathogen in the environment $\left(E_{i}^{t}\right)$ and site attractiveness $\left(A_{i}^{t}\right)$. The $A_{i}$ refers to the conditions at site $i$ that drive the orientation of movements (Taylor et al. 2016). In our model, $A_{i}$ was calculated as:

$$
A_{i}^{t}=e^{\lambda_{i}^{t}}
$$

where $\lambda_{i}^{t}$ is the bird density on site $i$ at time step $t$.

Since the spatial-temporal patterns of avian influenza outbreaks matched well with autumn migration (Xu et al. 2016; Si et al. 2009), we focused on autumn migration of greater whitefronted geese. We constructed directional links between sites at higher latitudes to sites at lower latitudes if their geographical distance was smaller than the maximum migration distance without stopping $\left(F_{\text {capability }}\right)$ observed for greater white-fronted geese in autumn migration (Kölzsch et al. 2016). We gave each link a geographic distance $\left(D_{i j}\right)$. During simulations, we also assigned two state variables to each link, migration resistance $\left(R_{i j}\right)$ and migration flow $\left(M F_{i j}^{t}\right)$. These state variables were calculated as (Taylor et al. 2016):

$$
\begin{aligned}
& R_{i j}=e^{\kappa \cdot D_{i j}} \\
& M F_{i j}^{t}=\frac{A_{j}^{t}-A_{i}^{t}}{R_{i j}}
\end{aligned}
$$

where $\kappa$ is a scale parameter.

Furthermore, we used three scenarios with different levels of site loss: a complete migration network with all sites; a migration network with moderate site loss, and migration network with severe site loss (see below).

A total of 10,000 greater white-fronted geese were simulated as agents in our model. Each bird had several state variables, including infection stage (either susceptible, infected, or recovered), body mass $\left(m^{t}\right)$, and infection route (either not infected, infected via direct contact or infected via indirect contact). The original body mass of each bird was randomly assigned according to a Gaussian distribution $N\left(\mu, \sigma^{2}\right)$, where $\mu$ is the average body mass of 
the migratory birds, and $\sigma$ the standard deviation (Allen et al. 2006). For simplification, we did not include any demographic events such as birth, mortality, or goal-oriented behaviour.

Each bird accumulates body mass when it is in a site. When the body mass reaches the migration threshold $(\varphi)$ the bird migrates. First of all, among all the out-going links whose $D_{i j}$ is larger than $D_{\operatorname{mini}}$ from the current site, such a bird selects the one with the largest $M F^{t}{ }_{i j}$ as target link for migration, where $D_{\operatorname{mini}}=D_{n s} / n, D_{n s}$ is the geographic distance between the northernmost site and the southernmost site, and $n$ is the expected numbers of refuelling during migration, i.e., the expected number of stop-over sites. If none of the out-going links has a large enough $D_{i j}$, the bird selects one with the largest $M F^{t}{ }_{i j}$.

Moreover, the site on the other end of the target link is the target site where the bird migrates to. Since variation and uncertainty in using stop-over sites are commonly observed from satellite telemetry studies (Batbayar et al. 2011; Kölzsch et al. 2016), in our model, each bird also has a small probability $(p)$ to randomly select a link from all the out-going links for migration.

After the selection of target link and target site, the bird moves to the target site if $D_{i j}$ of the target link is smaller or equal to the flying speed ( $\mathrm{km} /$ day), otherwise the bird moves along the target link towards its target site with the length of flying speed. After movement, the body mass is updated as $m^{t}=m^{t-1}+a-c d$, where $a$ is the body mass accumulation rate (g/day) when bird refuelling on a site, $c$ is the body mass consumption rate $(\mathrm{g} / \mathrm{km}) ; d$ is the distance of its movement $(\mathrm{km})$.

A bird can be either susceptible, infected, or recovered in our model. A susceptible bird can become infected via either direct contact (i.e., contact between susceptible bird and infected bird) or indirect contact (i.e., contact between susceptible bird and pathogens in the environment). An infected bird recovers when its infected period was longer than the infection period $(T)$, after which it could not become infected or susceptible again. We assume that a density independent transmission captures transmission among birds (de Jong et al. 1995). The infection probability during a time step $\left(\rho_{i}^{t}\right)$ for each susceptible bird at site $i$ and time step $t$ was calculated as:

$$
\rho_{i}^{t}=\frac{\beta\left(I_{i}^{t}+E_{i}^{t}\right)}{N_{i}^{t}}
$$


where $\beta$ is the transmission rate parameter $\left(d a y^{-1}\right), I$ is the number of infected birds, $N$ the number of birds. We used $E_{i}^{t}\left(\right.$ bird $\left.^{-I}\right)$ to estimate the amount of viruses per bird unit (Breban et al. 2009):

$$
E_{i}^{t}=(1-\eta) E_{i}^{t-1}+(1-\eta) I_{i}^{t-1}
$$

where $\eta$ is the pathogen decaying rate.

We calculated the effective reproduction number $R_{0}$ for each site at each time step. The effective $R_{0}$ was defined as the sum of the average number of new infections caused by direct contact from one infected bird, $R_{0}{ }^{\text {direct }}$, and the average number of new infections caused by indirect contact, $R_{0}{ }^{\text {indirect }}$ (De Rueda et al. 2015):

$$
\begin{gathered}
R_{0}^{\text {direct }}=\beta T \frac{s_{i}^{t}}{N_{i}^{t}} \\
R_{0}^{\text {indirect }}=\beta T\left(\frac{1}{\eta}-1\right) \frac{s_{i}^{t}}{N_{i}^{t}}
\end{gathered}
$$

where $S$ is the number of susceptible birds, and $T$ is the infection period.

In each network scenario, we initiated the model, with all birds at the northernmost site, and $1 \%$ of all birds being infected. All sites are healthy sites at the beginning of the simulations. In the models, one simulation time step is equivalent to one day. The simulations ended after 150 simulation time steps, so that we captured the full prevalence dynamics from the entire autumn migration, i.e. from the breeding sites to the wintering sites. For each network scenario, the simulation ran over 200 repetitions and outputs were averaged. For each time step, bird decisions are illustrated in Figure 4.1. Parameters and variables are summarized in Table 4.1 and Table 4.2, respectively. The agent-based model was built in NetLogo 6.0.1 (Wilensky 1999). 


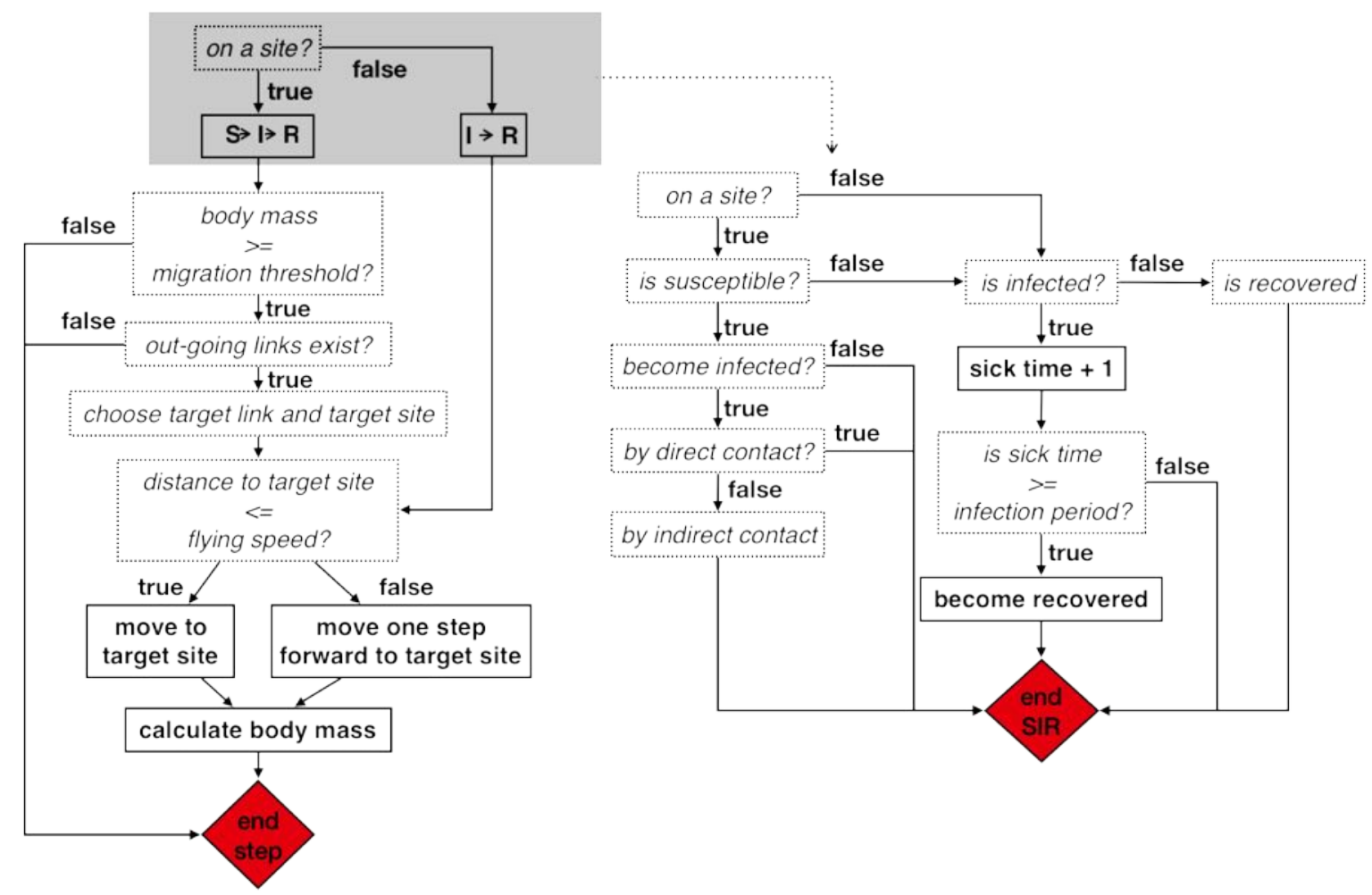

Figure 4.1 Diagram of bird decisions (dashed rectangles) and processes (solid rectangles) within a single time step. The left diagram illustrates the decisions and behaviour processes, the right diagram illustrates the susceptible-infected-recovered processes. 
Table 4.1 Parameters in the agent-based model, with their abbreviation, definition, value and unit.

\begin{tabular}{|c|c|c|c|c|}
\hline Parameter & Definition & Value & Unit & Reference \\
\hline$N$ & population size & 10,0000 & individual & (Rohani et al. 2009) \\
\hline$\mu$ & body mass average of the migratory population & $2075(2075-3000)$ & $\mathrm{g}$ & (Dunning and John 2008) \\
\hline$\sigma$ & standard deviation of body mass average & $220(218-220)$ & $\mathrm{g}$ & ( Dunning and John 2008) \\
\hline$\varphi$ & migration threshold & $15 \%$ & - & - \\
\hline$a$ & body mass accumulation rate & $38(22.5-88.0)$ & $\mathrm{g}_{\text {day }}{ }^{-1}$ & (Madsen and Klaassen 2006) \\
\hline$c$ & body mass consumption rate & $0.5(0.2-0.5)$ & $\mathrm{g} \mathrm{km}^{-1}$ & (Madsen and Klaassen 2006) \\
\hline$s$ & flying speed & $486(475.2-492.5)$ & $\mathrm{km} \mathrm{day}^{-1}$ & (Kölzsch et al. 2016) \\
\hline$n$ & expected number of stop-over sites & $7(0-10)$ & - & - \\
\hline$D_{n s}$ & $\begin{array}{l}\text { geographic distance between the northernmost site } \\
\text { and the southernmost site }\end{array}$ & 4509.709 & $\mathrm{~km}$ & Table S4.1 \\
\hline$p$ & random movement probability & 0.001 & - & - \\
\hline$F_{\text {capability }}$ & maximum migration distance without stop & 1201.2 & $\mathrm{~km}$ & (Kölzsch et al. 2016) \\
\hline$\phi$ & percentage of the initial infection & $1 \%$ & - & - \\
\hline$\beta$ & transmission rate parameter & $0.1(0-1.3)$ & day $^{-1}$ & (Breban et al. 2009) \\
\hline$\eta$ & virus decaying rate in environment & $0.1(0.01-0.25)$ & - & (Rohani et al. 2009) \\
\hline$T$ & infection period & 7 & day & (Webster et al. 1978) \\
\hline$\kappa$ & scale parameter for migration resistance & 0.1 & - & - \\
\hline
\end{tabular}


Table 4.2 Variables in the agent-based model, with their abbreviation, their owner and definition.

\begin{tabular}{ccc}
\hline Variable & Owner & Definition \\
\hline$N$ & site & the local number of birds \\
$E$ & site & the amount of virus in the environment \\
$A_{i}$ & site & site attractiveness \\
$D_{i j}$ & link & geographic distance \\
$M P_{i j}$ & link & migration pressure of a link \\
$m$ & bird & body mass \\
infection stage & bird & bird can be either susceptible, infected or recovered \\
infection route & bird & bird can be either not infected, infected by direct \\
$R_{0}$ & site & contact or infected by indirect contact \\
$R_{0}{ }^{\text {direct }}$ & site & average number of new infections caused by direct \\
$R_{0}{ }^{\text {indirect }}$ & site & contact to one infected bird ${ }^{\text {indirect }}$ \\
$\lambda_{i}$ & site & average number of new infections caused by contact \\
$R_{i j}$ & to the virus that was shed by one infected bird \\
$p$ & site & Bird density \\
$H P$ & site & infection probability to each susceptible individual \\
& & site popularity \\
\hline & & migration resistance of a link \\
& &
\end{tabular}

At each time step, target links and target sites were recorded into an output file, which were used to generated migration networks that were visited by our simulated birds. We calculated the frequency for each target site and used the frequency as index of site popularity. We calculated site-level network metrics (Banks et al. 2015; Dubé et al. 2011; Silk et al. 2017), including weighed in-degree and unweighed in-degree, and calculated network-level metrics, including number of sites, number of links, and link density. In addition, we also checked whether the networks were scale-free on the basis of the power-law degree distribution (Banks et al. 2015).

In order to study the dynamics of the infection prevalence in our migratory birds, we calculated the number of infected birds, the cumulative number of infected birds, the number of infected birds via direct contact, and the number of infected birds via indirect contact at each time step. We also performed sensitivity analyses on the number of infected birds by 
varying transmission rate parameter $\beta$ and the pathogen decaying rate in environment $\eta$, separately.

In order to study the pathogen dispersal among sites, we classified a site as healthy site if its effective $\mathrm{R}_{0}<1$. A site was classified as infectious site if its effective $\mathrm{R}_{0}>1$. In order to explore the infection probability for sites in our migration networks, we constructed Generalized Linear Models (GLMs) assuming a binomial distribution, using a logit link function. The response variable was the whether a site was classified as uninfected or infected, and the predictors were weighed in-degree, unweighed in-degree, and site popularity, respectively. All analyses were done in R 2.11.0 (R Development Core Team 2016).

\section{Results}

98 wetlands were selected by the logistic regression and were selected as sites for constructing the migration networks. Among these sites, except for 47 sites that did not lose any area, 4 sites lost a large proportion of their area (30\%-50\%) and 47 sites lost relatively small proportion of their area (0\%-30\%; Table S4.1). The area loss in the migration networks of greater white-fronted geese had a spatial heterogeneous pattern (Figure 4.2), as most of the sites with area loss were located in eastern China and Japan, where rapid urbanization and economic development occurred since 1992 (Seto 2005). We constructed a migration network with moderate site loss by removing sites with $30 \%-50 \%$ area loss, and with severe site loss by removing all sites with area loss (Figure 4.2D, E and F; Table 4.3). The number of visited sites by migrating birds was slightly lower than the total number of available sites in in each network scenario (Table 4.3). Due to extensive site removal, birds migrated over a shorter distance $(3682 \mathrm{~km})$ in the network with severe site loss, compared with the migration distance $(4423 \mathrm{~km})$ in the complete network and the network with moderate site loss (Figure 4.2D, E and F; Table 4.3). 
Table 4.3 Description of constructed migration networks, and the visited migration networks. $\mathrm{CMN}$ : complete migration networks, MMN: migration network with moderate site loss, SMN: migration network with severe site loss.

\begin{tabular}{|c|c|c|c|c|c|c|}
\hline \multirow{2}{*}{ Description } & \multicolumn{3}{|c|}{ Constructed migration networks } & \multicolumn{3}{|c|}{ Visited migration networks } \\
\hline & CMN & MMN & SMN & CMN & MMN & SMN \\
\hline Total number of sites & 98 & 94 & 47 & 92 & 87 & 42 \\
\hline Number of breeding sites & 4 & 4 & 2 & 2 & 2 & 1 \\
\hline Number of passage sites & 67 & 65 & 36 & 63 & 61 & 32 \\
\hline Number of wintering sites & 27 & 25 & 9 & 27 & 24 & 9 \\
\hline Number of links & 1385 & 1314 & 436 & 417 & 386 & 165 \\
\hline Link density & 0.15 & 0.15 & 0.20 & 0.05 & 0.05 & 0.10 \\
\hline Migration distance $(\mathrm{km})^{*}$ & 4423 & 4423 & 3682 & 4423 & 4423 & 3682 \\
\hline $\begin{array}{l}\text { Percentage of infectious } \\
\text { sites (i.e. effective } \mathrm{R}_{0}>1 \text { ) }\end{array}$ & & & & $33 \%$ & $36 \%$ & $49 \%$ \\
\hline
\end{tabular}

* The migration distance is calculated as the geographic distance between the northernmost and the southernmost sites $\left(1^{\circ}\right.$ in latitude $\left.=111 \mathrm{~km}\right)$.

In all scenarios, the degree distribution of migration network followed a power-law distribution (Kolmogorov-Smirnov test, $\mathrm{P}>0.05$; Figure S4.1). Furthermore, the link density increased from 0.05 in the complete network and the network with moderate site loss to 0.1 in the network with severe site loss, while the percentage of infectious sites increased from $33 \%$ in the complete network to $49 \%$ in the network with severe site loss (Table 4.3 ).

Overall, the three network scenarios generated similar patterns of infection dynamics in birds, with two infection peaks and an extremely low prevalence between peaks (Figure 4.3A). These infection peaks are temporally consistent with infection peaks that were caused via direct contact and indirect contact, and infection peaks are mainly dominated by indirect contact (Figure 4.3C and D). Moreover, the infection prevalence from the migration network with severe site loss had a faster growth rate, with an earlier and higher infection peak compared with that in the other two networks (Figure 4.3A, C and D). 

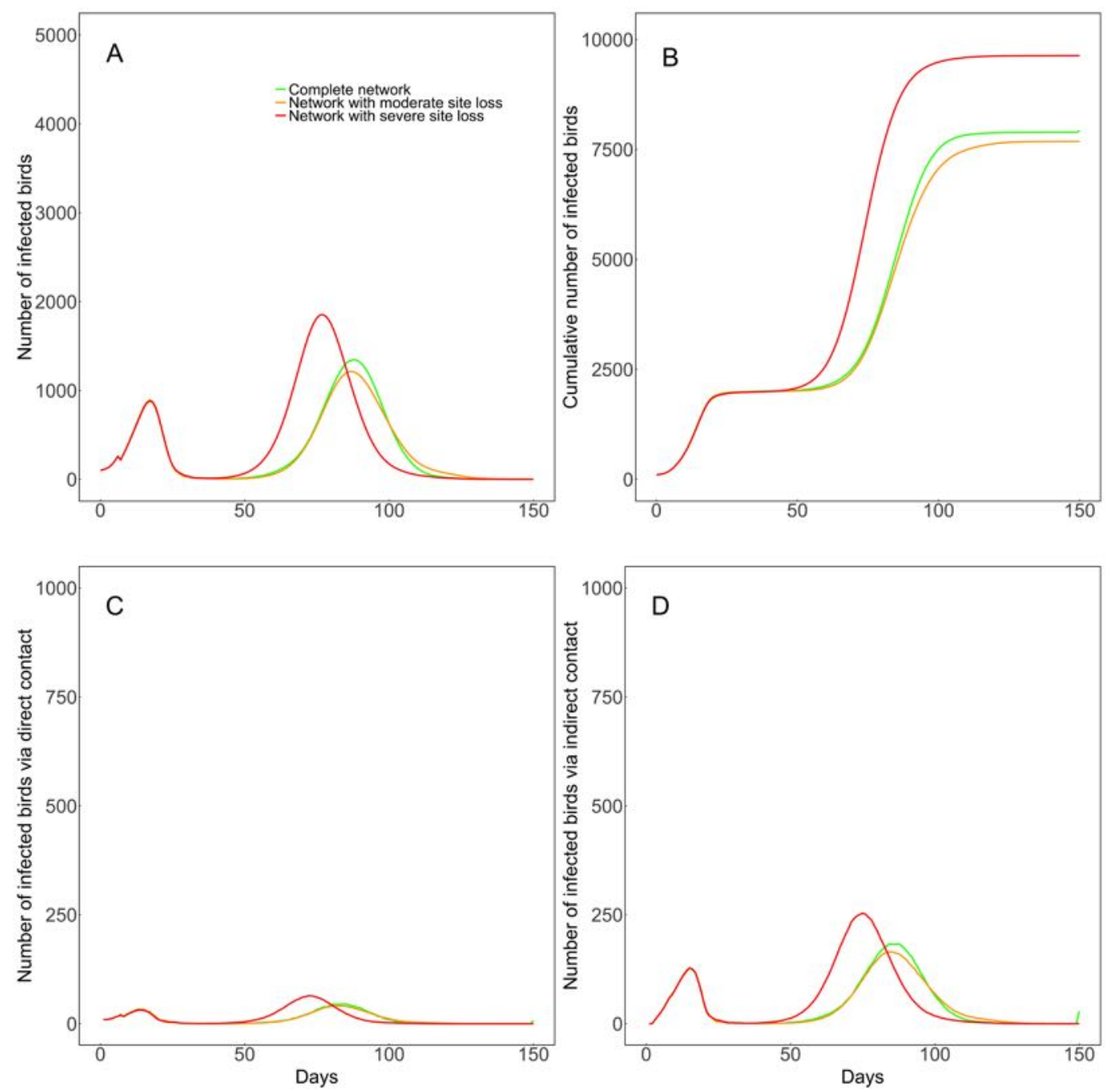

Figure 4.3 Simulated infection dynamics in migratory populations. The number of infected birds, $\mathrm{A}$; the cumulative number of infected birds, B; the number of infection via direct contact, $\mathrm{C}$; the number of infection via indirect contact, D. Green lines: complete migration network; yellow lines: migration network with moderate site loss; red lines: migration network with severe site loss.

Generally, the infection prevalence grew slower, with a delayed and lower infection peak, with a decreasing transmission rate parameter, $\beta$ (Figure 4.4A). The reduction effect on the number of infected birds during the first infection peak was relatively linear with a decrease in $\beta$. However, the reduction effect became less linear during the second peak (Figure 4.4A), partly due to the lower number of susceptible birds as many birds became infected during the first peak. In contrast, with an increase in the pathogen decaying rate in the environment, $\eta$, the infection prevalence grew slower, with delayed and lower infection peak (Figure 4.4B). The reduction effects were generally linearly related to the change in $\eta$ in both the first and second infection peak. The infection prevalence reduced to zero when no virus could persist in the environment (i.e., $\eta=1$; Figure 4.4B). 

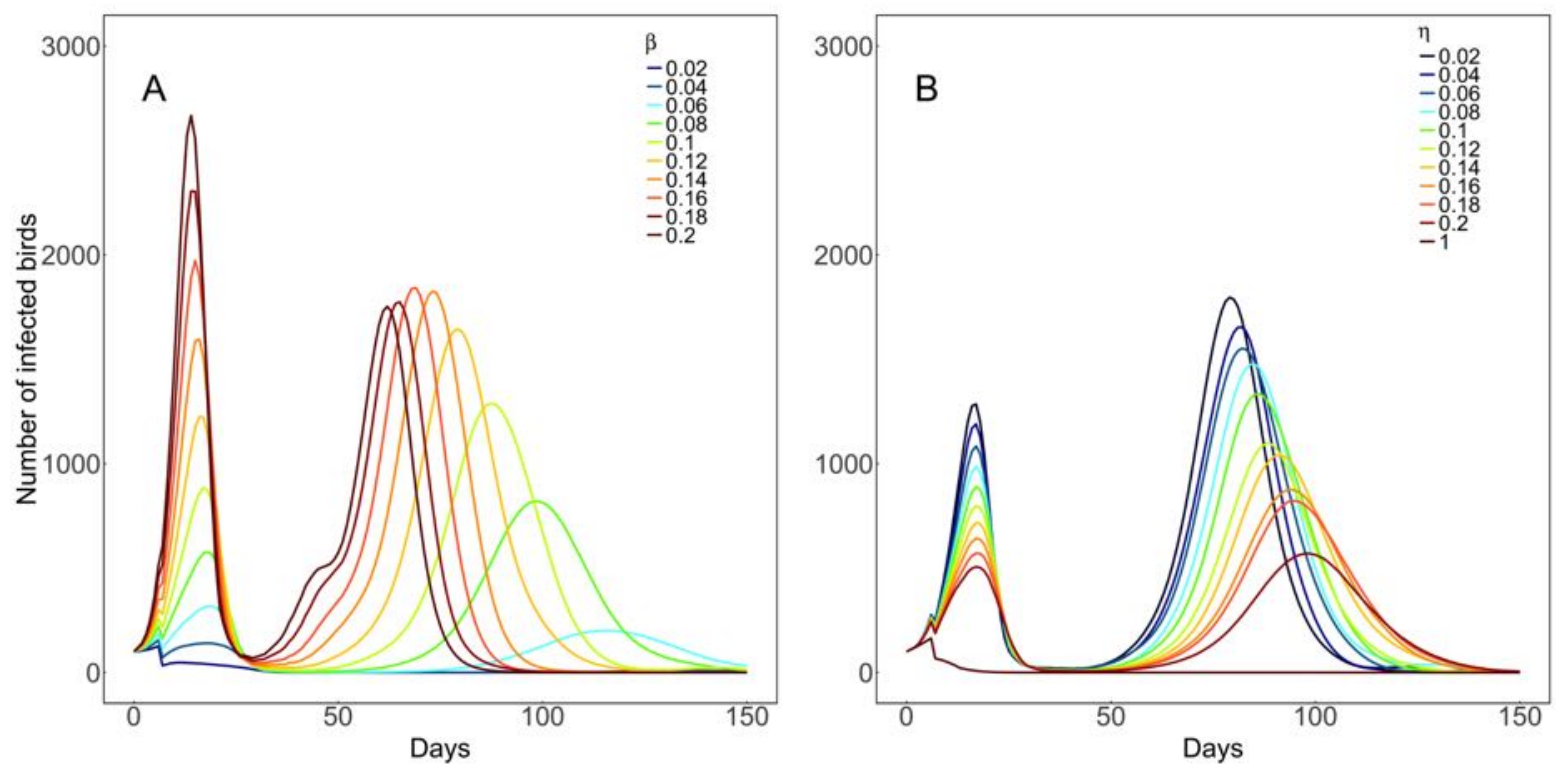

Figure 4.4 Sensitivity analyses of the effect of the transmission rate parameter, $\beta(A)$, and the pathogen decaying rate in the environment, $\eta(B)$, on the number of infected birds. The colours represent various levels of $\beta$ and $\eta$. All simulations were performed in the complete migration network with all sites.

Infection probability for sites was strongly correlated with weighed in-degree, unweighed in-degree and site popularity (Figure 4.5), i.e. sites that received more connections and more birds had higher probability to be infected. Moreover, in the network with severe site loss, sites became earlier infectious compared with sites in other networks, especially in terms of the relationships with weighed in-degree and unweighed in-degree, respectively (Figure 4.5A and B). 
Chapter 4 Habitat Loss Facilitates AIV Dispersal and Prevalence 

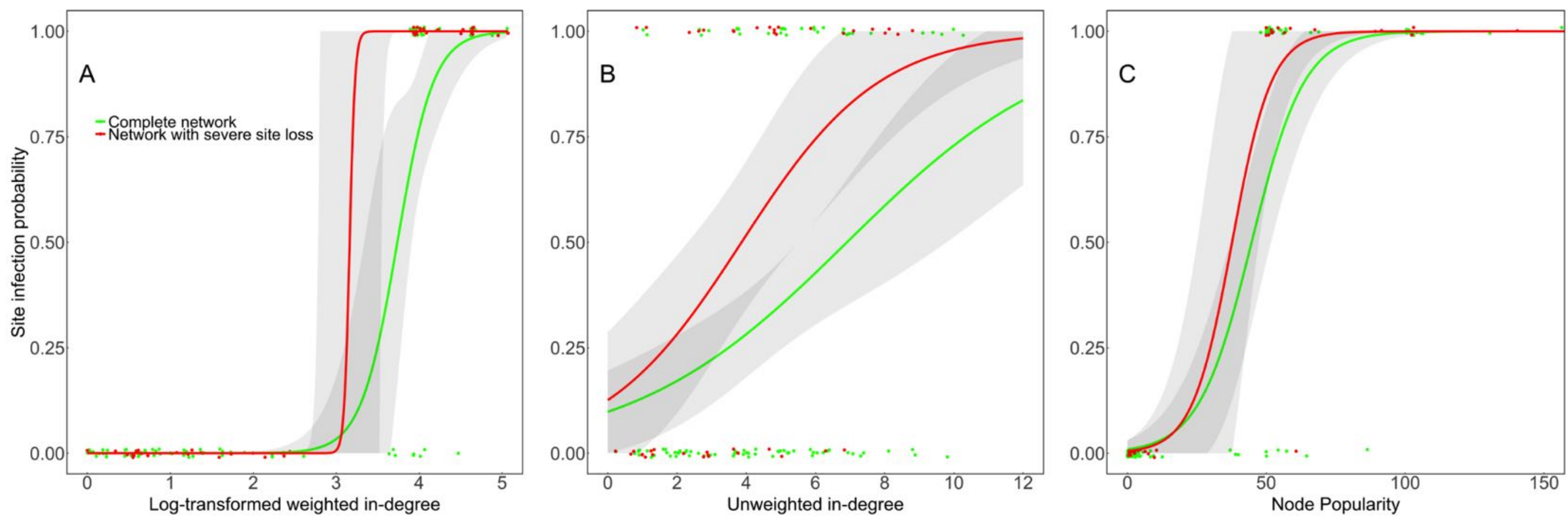

Figure 4.5 Logistic regression results between infection probability for sites and log-transformed weighed in-degree (A), unweighed in-degree (B), and site popularity (C). The grey shaded areas represent the $95 \%$ CIs. Green lines: complete migration network; red lines: migration network with severe site loss. The comparison among all three scenarios is illustrated in Figure S4.5. 


\section{Discussion}

We build an agent-based model of bird migration, combined with pathogen transmission and migration network to provide insights into the consequences of habitat loss on infection prevalence in migratory animals, and long-distance pathogen dispersal. Our simulations clearly indicate that migration allows migratory birds to escape from pathogens that persist in the environment, thereby temporally reducing the infection prevalence in the migratory population. Extensive habitat loss, however, can decrease the migration distance, and consequently, migratory birds shifted their overwintering sites northwards. This shift can cause a faster growth of pathogen infection after migration. Furthermore, the fewer remaining stop-over sites under severe site loss are more likely to become hotspots of infection outbreak.

Migratory birds spent nearly the same amount of time for refuelling on sites during their migration in the three migration networks (Figure S4.2), due to the linear dynamic of body mass in our model. As birds use stop-over sites for a similar amount of time, their infection prevalence may not differ over the three scenarios of site loss (Figure 4.3). The birds in the network with severe site loss, however, migrated a shorter total distance (Figure 4.2C and E; Table 4.3), due to spatial heterogeneous site loss (Figure 4.2A), and consequently, the birds terminated their migration approximately 10 days earlier than birds from other networks (Figure S4.3), which facilitates infection growth on their wintering sites (Figure 4.3, Figure S4.3).

Apart from the site loss, reduced migration distance can also be caused by other factors such as climate. Migratory waterfowl aggregate along the $0^{\circ}$ isotherm for overwintering $(\mathrm{Xu}$ et al. 2016; Reperant et al. 2010), a strategy that enables them to forage on unfrozen water body and preserve energy from migrating longer distances (Reperant et al. 2010). Therefore, in warmer winters, migratory birds may terminate their migration at higher latitudes (La Sorte and Thompson 2007; Lehikoinen et al. 2013; Jensen et al. 2008), resulting thereby in a reduced migration distance that can trigger a faster growth of infection prevalence.

Large bird aggregations in a network with severe site loss also increased the growth of infection prevalence. In the other two networks, birds terminated their migration at two separate wintering sites (i.e., site 96 in southern Japan and site 98 in the Yangtze River Basin; Figure S4.4), but in the network with severe site loss, birds aggregated in a single site (i.e., site 86$)$ at the end of migration. Although this pattern was generated by a simplified 
migration decision algorithm (Taylor et al. 2016), empirical studies showed that greater white-fronted geese that breed in Siberia indeed overwinter in multiple areas, including southern Japan and Yangtze River Basin (BirdLife \& Nature Serve 2014). Suitable habitats in Japan and Yangtze River Basin, however, decreased over the past 20 years (Table S4.1), and removal of these sites can result in an intensive aggregation, leading to an earlier and higher infection peak (Figure 4.2).

In our three scenarios, infection prevalence was extremely suppressed during migration (Figure 4.2A), which is in line with migration escape (Altizer et al. 2011), which has also been observed in other species, including reduced warble fly transmission in reindeer Rangifer tarandus, reduced seroprevalence of avian influenza virus in lesser black-backed gulls Larus fuscus, and reduced infection prevalence of a protozoan parasite Ophryocystis elektroscirrha in monarch butterfly (Altizer et al. 2011; Arriero et al. 2015; Satterfield et al. 2015). Infection prevalence, however, increased again when the migratory birds aggregated at their overwintering sites. It is unlikely that migratory birds can completely get rid of the pathogens in our model, because pathogens shed by previous birds can be picked up by birds arriving later, a so-called 'relay effect' (Gaidet et al. 2010; Prosser et al. 2011). For future studies, a stochastic process should be considered for exploring whether pathogen infection can be lost in a migratory population, especially during periods of infection suppression. This is crucial for understanding pathogen perpetuation of in a migratory population and the mechanism of long-distance dispersal (Verhagen et al. 2015).

Simulated migration networks were scale-free, either with or without site removal. This scale-free topology is determined by the pattern of bird migration since the birds always migrate from a site, which was linked with previous visited sites to new sites. This pattern of link generation in a migration network is similar to that in a network of real-world trade or transportation, also called 'preferential attachment' (Li et al. 2012; Barthélemy 2011). This scale-free topology increases the likelihood of pathogen dispersal (Banks et al. 2015), especially when the 'hub' sites that contain a large number of links are infected; pathogens may not need to be very infectious to infect a large amount of sites due to cascading effect (Bigras-Poulin et al. 2007; Banks et al. 2015). Different clades of avian influenza viruses from two flyways were traced back to one ancestor virus in the common breeding habitat of two migratory species, which is highly connected to numerous habitats (Tian et al. 2015). The 'hub' sites in a network correspond to that are used by migratory birds arriving from various previous sites such as those at junctions of different flyways or common breeding or 
wintering sites. These sites should receive a high priority when monitoring infection dynamic in wild migratory birds for better understanding the global dispersal of pathogens.

Moreover, our simulations are in line with our expectation that migratory birds use stopover sites more intensively under severe site loss, which increases the percentage of infected sites and the probability of site infection (Table 4.3, Figure 4.5 and Figure S4.5). Therefore, site loss in a migration network favours the dispersal of pathogens. Many empirical studies that are trying to understand the dispersal of pathogens over long-distances focused on the spatial-temporal correlations and phylogeographic correlations among migratory birds, poultry trade, poultry distribution and distribution of infection outbreaks (Si et al. 2009; Tian et al. 2015; Gilbert et al. 2014). However, our simulations suggested that habitat loss in a migration flyway can affect long-distance pathogen dispersal. Therefore, we call for more studies using a network approach to better understand pathogen dispersal.

In our study, we assumed a constant population size under different levels of habitat loss, however, habitat loss can also cause population declines (Berger et al. 2008; Newton 2007; $\mathrm{Xu}$ et al. 2018). Since pathogen transmission among birds depends on population size, especially for density independent transmission, further studies should include the impact of changing population sizes. Furthermore, we only focused on suitable habitats of the greater white-fronted goose, which has a narrow, long distribution in the East Asian-Australian Flyway. Other migratory species, however, have different distributions. For example, the Swan goose has a broad, short distribution over the same flyway (BirdLife \& Nature Serve 2014). Therefore, habitat loss, especially with a spatial heterogeneous pattern, will have different effects on the configurations of the migration network of other species, changing infection prevalence dynamics and pathogen dispersal. 


\section{Appendix to Chapter 4}

Table S4.1 Descriptions of the sites selected for generating networks

\begin{tabular}{|c|c|c|c|c|c|c|c|c|}
\hline ID & Longitude & Latitude & Water (92) & Grass (92) & Water (12) & Grass (12) & Location & Type \\
\hline 1 & 134.3 & 69.1 & 110.2 & 43.1 & 120.4 & 61.9 & Russia & B \\
\hline 2 & 143.1 & 68.7 & 291.7 & 312.8 & 300.4 & 300.7 & Russia & B \\
\hline 3 & 143.8 & 67.7 & 1359.5 & 1062.3 & 1368.6 & 1441.5 & Russia & B \\
\hline 4 & 153.1 & 67.5 & 898.3 & 363.1 & 836.7 & 373.2 & Russia & B \\
\hline 5 & 159.3 & 66.5 & 238.6 & 857.4 & 238.6 & 913.1 & Russia & $\mathrm{S}$ \\
\hline 6 & 151.1 & 66.4 & 612.2 & 128.0 & 597.1 & 132.3 & Russia & $\mathrm{S}$ \\
\hline 7 & 156.4 & 65.9 & 3.0 & 165.5 & 3.0 & 145.7 & Russia & $\mathrm{S}$ \\
\hline 8 & 160.3 & 65.2 & 40.4 & 169.5 & 40.4 & 175.2 & Russia & $\mathrm{S}$ \\
\hline 9 & 138.7 & 64.9 & 52.9 & 196.1 & 52.9 & 415.8 & Russia & $\mathrm{S}$ \\
\hline 10 & 152.4 & 64.7 & 226.3 & 236.5 & 233.8 & 174.2 & Russia & $\mathrm{S}$ \\
\hline 11 & 161.5 & 64.4 & 43.4 & 706.8 & 43.4 & 766.7 & Russia & $\mathrm{S}$ \\
\hline 12 & 153.9 & 63.9 & 104.5 & 74.1 & 107.8 & 71.7 & Russia & $\mathrm{S}$ \\
\hline 13 & 149.9 & 63.4 & 4.8 & 80.3 & 4.8 & 165.4 & Russia & $\mathrm{S}$ \\
\hline 14 & 147.8 & 63.1 & 200.9 & 374.7 & 203.1 & 753.6 & Russia & $\mathrm{S}$ \\
\hline 15 & 154.0 & 63.1 & 2.8 & 129.5 & 2.8 & 162.0 & Russia & $\mathrm{S}$ \\
\hline 16 & 152.5 & 62.5 & 114.8 & 100.4 & 123.3 & 139.5 & Russia & $\mathrm{S}$ \\
\hline 17 & 149.3 & 62.1 & 298.3 & 91.5 & 294.3 & 139.5 & Russia & $\mathrm{S}$ \\
\hline 18 & 159.8 & 61.9 & 160.6 & 1762.1 & 160.5 & 1840.2 & Russia & $\mathrm{S}$ \\
\hline 19 & 154.5 & 61.5 & 15.9 & 120.9 & 15.9 & 148.5 & Russia & $\mathrm{S}$ \\
\hline 20 & 140.4 & 61.1 & 423.8 & 629.1 & 424.7 & 641.1 & Russia & $\mathrm{S}$ \\
\hline 21 & 149.3 & 60.5 & 966.0 & 2950.1 & 963.3 & 3862.5 & Russia & $\mathrm{S}$ \\
\hline 22 & 143.4 & 60.5 & 16.9 & 102.4 & 16.9 & 131.3 & Russia & $\mathrm{S}$ \\
\hline 23 & 145.1 & 60.2 & 45.6 & 104.6 & 45.6 & 109.2 & Russia & $\mathrm{S}$ \\
\hline 24 & 143.6 & 59.6 & 218.4 & 1275.6 & 226.4 & 1346.0 & Russia & $\mathrm{S}$ \\
\hline 25 & 160.5 & 59.5 & 19.4 & 61.2 & 19.4 & 76.4 & Russia & $\mathrm{S}$ \\
\hline 26 & 136.1 & 58.9 & 0.6 & 18.0 & 0.6 & 16.6 & Russia & $\mathrm{S}$ \\
\hline 27 & 159.4 & 58.6 & 33.3 & 1069.9 & 33.3 & 1112.9 & Russia & $\mathrm{S}$ \\
\hline 28 & 161.7 & 57.6 & 58.9 & 136.2 & 58.9 & 127.5 & Russia & $\mathrm{S}$ \\
\hline 29 & 158.7 & 57.4 & 53.8 & 1533.5 & 53.1 & 1491.7 & Russia & $\mathrm{S}$ \\
\hline 30 & 131.8 & 57.4 & 146.1 & 28.2 & 146.1 & 24.9 & Russia & $\mathrm{S}$ \\
\hline 31 & 156.4 & 56.6 & 248.2 & 4604.6 & 244.9 & 4655.9 & Russia & $\mathrm{S}$ \\
\hline 32 & 135.6 & 56.5 & 45.1 & 294.8 & 45.1 & 360.7 & Russia & $\mathrm{S}$ \\
\hline 33 & 160.9 & 56.4 & 399.8 & 629.3 & 397.7 & 584.5 & Russia & $\mathrm{S}$ \\
\hline 34 & 130.6 & 56.0 & 109.9 & 61.5 & 109.9 & 89.7 & Russia & $\mathrm{S}$ \\
\hline 35 & 159.5 & 55.7 & 43.2 & 112.7 & 43.2 & 96.2 & Russia & $\mathrm{S}$ \\
\hline 36 & 156.9 & 55.4 & 5.3 & 365.7 & 5.3 & 359.6 & Russia & $\mathrm{S}$ \\
\hline 37 & 159.7 & 54.9 & 280.2 & 268.0 & 280.2 & 280.8 & Russia & $\mathrm{S}$ \\
\hline
\end{tabular}




\begin{tabular}{|c|c|c|c|c|c|c|c|c|}
\hline ID & Longitude & Latitude & Water (92) & Grass (92) & Water (12) & Grass (12) & Location & Type \\
\hline 38 & 155.8 & 54.5 & 124.3 & 2486.0 & 124.3 & 2590.4 & Russia & $\mathrm{S}$ \\
\hline 39 & 127.9 & 54.3 & 2340.9 & 646.2 & 2408.9 & 695.9 & Russia & $\mathrm{S}$ \\
\hline 40 & 134.2 & 54.3 & 54.8 & 136.1 & 54.8 & 59.8 & Russia & $\mathrm{S}$ \\
\hline 41 & 132.7 & 54.0 & 14.7 & 92.5 & 14.7 & 77.6 & Russia & $\mathrm{S}$ \\
\hline 42 & 134.9 & 53.8 & 0.5 & 53.1 & 0.5 & 42.8 & Russia & $\mathrm{S}$ \\
\hline 43 & 139.9 & 53.5 & 565.4 & 979.1 & 619.7 & 1216.1 & Russia & $\mathrm{S}$ \\
\hline 44 & 158.1 & 53.1 & 93.7 & 221.3 & 93.4 & 236.5 & Russia & $\mathrm{S}$ \\
\hline 45 & 136.4 & 52.8 & 14.8 & 915.7 & 14.7 & 819.8 & Russia & $\mathrm{S}$ \\
\hline 46 & 156.6 & 52.3 & 428.2 & 1535.5 & 422.9 & 1588.9 & Russia & $\mathrm{S}$ \\
\hline 47 & 140.0 & 51.8 & 1221.0 & 4397.8 & 1457.6 & 5155.5 & Russia & $\mathrm{S}$ \\
\hline 48 & 136.5 & 51.8 & 589.2 & 2953.7 & 597.2 & 2861.1 & Russia & $\mathrm{S}$ \\
\hline 49 & 127.9 & 50.5 & 447.6 & 14007.3 & 458.4 & 12995.4 & Russia & $\mathrm{S}$ \\
\hline 50 & 119.2 & 50.4 & 18.5 & 3455.7 & 18.5 & 3523.9 & China & $\mathrm{S}$ \\
\hline 51 & 115.8 & 50.0 & 1073.0 & 7833.9 & 552.1 & 8040.4 & Russia & $\mathrm{S}$ \\
\hline 52 & 129.7 & 49.5 & 228.8 & 7303.7 & 238.5 & 7009.2 & Russia & $\mathrm{S}$ \\
\hline 53 & 123.7 & 49.2 & 2.6 & 1799.9 & 2.6 & 1673.3 & China & $\mathrm{S}$ \\
\hline 54 & 135.8 & 49.2 & 2891.7 & 25034.9 & 3206.1 & 24557.5 & Russia & $\mathrm{S}$ \\
\hline 55 & 114.4 & 48.6 & 86.3 & 430.2 & 63.2 & 411.3 & Mongolia & $\mathrm{S}$ \\
\hline 56 & 115.5 & 48.5 & 1.7 & 330.1 & 1.7 & 325.1 & Mongolia & $\mathrm{S}$ \\
\hline 57 & 126.3 & 48.2 & 212.3 & 21725.0 & 247.9 & 21275.7 & China & $\mathrm{S}$ \\
\hline 58 & 132.7 & 47.9 & 395.9 & 7746.0 & 472.1 & 7672.1 & China & $\mathrm{S}$ \\
\hline 59 & 118.0 & 47.6 & 3968.6 & 44776.6 & 3413.3 & 46352.4 & Mongolia & $\mathrm{S}$ \\
\hline 60 & 142.7 & 47.4 & 45.6 & 1.6 & 45.6 & 1.0 & Russia & $\mathrm{S}$ \\
\hline 61 & 143.0 & 46.7 & 403.4 & 27.5 & 402.6 & 28.4 & Russia & $\mathrm{S}$ \\
\hline 62 & 131.7 & 46.0 & 5412.5 & 39431.6 & 5481.1 & 39660.9 & China & $\mathrm{S}$ \\
\hline 63 & 134.7 & 45.9 & 9.0 & 392.9 & 9.0 & 579.5 & Russia & $\mathrm{S}$ \\
\hline 64 & 141.9 & 45.2 & 65.0 & 19.5 & 64.3 & 22.0 & Japan & W \\
\hline 65 & 123.7 & 44.5 & 5253.1 & 173233.3 & 5839.2 & 171488.4 & China & $\mathrm{S}$ \\
\hline 66 & 128.6 & 43.7 & 152.8 & 3644.4 & 160.8 & 4031.6 & China & W \\
\hline 67 & 122.8 & 43.6 & 21.2 & 2134.6 & 21.2 & 2094.2 & China & W \\
\hline 68 & 116.7 & 43.3 & 244.5 & 3868.9 & 245.3 & 3852.0 & China & $\mathrm{S}$ \\
\hline 69 & 132.0 & 43.3 & 138.4 & 349.7 & 136.1 & 398.1 & Russia & $\mathrm{S}$ \\
\hline 70 & 142.7 & 43.2 & 993.1 & 506.0 & 996.8 & 549.2 & Japan & W \\
\hline 71 & 143.5 & 42.6 & 54.2 & 33.5 & 54.2 & 34.2 & Japan & W \\
\hline 72 & 130.6 & 42.5 & 228.4 & 1071.9 & 231.6 & 1241.7 & Russia & W \\
\hline 73 & 120.7 & 41.1 & 24.9 & 2861.4 & 23.9 & 2756.1 & China & $\mathrm{W}$ \\
\hline 74 & 122.7 & 41.0 & 690.4 & 4993.9 & 622.6 & 4989.0 & China & W \\
\hline 75 & 119.7 & 40.7 & 6.3 & 1198.0 & 6.3 & 1201.2 & China & W \\
\hline 76 & 115.7 & 40.3 & 61.2 & 3170.9 & 45.6 & 2906.3 & China & $\mathrm{S}$ \\
\hline 77 & 125.0 & 40.1 & 2530.3 & 39241.6 & 2519.5 & 42828.9 & $\begin{array}{l}\text { North } \\
\text { Korea }\end{array}$ & W \\
\hline 78 & 119.2 & 39.8 & 134.2 & 2296.1 & 112.0 & 2106.4 & China & W \\
\hline
\end{tabular}




\begin{tabular}{|c|c|c|c|c|c|c|c|c|}
\hline ID & Longitude & Latitude & Water (92) & Grass (92) & Water (12) & Grass (12) & Location & Type \\
\hline 79 & 127.5 & 39.8 & 92.5 & 1254.6 & 91.4 & 1345.1 & $\begin{array}{l}\text { North } \\
\text { Korea }\end{array}$ & W \\
\hline 80 & 117.7 & 39.1 & 2700.4 & 21360.9 & 2537.7 & 19341.0 & China & $\mathrm{W}$ \\
\hline 81 & 139.9 & 38.9 & 4.9 & 36.0 & 4.9 & 34.2 & Japan & W \\
\hline 82 & 140.3 & 38.2 & 1322.2 & 2350.8 & 1352.8 & 1335.7 & Japan & $\mathrm{W}$ \\
\hline 83 & 118.9 & 37.9 & 481.9 & 1465.2 & 530.8 & 1397.4 & China & W \\
\hline 84 & 115.6 & 37.6 & 35.9 & 1894.4 & 35.9 & 1725.3 & China & $\mathrm{S}$ \\
\hline 85 & 116.1 & 36.1 & 185.5 & 2428.8 & 211.5 & 2039.0 & China & W \\
\hline 86 & 127.7 & 35.9 & 1285.2 & 23804.2 & 1255.4 & 26494.7 & $\begin{array}{l}\text { South } \\
\text { Korea }\end{array}$ & W \\
\hline 87 & 136.8 & 35.7 & 1098.1 & 1699.7 & 1090.9 & 799.8 & Japan & W \\
\hline 88 & 133.1 & 35.4 & 205.3 & 44.8 & 204.9 & 19.2 & Japan & W \\
\hline 89 & 110.6 & 34.9 & 61.2 & 2853.9 & 90.1 & 2512.9 & China & S \\
\hline 90 & 135.3 & 34.7 & 34.9 & 286.2 & 32.0 & 135.4 & Japan & $\mathrm{S}$ \\
\hline 91 & 134.1 & 34.4 & 342.7 & 784.4 & 322.5 & 387.6 & Japan & $\mathrm{W}$ \\
\hline 92 & 120.2 & 34.2 & 252.1 & 182.2 & 265.3 & 149.4 & China & W \\
\hline 93 & 130.7 & 33.5 & 315.0 & 424.2 & 311.3 & 311.3 & Japan & $\mathrm{W}$ \\
\hline 94 & 114.2 & 33.0 & 60.2 & 62.6 & 78.1 & 37.0 & China & $\mathrm{S}$ \\
\hline 95 & 118.2 & 33.0 & 21414.6 & 42342.3 & 20521.7 & 37730.7 & China & $\mathrm{W}$ \\
\hline 96 & 131.3 & 32.0 & 73.6 & 60.4 & 73.5 & 46.5 & Japan & W \\
\hline 97 & 112.4 & 30.4 & 395.3 & 28.5 & 395.7 & 26.8 & China & W \\
\hline 98 & 112.8 & 29.3 & 3827.7 & 1004.1 & 3169.1 & 1418.3 & China & W \\
\hline
\end{tabular}

Water (92), Grass (92), Water (12), Grass (12) are the sizes of water body and grassland in 1992 and 2012, separately. Location indicates the country where the site located. B, S, W represent for breeding site, wintering site and stopover site. 

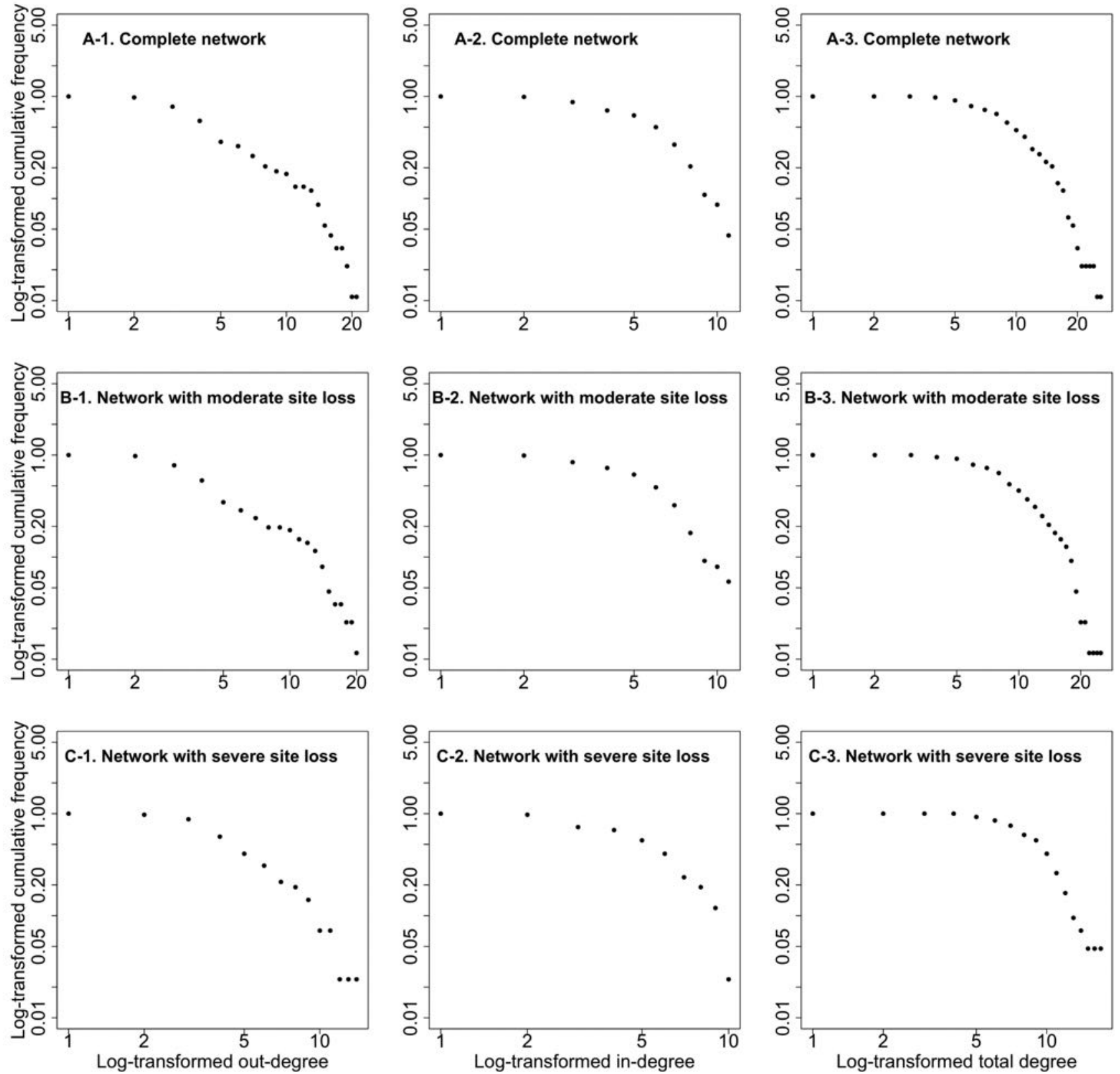

Figure S4.1 Degree distributions of visited migration networks. Top panels are the degree distributions from complete migration networks; middle panels are the degree distributions from migration networks with moderate site loss; bottom panels are the degree distributions from migration networks with severe site loss. From left to right, panels are the degree distributions of logtransformed out-degree, log-transformed in-degree, and log-transformed total degree, respectively. 


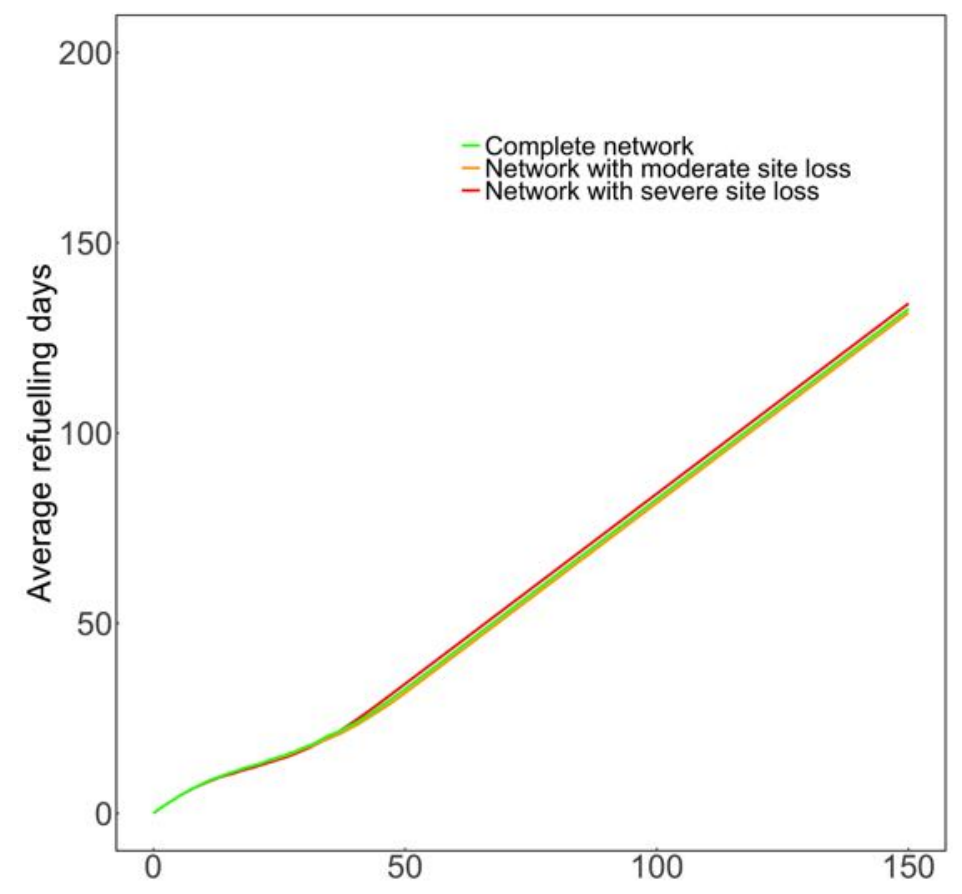

Figure S4.2 The number of average refueling days during migration. The lines are the average of all birds in the same migration network.

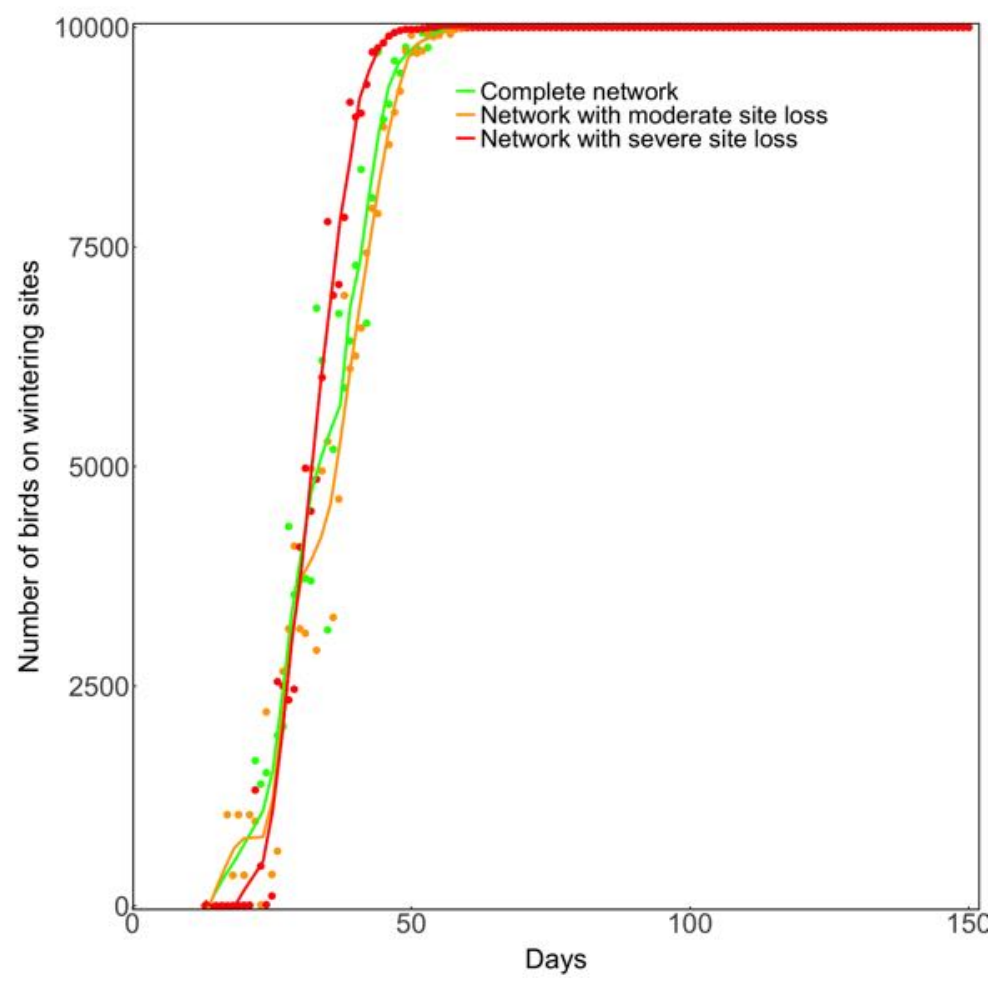

Figure S4.3 The number of birds on wintering sites. The lines are the sums of birds in all wintering sites (blue shaded area in Figure 4.2). 

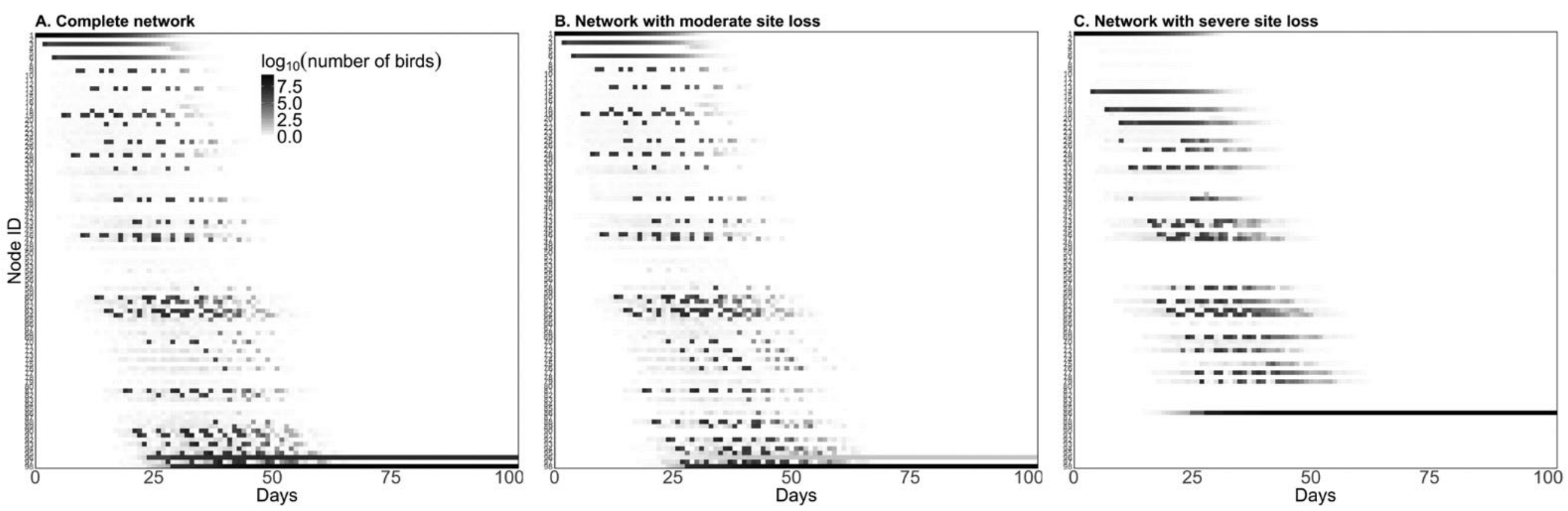

Figure S4.4 The log-transformed number of birds on each site at every time step. 

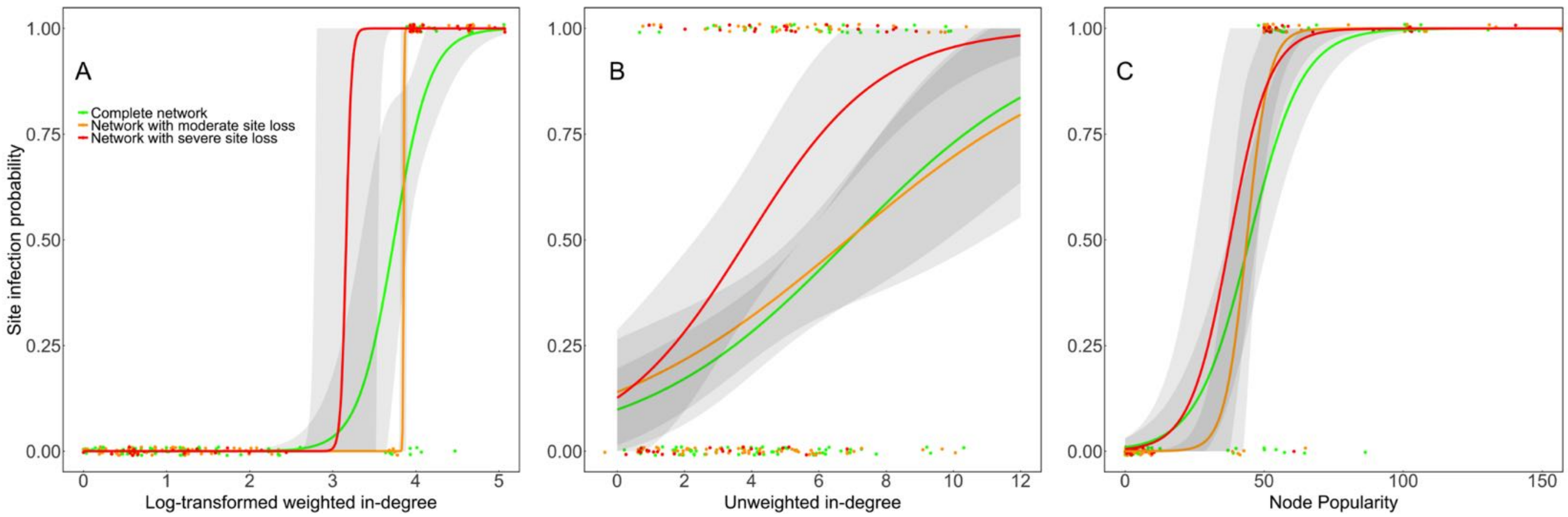

Figure S4.5 Logistic regression results between infection probability for sites and log-transformed weighed in-degree (A), unweighed in-degree (B), and site popularity (C). The grey shaded areas represent the 95\% CIs. Green lines: complete migration network; red lines: migration network with severe site loss 


\section{Chapter 5}

Comparing outbreak patterns of highly pathogenic avian influenza viruses between bar-headed goose and swan goose

S. Yin, Y. Xu, N. Batbayar, J.Y. Takekawa, Y. Si, D.J. Prosser, H.H.T. Prins, W.F. de Boer (2018). Comparing outbreak patterns of highly pathogenic avian influenza viruses between bar-headed goose and swan goose. 


\begin{abstract}
Due to potential threats for wildlife and human health, dispersal of highly pathogenic avian influenza viruses and interactions between the viruses and migratory waterfowl have attracted large attention. Swan goose and bar-headed goose are congeneric species with overlapping breeding grounds but separated migratory routes. Since outbreaks of highly pathogenic avian influenza virus are frequently recorded in bar-headed goose but rarely recorded in swan goose, we presume that bar-headed goose has a larger probability of coming into contact with the outbreak areas during migration. We therefore compared distances between outbreak areas and individual locations of GPS-tracked geese. We found that, in contrast to our expectations, swan geese were more likely to come into contact with outbreak areas of highly pathogenic avian influenza virus, but had a lower chance of being infected. Moreover, barheaded geese were less likely to come into contact with outbreak areas of highly pathogenic avian influenza virus but have been infected multiple times. We proposed two possible explanations for this pattern: 1) frequent contact and long contact history with domestic ducks causes higher levels of innate immunity in swan goose, and/or 2) the migration strategy of bar-headed goose compromises immunity, so that bar-headed geese are more vulnerable to highly pathogenic avian influenza virus infection.
\end{abstract}




\section{Introduction}

Highly pathogenic avian influenza viruses (HPAIVs) have attracted lots of attention due to their rapid and wide-ranging dispersal and threats to animals and humans (Verhagen et al. 2015; WHO 2018). For example, the HPAI H5N1 was first detected in Hong Kong in 1997, then surfaced several times in poultry and wild birds in Asian countries, followed by subsequent detections in Europe, the Middle East, Africa, and North America (Verhagen et al. 2015). The infection of HPAI H5N1 outbreak in Qinghai Lake in 2005 caused the death of more than 6000 wild migratory waterfowl, of which more than $90 \%$ was bar-headed geese Anser indicus (Chen et al. 2005; Liu et al. 2005). Besides, more than 860 human cases of HPAI H5N1 infection have been confirmed since 2013, with a nearly 50\% mortality. Another subtype, HPAI H7N9, has caused more than 1500 human cases with 40\% mortality (Kile et al. 2017; WHO 2018). Due to these impacts, efforts have been made to understand the dispersal of HPAIVs and the interactions between migratory waterfowl hosts and HPAIVs (Tian et al. 2015; Verhagen et al. 2015).

It has been suggested that high density of domestic ducks and aggregations of migratory waterfowl delineate the risk areas of HPAIV outbreaks (Gilbert et al. 2012; Cappelle et al. 2014). Previous studies suggested that HPAIVs originated from domestic ducks, especially in environment with high densities and low bio-security when one co-infected with multiple subtypes of low pathogenic avian influenza viruses (LPAIVs) (Fearnley 2015; Takekawa et al. 2010). Moreover, the domestic ducks are one of the main natural reservoirs of HPAIVs (Hill et al. 2012) and their habitat facilitates virus persistence in the environment and transmission between hosts (Hénaux and Samuel 2011; Stallknecht et al. 1990; Prosser et al. 2016). Therefore, areas with high densities of domestic ducks, such as southeast China, are considered HPAIV outbreak hotspots (Prosser et al. 2013).

Furthermore, migratory waterfowl may be infected with HPAIVs from domestic ducks when they contact each other (Prosser et al. 2016; Takekawa et al. 2010). Although the direct evidence is rare, indirect evidence from LPAIVs outbreaks showed that arrival of migratory waterfowl amplifies infection prevalence of local circulating LPAIVs (Verhagen et al. 2015; Lisovski et al. 2018). Moreover, since wild migratory waterfowl infected with HPAIVs migrate over long distances (Gilbert et al. 2012), migratory waterfowl can disperse HPAIVs from one location to another (Verhagen et al. 2015; Altizer et al. 2011). 
Previous studies about HPAIVs dispersal and interactions between migratory waterfowl and HPAIVs have focused on the spatial-temporal correlations between waterfowl migration and HPAIV outbreaks (Si et al. 2009; Newman et al. 2009; Verhagen et al. 2014), phylogenetic relationships among outbreaks (Xu et al. 2016; Tian et al. 2015), and various outbreak drivers (Gilbert et al. 2007; Prosser et al. 2013). Few studies, however, have compared HPAIV outbreak patterns in different but genetically related migratory waterfowl species, which could improve our understanding of the HPAIVs dispersal, and the interactions between migratory waterfowl species and HPAIVs.

Swan goose Anser cygnoides and bar-headed goose are two congeneric species, and they can interbreed producing fertile offspring (Ottenburghs et al. 2016). Both goose species breed in Mongolia (Batbayar et al. 2011), with overlapping breeding areas, but separate migration routes (Batbayar 2013). Swan goose use the Yalu River Estuary as stopover site, and migrate to Poyang Lake in southeast China for overwintering via the East Asian-Australasian Flyway (Batbayar et al. 2011), while bar-headed goose that breed in Mongolia use Qinghai Lake as stopover site, and migrate to Tibet or India for overwintering via the Central Asian Flyway (Takekawa et al. 2017).

HPAIV outbreaks in swan goose are rarely recorded, neither in passive nor active surveillance (Welte and Terán 2004), on the contrary, HPAIV outbreaks in bar-headed goose were continuously recorded in 2004-2017 (Chen et al. 2005; Takekawa et al. 2010). In this study, we compared HPAIV outbreak patterns between swan goose and bar-headed goose and discuss possible mechanisms that result in the difference between their outbreak patterns. Since HPAIV outbreaks in migratory waterfowl require contacts with HPAIV outbreaks in domestic birds or wild birds, the possible explanation is that bar-headed goose is more likely to contact HPAIV outbreaks during migration.

However, the influences of other facts such as historical exposure to domestic ducks and migration strategy are discussed as well, since they might influence immune defense in migratory birds, and thereby, influence their vulnerability to HPAIVs. 


\section{Method}

\section{GPS tracking data}

We obtained GPS tracking data of swan goose, bar-headed goose and whooper swan Cygnus Cygnus from the United States Geological Survey (USGS) and Department of Earth System Science at Tsinghua University in China. The whooper swan population was included in order to examine whether HPAIV outbreak patterns are correlated with densities of domestic ducks, and cannot be attributed to a species effect. A total of 63 swan geese, 38 bar-headed geese and 10 whooper swans were captured and fitted with GPS transmitters in either their overwintering area or breeding area (Table 5.1). The weight of transmitters was $<3 \%$ of the tracked birds' body mass. The transmitters were programmed to record GPS locations at a 2$\mathrm{h}$ interval for swan goose and whooper swans and a 4-h interval for bar-headed goose. More details about the capture and transmitters are available in Table 5.1 and previous studies (S. H. Newman et al. 2009, 2012; Batbayar 2013). 
Table 5.1 Information of satellite telemetry for each population.

\begin{tabular}{|c|c|c|c|c|c|c|}
\hline Population & $\begin{array}{l}\text { Number of } \\
\text { individual }\end{array}$ & $\begin{array}{l}\text { Tracking } \\
\text { duration (days) }\end{array}$ & Capture time & Capture location & Transmitter & Source \\
\hline $\begin{array}{l}\text { Swan goose } \\
\text { Anser cygnoides }\end{array}$ & 18 & 1211 & 2006,2008 & $\begin{array}{l}\text { Khaichiin Tsagaan Lake, } \\
\text { Khorin Tsagaan Lake and } \\
\text { Khokh Lake, Mongolia }\end{array}$ & $\begin{array}{l}\text { solar-powered Argos- } \\
\text { GPS platform } \\
\text { transmitter terminals }{ }^{1}\end{array}$ & USGS \\
\hline $\begin{array}{l}\text { Swan goose } \\
\text { Anser cygnoides }\end{array}$ & 45 & 435 & July 2015, 2016 & Poyang Lake and Wulanpao, China & $\begin{array}{l}\text { GPS-GSM solar- } \\
\text { powered loggers }\end{array}$ & $\begin{array}{l}\text { Tsinghua } \\
\text { University }\end{array}$ \\
\hline $\begin{array}{l}\text { Whooper swan } \\
\text { Cygnus cygnus }\end{array}$ & 10 & 820 & August 2006 & $\begin{array}{l}\text { Khorin Tsagaan Nuur and Delger Tsagaan } \\
\text { Lake, Mongolia }\end{array}$ & $\begin{array}{l}\text { solar-powered Argos- } \\
\text { GPS platform } \\
\text { transmitter terminals }{ }^{1}\end{array}$ & USGS \\
\hline $\begin{array}{l}\text { Bar-headed goose } \\
\text { Anser indicus }\end{array}$ & 38 & 788 & July 2008, 2009 & $\begin{array}{l}\text { Terkhiin Tsagaan Lake, Mongolia } \\
\text { Chilika Lake, east India } \\
\text { Koonthankulum Bird Sanctuary, south } \\
\text { India }\end{array}$ & $\begin{array}{l}\text { solar-powered Argos- } \\
\text { GPS platform } \\
\text { transmitter terminals }{ }^{1}\end{array}$ & USGS \\
\hline
\end{tabular}

${ }^{1}$ PTTs: Microwave Telemetry, Inc., Columbia, MD, USA.

${ }^{2}$ Global Positioning System - Global System for Mobile Communications. The loggers are necked IBIS series, Ecotone Telemetry, Gdynia, Poland and necked HQNG series, Hunan Global Messenger Technology Co. Ltd., Xiangtan, China. 


\section{Estimating migration route}

We used dynamic Brownian Bridge Movement Models (dBBMMs) to estimate utilization distributions (UDs) of the tracked populations. The dBBMMs assumes behaviourally heterogeneous GPS tracks from animal, and thereby, it estimates UDs with a sliding window of GPS locations for detecting behavioural changes (Kranstauber et al. 2012).

For all individuals, we calculated their UDs at the same spatial extent at a resolution of 10 $\mathrm{km}$, with sliding window size of 23 locations, a margin of 11 locations and a location error of $23 \mathrm{~m}$ (Palm et al. 2015). We set the time step at 8 for swan goose and whooper swan and at 4 for bar-headed goose, due to different GPS recording intervals.

Since the tracking duration varied among individuals, we weighed their individual UDs, multiplying all raster values by elapse of their tracking days, separately. Furthermore, the population level UDs were the sum of weighed individual UDs. We generated $90 \%$ cumulative probability contours to represent their main sites, includes breeding areas, stopover sites and overwintering areas, and used $99 \%$ cumulative probability contours to represent the migration routes (Palm et al. 2015).

Apart from available GPS data from a tracked whooper swan population that migrates between Mongolia and South Korea (with high poultry densities), data from another whooper swan population that migrates between Russia and Japan (with low poultry densities) were available (Shimada et al. 2014). We extracted coordinates of main sites (i.e., wintering sites, stopover sites and breeding sites) of this latter whooper swan population via geo-referencing, and created buffer zones around each of these geo-referenced sites with a radius of $32.5 \mathrm{~km}$, i.e., the maximum foraging distance of waterfowl (Johnson et al. 2014).

\section{Poultry density}

To evaluate the differences in contact probability with domestic ducks among migratory populations, we summarized densities of domestic ducks from each raster cell in the main sites and in migration routes. The differences in poultry densities between different migratory populations were tested with Bonferroni corrected post- hoc at the significance level of $\alpha=0.05$. We obtained densities of domestic ducks from the Livestock Geo-Wiki (https://livestock.geo-wiki.org). 


\section{HPAIV outbreaks}

We obtained confirmed HPAIV outbreaks in 2004-2017 in Asia from EMPRES-i Global Animal Disease Information System (Welte and Terán 2004). We assumed an outbreak window of 30 days (i.e., the outbreak observation date is the median date), during which the virus can be transmitted to wild migratory birds that visiting the range of outbreaks (Si et al. 2009). Furthermore, we extracted GPS locations of tracked individuals during each outbreak window and examined the distributions of distances between individual locations and HPAIV outbreaks. The differences among the empirical cumulative distribution of these distances were tested with a Kolmogorov-Smirnov test at the significance level of $\alpha=0.05$.

We ran all analysis in R 3.4.3 (R Development Core Team 2016) and QGIS 2.18 (QGIS Development Team 2015).

\section{Ethics statements}

This study was carried out in accordance with the recommendations of the Ornithological Council 'Guidelines to the Use of Wild Birds in Research'. Transmitter weights were less than $3 \%$ of the body mass of animals, as recommended by the ornithological council (Gaunt et al. 1997). Capture permits were obtained from the relevant government authority in India, China and Mongolia. Procedures for capture, handling, and marking were approved by a U.S. Geological Survey Animal Care and Use Committee and the University of Maryland Baltimore County Institutional ACUC (Protocol EE070200710), by the Jiangxi Provincial Forestry Bureau (reference number: Ganlinban201514 and 201570) and by the Animal ethics committee at Tsinghua University (reference number: IACUC15-SYL1).

\section{Results}

Overall, our estimated main sites and migration routes for swan goose and whooper swan fell into the spatial extent of East Asian-Australasian Flyway, and the main sites and migration route for bar-headed goose fell into the Central Asian Flyway (Figure 5.1) (Palm et al. 2015). 


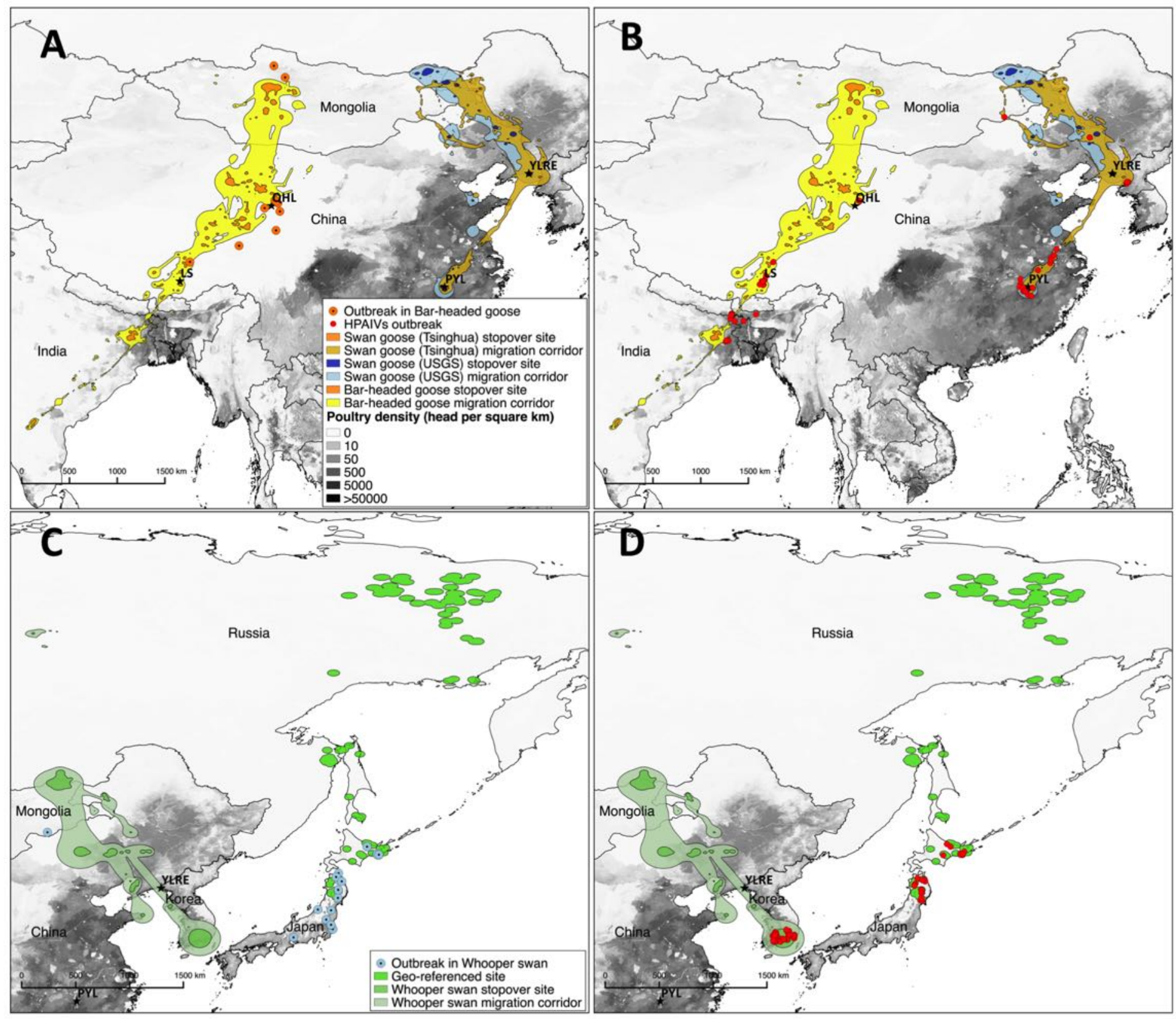

Figure 5.1 Estimated main sites and migration corridors of bar-headed goose, swan goose and whooper swan. The black shade represents the density of domestic ducks and geese. Black star represents important site for the migratory goose, including Qinghai Lake (QHL), Yalu River Estuary (YLRE), Poyang Lake (PYL), and Lhasa region (LS). Orange circle represents for HPAIVS outbreaks in bar-headed goose. Blue circle represents for HPAIVS outbreaks in whooper swan. Red dots are the confirmed HPAIVs outbreaks in wild birds and domestic birds.

The two swan goose populations $(n=18$ and $n=45)$ both bred in northeast Mongolia, used Yalu River Estuary (YLRE) at the China-North Korea border as a stopover site and overwintered in Poyang Lake (PYL; Figure 5.1A and B). The bar-headed goose population bred at northwest Mongolia and migrated over the Gobi Desert and Qinghai-Tibetan Plateau (Figure 5.1A and B). 8 of these 36 bar-headed geese crossed the Himalayas and overwintered 
in India, whereas the rest geese overwintered in Lhasa region (LS), China (Figure 5.1A and B). The tracked whooper swan population bred at the Mongolia-Russia border and migrated to southern South Korea for overwintering, whereas the geo-referenced sites for the other whooper swan population located in northeast Russia and south Japan (Figure 5.1C and D).

There were no HPAIV outbreaks in swan goose in the EMPRES-i database in 2004-2017, but there were 11 HPAIV outbreaks in bar-headed goose and 42 HPAIV outbreaks in whooper swan (Table 5.2). The HPAIV outbreaks in bar-headed goose occurred in Mongolia, Qinghai Lake region and Lhasa regions, while HPAIV outbreaks in whooper swan occurred mainly in Japan (Figure 5.1A and C).

Table 5.2 Number of HPAIVs outbreaks in swan goose, bar-headed goose and whooper swan, and number of outbreaks in their migration corridors.

\begin{tabular}{ccc}
\hline Population & Number of outbreaks ${ }^{1}$ & $\begin{array}{c}\text { Number of outbreaks in }^{\text {migration corridor }}{ }^{2} \\
\text { Swan goose (USGS) }\end{array}$ \\
Swan goose (Tsinghua) & 0 & 20 \\
Bar-headed goose & 11 & 20 \\
Whooper swan & 0 & 68 \\
Whooper swan (Russia-Japan) & 37 & 44 \\
\hline reaks in swan goose, bar-headed goose or whooper swan. \\
reaks in wild birds and poultry birds.
\end{tabular}

Consistently, there were less HPAIV outbreaks, i.e., outbreaks in domestic and wild birds, in swan goose migration route compared with that of the other species. A total of only 20 HPAIV outbreaks occurred in the migration route of swan goose, whereas 48 outbreaks occurred in the migration route of bar-headed goose (Table 5.2). Furthermore, a total of 67 outbreaks occurred in the main sites of the tracked whooper Swan, and 44 outbreaks occurred in the geo-referenced sites of whooper swan in Russia-Japan (Table 5.2).

During these outbreaks, swan geese were much closer to the outbreak locations than barheaded geese and whooper swans, especially within a radius of $500 \mathrm{~km}$ (Figure 5.2). Furthermore, the densities of domestic ducks in both main sites and migration routes of swan goose were higher than those for bar-headed goose (Figure 5.3). Moreover, the densities of domestic ducks in the main sites (i.e., $90 \%$ cumulative probability contours) of the tracked 
whooper swan population was higher than that for the other whooper swan population in Russia-Japan (Figure 5.4).

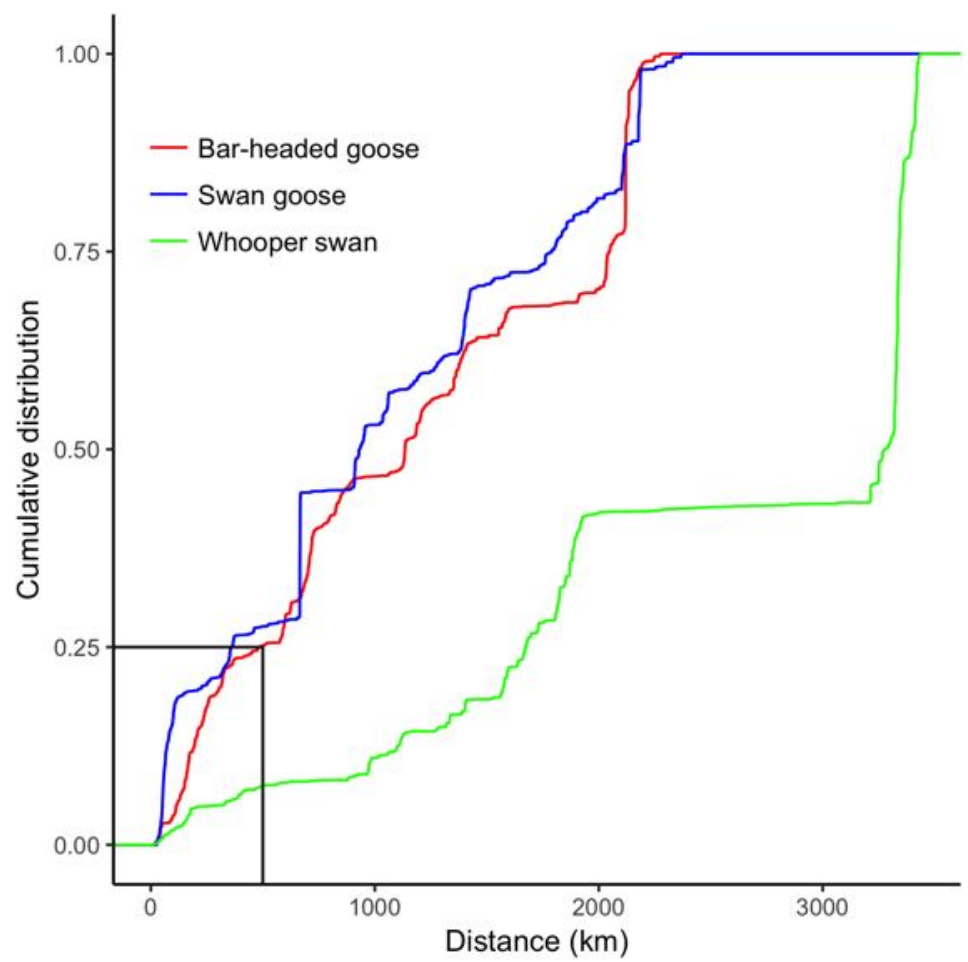

Figure 5.2 Cumulative density distribution of geographic distances between migratory geese and HPAIVs outbreaks.
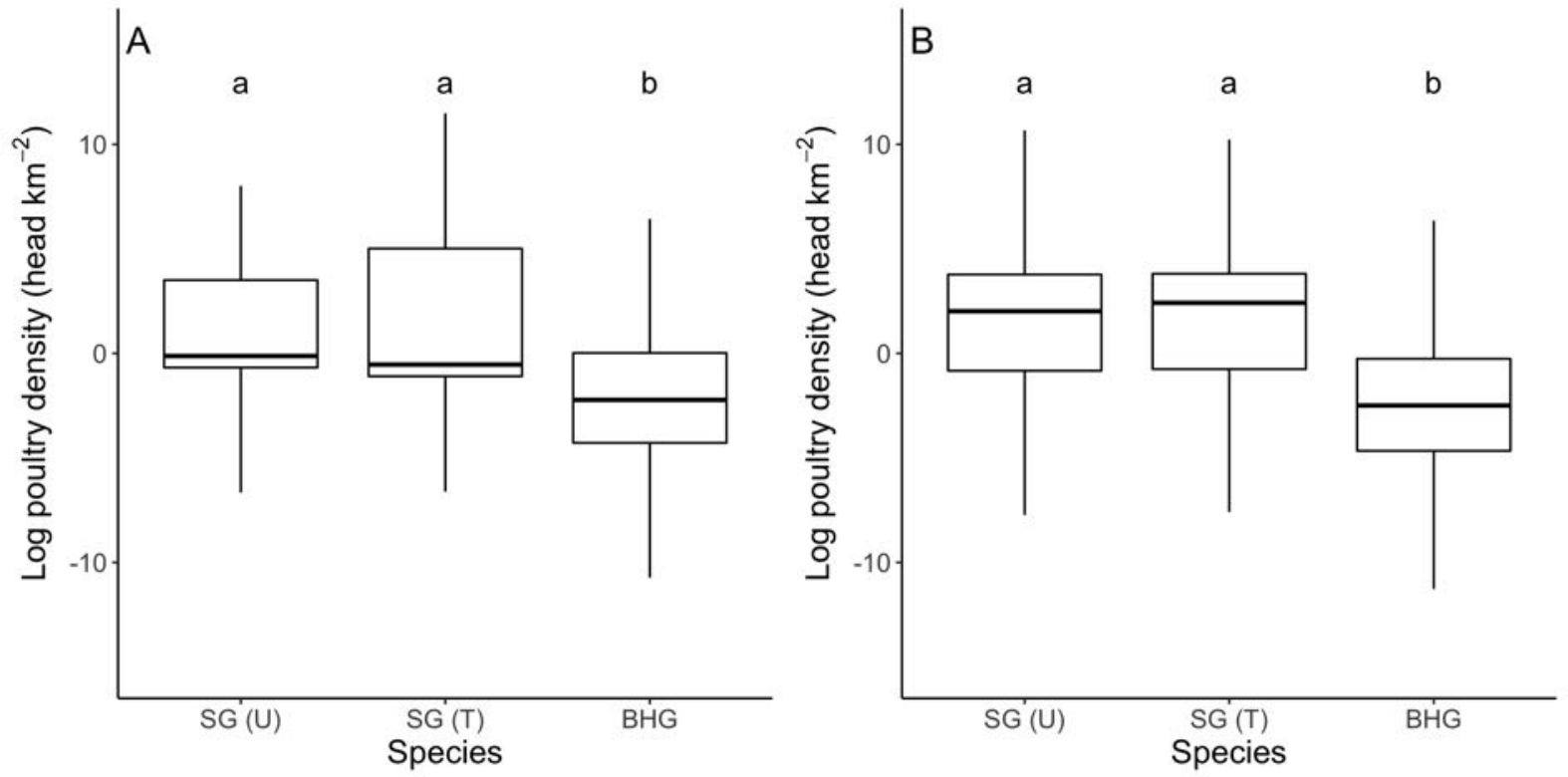

Figure 5.3 Differences among densities of domestic ducks and geese in stopover sites (A) and migration corridors (B) of swan goose (SG) and bar-headed goose (BHG). Letters indicate significant different groups on the basis of a Bonferroni corrected post hoc test. 


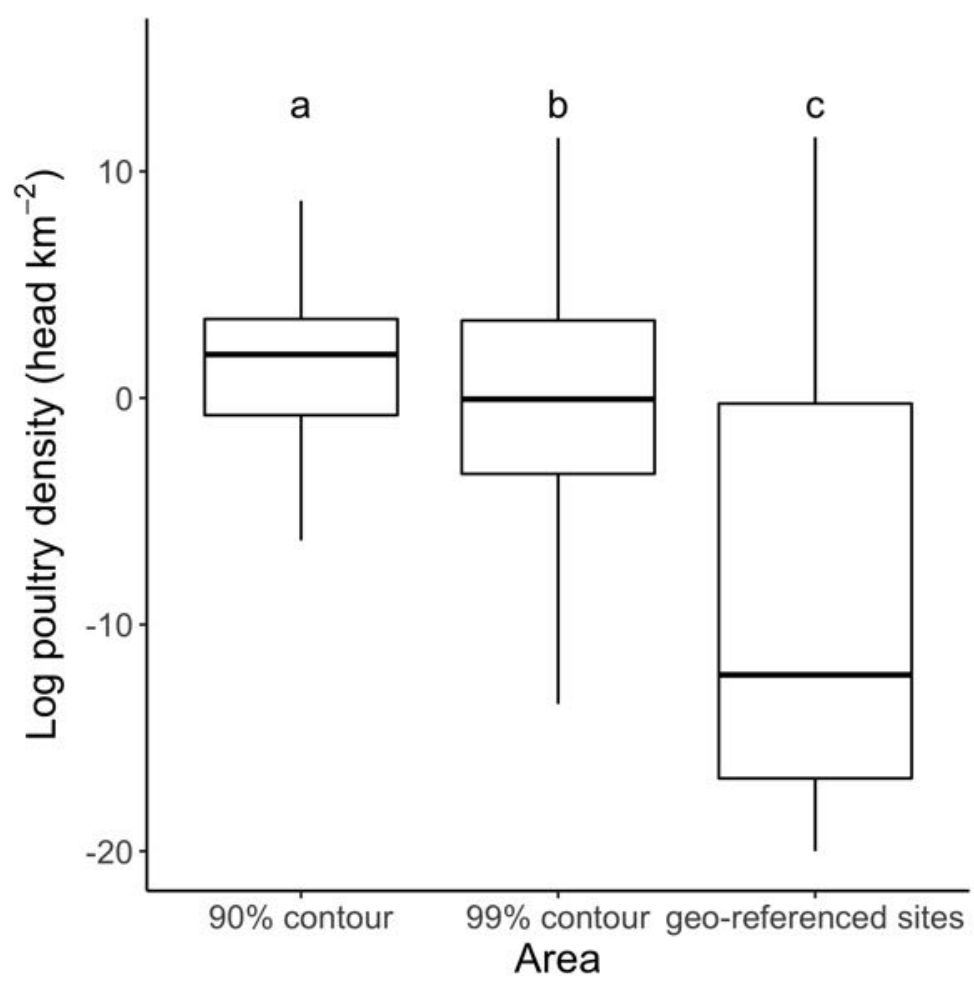

Figure 5.4 Differences among densities of poultry ducks and geese in stopover sites, migration corridors, and geo-referenced sites of whooper swan. Letters indicate significant different groups on the basis of a Bonferroni corrected post hoc test.

\section{Discussion}

By comparing HPAIV outbreak patterns between two congeneric species, i.e., swan goose and bar-headed goose, our results showed (1) there are no recorded HPAIV outbreaks in swan goose, but multiple recorded HPAIV outbreaks in bar-headed goose and whooper swan populations; (2) during HPAIV outbreaks, swan geese were closer to outbreaks than barheaded goose and whooper swan; (3) densities of domestic ducks in and around the main sites and migration routes of swan goose were significantly higher than those for bar-headed goose and whooper swan.

Although most of the HPAIV outbreaks fell in our estimated migration routes, a few outbreaks were located outside these routes (Figure 5.1A and C). This probably resulted from a limited capturing and tracking effort which does not cover all populations of each species. For example, there is another bar-headed goose population that breed at Qinghai Lake region and overwinters in Lhasa, China (Prosser et al. 2009; Namgail et al. 2017). Including more tracking data can definitely contribute to more accurate estimations of migration route and to better understand the dispersal of HPAIVs and the interactions between migratory waterfowl host and HPAIVs. Nevertheless, our estimated migration routes cover the well-known 
overwintering sites and stopover sites such as Qinghai Lake, Lhasa region, Poyang Lake and Yalu River Estuary and majority of the outbreaks of these migratory goose species (Figure $5.1)$.

During the HPAIV outbreaks, swan geese were much closer to the outbreak locations (Figure 5.2), and hence it can be suggested that swan geese were more likely to contact HPAIV infected birds, and be infected with HPAIVs during migration than the other species. This result is in contrast to our presumption that bar-headed goose had a closer and more contacts with HPAIV outbreaks. However, the difference in HPAIV outbreak patterns between swan goose and bar-headed goose might be explained by differences in their contact histories with domestic ducks and differences in migration strategies.

Firstly, frequent contacts with domestic ducks might trigger a higher level of innate immunity in swan goose. Previous study revealed that migratory birds have large innately immunological organs compared with resident birds, probably, due to their frequent exposures to diverse pathogens along migration routes. We found that the densities of domestic ducks are significantly higher on the East Asian-Australasian Flyway (Figure 5.1 and Figure 5.3), especially for the Poyang Lake region where approximately 14 million domestic ducks were produced every year (Cappelle et al. 2014), and the ratio of domestic ducks to wild birds is approximately 5:1 (Takekawa et al. 2010). It suggests that the contact probability between swan geese and domestic ducks, and the transmission risk for avian influenza viruses are substantially high (Wang et al. 2013; Cappelle et al. 2014).

Besides the densities of only domestic ducks, we also compared the distribution of swan geese with the densities of domestic birds (i.e., domestic ducks and chickens), and the results again showed that swan geese had a larger contact probability with these domestic birds (Figure S5.1). Moreover, the whooper swan population that had a higher probability of coming into contact with domestic ducks had no HPAIV outbreak records, whereas the whooper swan population that had a lower probability of coming into contact with domestic ducks was associated with more HPAIV outbreaks (Table 5.2, Figure 5.4). This is consistent with the difference between swan goose and bar-headed goose, namely that wild birds with a higher probability to contact domestic birds had fewer HPAIV outbreaks, which might result from a higher level of innate immunity, induced by frequent contacts between domestic and wild birds. 
Furthermore, swan geese have a longer contact history with domestic ducks in the East Asian-Australasian Flyway, which may result in their higher level of innate immunity as well. Documentation of raising domestic ducks can even be found in Qi Min Yao Shu, which was written in 544 A.D. (Darwin 1859). Moreover, in the Ming dynasty (1368-1644 A.D.), domestic ducks were also used for pest control in Chinese rice paddies (Niu 2016). This long contact history might be a selective driver for a higher level of innate immunity in swan goose, since exposure to diverse pathogens during migration may result in larger immune organs in birds (Møller and Erritzøe 1998). Hence, swan goose has fewer HPAIVs outbreaks than bar-headed goose (Table 5.2).

Second, the migration strategy might affect immune defences of bar-headed goose. Migration is the most energetically costly activity in birds' life history, which even can lead to 10 times higher metabolic rate than the basal rate (Battley and Piersma 2005). This energetic cost, however, has to be balanced against other expenses such as immunity (van Dijk and Matson 2016; Altizer et al. 2011). For example, migratory barn swallows Hirundo rustica (Møller and Erritzøe 1998), thrushes Catharus ustulatus, C. fuscescens and Hylocichla mustelina were all immunocompromised compared with non-migratory conspecifics (Owen and Moore 2006).

Our tracked bar-headed geese migrated $3000 \mathrm{~km}-5000 \mathrm{~km}$, and some of the individuals even crossed the Himalayas (Figure 5.1A and B). This long-distance and high-altitude migration strategy is energetically challenging (Hawkes et al. 2011). Although another barheaded goose population migrates over shorter distances between Qinghai Lake and Lhasa region, i.e., approximately $850 \mathrm{~km}$, the population has to allocate more energy for withstanding the harsh climate in Tibet, China (Takekawa et al. 2017), which may also be energetically costly. This intensive energetic challenge might suppress immune defenses (van Dijk and Matson 2016), and the bar-headed goose becomes more vulnerable to HPAIVs infection during migration.

This migration induced immunosuppression in bar-headed goose may be supported by experimental infection studies. Although bar-headed goose is a well-known victim of HPAIVs outbreak in wild (Chen et al. 2005; Takekawa et al. 2010), only 2 of 8 bar-headed geese died in experimental HPAI H5N1 infection (Nemeth et al. 2013; Brown et al. 2008). This mortality rate $(25 \%)$ is lower compared with other waterfowl species such as ruddy shelduck Tadorna ferruginea $(100 \%, \mathrm{n}=3)$, cackling goose Branta hutchinsii $(75 \%, \mathrm{n}=4)$, 
black swan Cygnus atratus $(100 \%, \mathrm{n}=5)$, trumpeter swan Cygnus buccinator $(100 \%, \mathrm{n}=5)$, whooper swan $(100 \%, \mathrm{n}=4)$ and mute swan Cygnus olor $(100 \%, \mathrm{n}=5)($ Nemeth et al. 2013; Brown et al. 2008), indicating that bar-headed goose is less vulnerable to HPAI H5N1 infection compared to other waterfowl species. Hence, its high mortality in the wild can be due to migration induced immunosuppression.

This study largely depends on accuracy and representativeness of HPAIV outbreak records in the EMPRES-i database (Welte and Terán 2004). After the detection of HPAI H5N1 outbreak in wild migratory birds at Qinghai Lake in 2005 (Liu et al. 2005; Chen et al. 2005), field surveillance and monitoring efforts have been improved in both the Central Asian Flyway and the East Asian-Australasian Flyway (Yong et al. 2015). Furthermore, field surveillance and monitoring are more easily carried out in the East Asian-Australasian Flyway than that in the Central Asian Flyway. Moreover, the EMPRES-i database incorporated outbreak reports from various official sources, such as country or regional projects, field missions, Non-Governmental Organizations, and unofficial sources such as incountry assistance projects, and personal contacts with NGOs and other institutions (Welte and Terán 2004). With all these efforts, missing HPAIV events will still exist, but the outbreak records in the EMPRES-i database is expected to reflect general differences in outbreak patterns between swan goose and bar-headed goose.

In general, we found an unexpected HPAIVs outbreak pattern between swan goose and barheaded goose, suggesting that, although swan geese were more likely to contact HPAIV outbreaks during migration, they had a lower chance of being infected with HPAIVs. Whereas bar-headed geese were less likely to contact HPAIVs outbreaks during migration, but had multiple HPAIV outbreaks. We proposed two possible explanations for this distinctive pattern: 1) frequent contact and long contact history with domestic ducks might cause greater levels of innate immunity in swan goose; 2) migration strategy of bar-headed goose compromises immunity, and thereby bar-headed goose is more vulnerable to HPAIVs infection.

We are calling for comparative studies that examine innate immunological differences among migratory waterfowl species, testing whether the densities of domestic ducks that they encountered during migration stimulate the selection of higher level of innate immune reactions against HPAIVs. Furthermore, we are also calling for physiological studies that examine variations in immunological conditions of migratory waterfowl before and during 
their migration, testing whether migration strategies result in different levels of suppression of immune defences. These efforts can be helpful for understanding the HPAIV outbreak pattern between swan goose and bar-headed goose, and thereby, also improve our understanding of pathogen dispersal via interactions between migratory host and pathogen. 


\section{Appendix to Chapter 5}
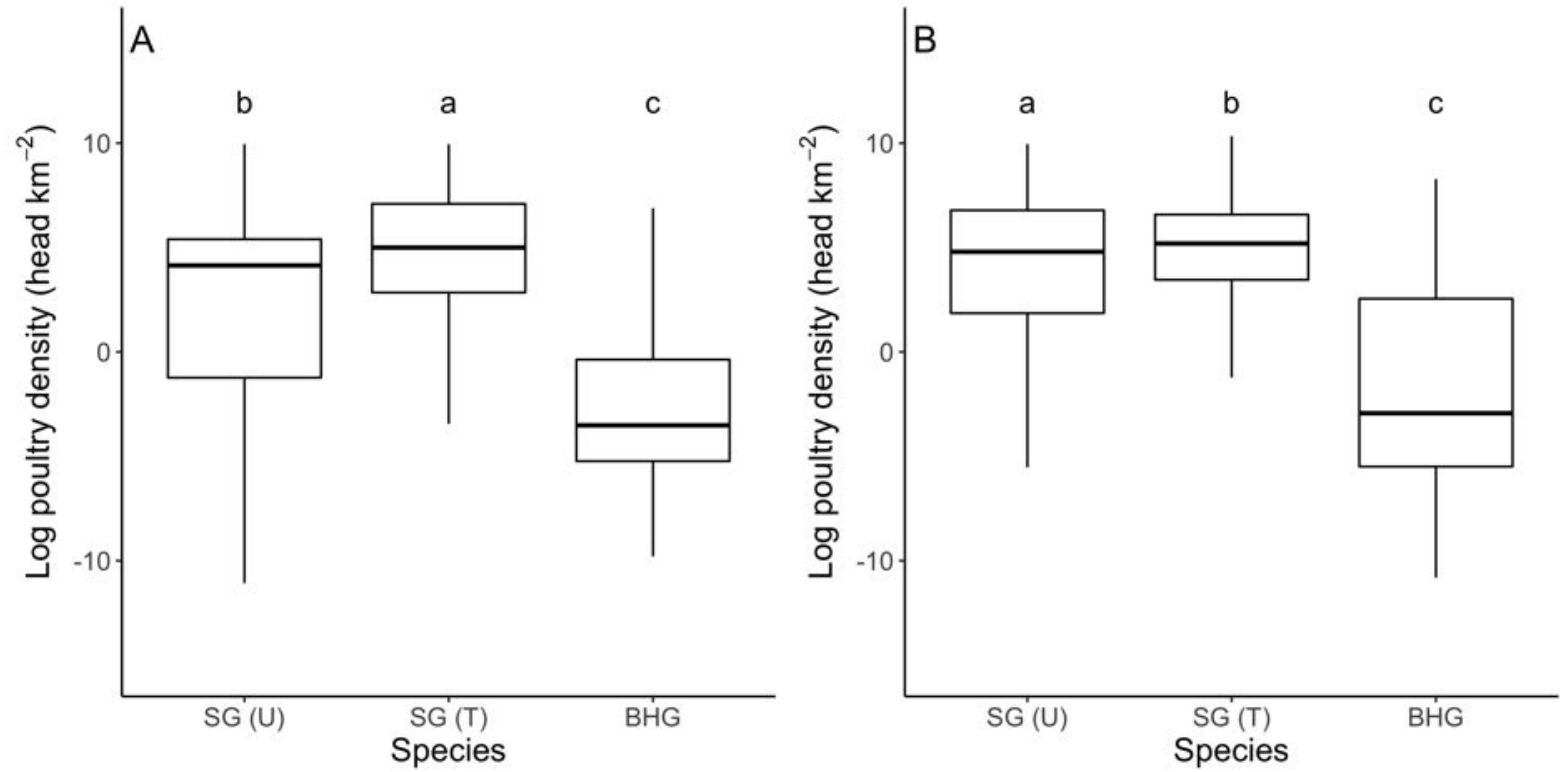

Figure S5.1 Differences among densities of domestic ducks and chickens in stopover sites (A) and migration corridors (B) of swan goose (SG) and bar-headed goose (BHG). Letters indicate significant different groups on the basis of a Bonferroni corrected post hoc test. 


\section{Chapter 6}

Synthesis 


\section{Migratory waterfowl disperse highly pathogenic avian influenza viruses}

Highly pathogenic avian influenza viruses (HPAIVs) H5N1 were first detected in wild birds in 2004 in China, and these viruses rapidly dispersed over the globe (Verhagen et al. 2015). The time and direction of the dispersal is correlated with bird migration (Verhagen et al. 2015; Xu et al. 2016; Si et al. 2009; Newman et al. 2012). For example, some migratory duck species such as mallard can asymptomatically be infected with HPAIVs during migration (Gaidet et al. 2010; Jeong et al. 2014; Chen et al. 2006; Kou et al. 2005; Kilpatrick et al. 2006; Keawcharoen et al. 2008; Olsen et al. 2006), and it has been suggested that some duck species can carry HPAIVs over long distances. However, HPAIVs infection commonly causes severe symptoms in migratory goose species, resulting in negative effects on their migration capability and even increase mortality rates (Chen et al. 2005; Takekawa et al. 2010). Therefore, it has been suggested that long-distance dispersal of HPAIVs by migratory goose species largely depends on the relay effect, which means that successive infection of migratory birds during migration leads to long-distance dispersal, rather than direct dispersal (Gaidet et al. 2010).

However, some migratory goose species might be more resistant to HPAIVs infection, and thereby, possibly be able to contribute to long-distance HPAIVs dispersal directly (Chapter 5). The asymptomatic infection of mallard to HPAIVs may be the result of co-evolution between HPAIVs and mallard (Hill and Runstadler 2016). Similar co-evolution might occur between HPAIVs and migratory goose species as well, if migratory goose species have a long contact history and/or frequent contact with domestic birds, which are the origin of HPAIVs (Takekawa et al. 2010). The co-evolution may lead to higher levels of innate immunity, which results in a mild disease in migratory geese (Webster et al. 1992; Brunham 1993; Møller and Erritzøe 1998).

Co-evolution is frequently observed in host-pathogen systems. A well-known example is the European rabbit-myxoma virus system, where the rabbits built up resistance to the lethal infection of the myxoma virus (Fenner and Fantini 1999). More examples have been described in other host systems such as bacteria (Weitz et al. 2005; Koskella and Brockhurst 2014), plants (Dodds and Rathjen 2010; Jousimo et al. 2014), invertebrates (Ebert 2008; Morran et al. 2011), and vertebrates (Kerr 2012). Therefore, I propose that a long contact history and higher contact frequency with HPAIVs can result in higher levels of immunity in migratory geese (Figure 6.1). Future studies that examine goose immunity can bring more 
insights into the interactions between migratory waterfowl and HPAIVs, and mechanisms of HPAIVs dispersal.

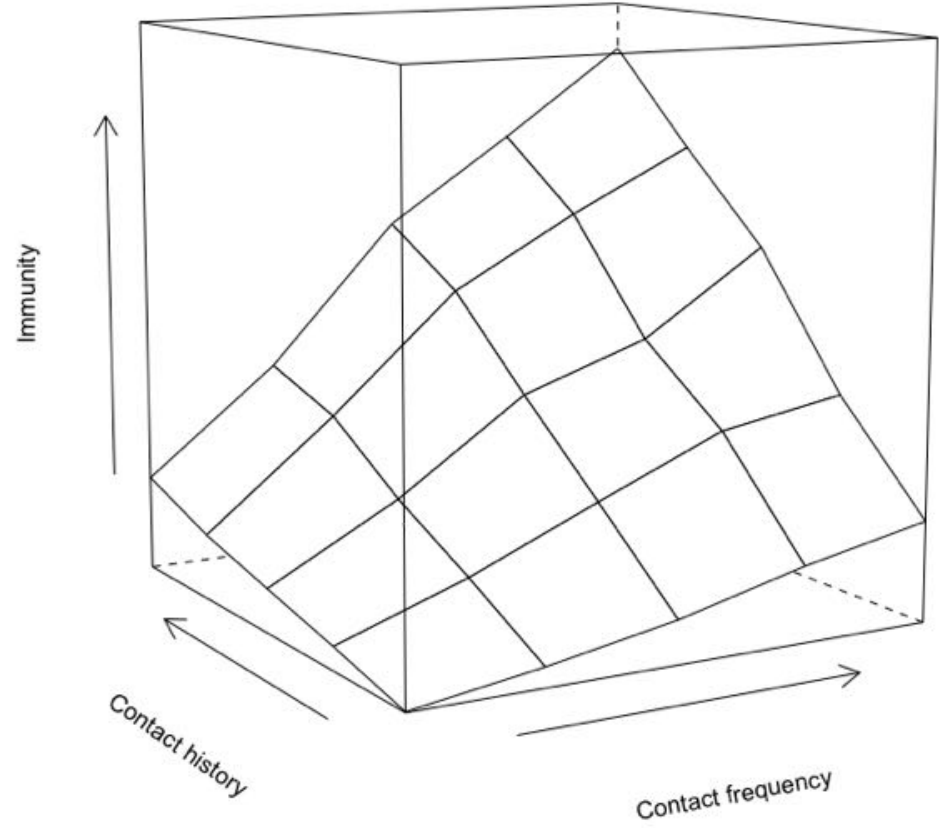

Figure 6.1 An illustration of the effect that long contact history and higher contact frequency with HPAIVs can lead to higher levels of innate immunity.

\section{Migratory waterfowl disperse low pathogenic avian influenza viruses}

Migratory waterfowl can disperse low pathogenic avian influenza viruses (LPAIVs) during their seasonal migration (Kleijn et al. 2010; Lisovski et al. 2018; Olsen et al. 2006), but the roles of ducks and geese may differ over seasons. Since infection prevalence peaks after breeding season in migratory duck species, and gradually decreases during autumn migration, ducks are likely to be responsible for southward dispersal of LPAIVs (Latorre-Margalef et al. 2014). However, migratory goose species develop their infection prevalence of LPAIVs on wintering sites, and the infection peaks before spring migration, so that migratory goose species probably facilitate northward dispersal (Y. Xu et al. 2016; Kleijn et al. 2010) (Chapter 2; Figure 6.2). It has been suggested that their different behaviours such as defecating in water or on land, and dependence on open water, contribute to their seasonal differences in dispersing LPAIVs (Kleijn et al. 2010), although these suggestions have rarely been investigated. Thus, duck and goose migration together accomplish the north-south dispersal of avian influenza viruses (AIVs). 


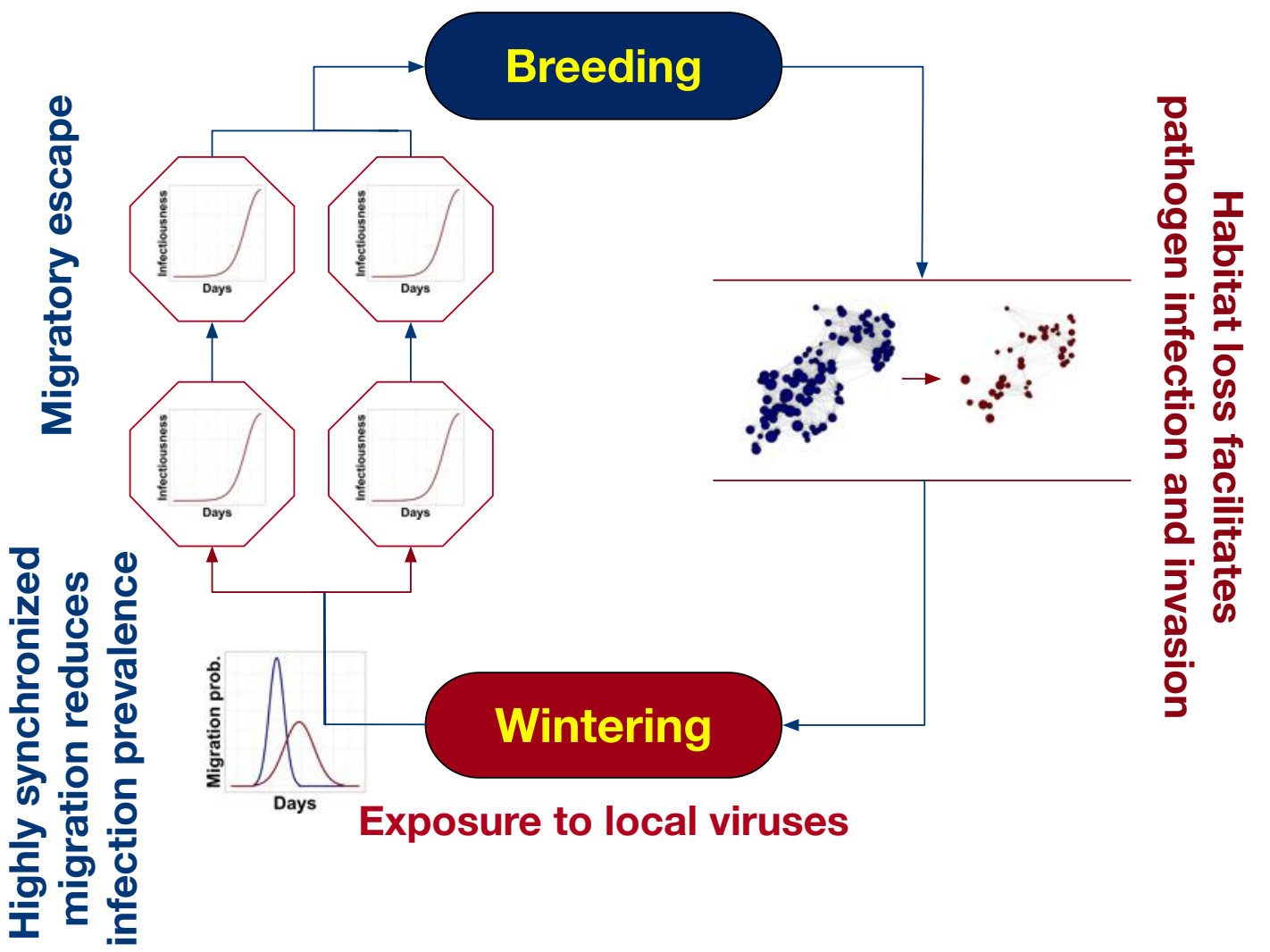

Figure 6.2 Diagram for generally summarizing the processes that can increase (red text and lines) or decrease (blue text and lines). The ovals are breeding site and wintering sites. The polygons are stopover sites.

Moreover, it is well-known that AIVs can persist in the environment at breeding sites (Stallknecht et al. 1990; Brown et al. 2009) where migratory waterfowl from different migration corridors can mix (Batbayar 2013; Ely et al. 2013). However, goose populations cannot preserve LPAIVs infection over the breeding season (Ely et al. 2013; Kleijn et al. 2010; Yin et al. 2017) (Figure 6.2). It is not clear whether this is related to the environmental conditions, physiological condition, and/or nesting preference (colonial or dispersed nesting). Future studies for examining AIVs persistence in migratory geese, especially during their breeding season, are required to better understand the mechanisms for global LPAIVs dispersal.

Although migration allows hosts to escape contaminated habitat sites and thereby reduce infection prevalence in the population, spring and autumn migration may have different efficiencies in escaping due to different migration patterns. Satellite telemetry revealed that migratory geese usually migrate over a wide front (i.e., using parallel stopover sites) in spring migration, probably because they need to wait for plant development in spring ( $\mathrm{Si}$ et al. 2015) and this broad migration front reduces competition among each other. These migratory geese 
consequently stay longer on their stopover sites, and thereby have higher infection risks (Figure 6.2). During autumn migration, on the other hand, migratory geese usually migrate over a narrow front (i.e., using serial stopover sites), probably because there is no food limitation along their migration route (Kölzsch et al. 2016), and they need to arrive at their wintering sites as soon as possible due to decreasing temperatures. The migratory geese thereby stay relative short on their stopover sites (Kölzsch et al. 2016), and have more opportunities to escape habitat sites contaminated with AIVs, leading to a lower infection risk. Therefore, autumn migration might be more efficient in reducing infection risk compared to spring migration.

Although migration allows a population to reduce its infection risk via escaping, it seems unlikely that a migratory population can lose AIVs infection completely during migration because resting individuals can be infected with the viruses from the environment (Bengtsson et al. 2016), especially for a population with low migration synchrony (Chapter 3; Figure 6.2). In my simulations, the brought-in viruses, which were introduced by migratory waterfowl, cause new infection outbreaks in the arriving migratory population (Chapter 4). However, empirical studies suggested that brought-in viruses act as materials for gene flow rather than causing large outbreaks (Hill et al. 2012). Hence, the frequently observed increase in infection prevalence associated with arrival of migratory birds is more likely caused by an amplified infection of locally circulating viruses (Newman et al. 2009; Verhagen et al. 2014). Future studies focusing on whether the brought-in viruses can cause new infection outbreak, can provide a new angle to examine the roles of bird migration in dispersing of AIVs and causing infection outbreaks.

\section{Network analysis as a promising approach}

My simulations showed that the configuration of a migration network affects infection dynamics in migratory populations (Chapter 2; Figure 6.2), and habitat loss facilitates the AIVs dispersal (Chapter 3; Figure 6.2). Moreover, previous modelling and empirical studies showed that, if an infection decreases migration capacity or increases mortality, migration can reduce the infection prevalence by separating healthy from infected individuals in the population (Bradley and Altizer 2005; Satterfield et al. 2015), hence, a shortened migration distance can lead to a higher infection prevalence after migration (Figure 6.2), as infected and healthy individuals have less opportunities to be separated (Bowlin et al. 2010; Zhao et al. 2017; Yamaguchi et al. 2008). These findings indicate that having a holistic perspective of 
migration, rather than focusing on single sites, can be more relevant to capture AIVs dispersal and infection dynamics.

Furthermore, whether birds visit a habitat site depends on various factors such as distance between sites, wind speed, wind direction and food availability at sites (Newton 2007; Rappole 2013). It is necessary to integrate these effects for understanding why and why not birds visit a particular stopover site, and thereby obtain a better understanding of AIVs dispersal and ultimately be able to predict AIVs dispersal, especially under influences of habitat availability changes.

Network analysis is a promising framework, and it is able to integrate these factors for studying AIVs dispersal under influence of host migration (Newman 2003; Bauer and Hoye 2014). The impacts of the mentioned factors can be analysed by calculating, e.g., weighed network metrics (Newman 2003; Bauer and Hoye 2014). For example, distance between sites, wind speed and wind direction can be integrated through calculating link weights, while food availability on sites can be integrated by calculating site weights. The various migration patterns may be represented by weighed network metrics. For instance, migratory populations in autumn tend to use a shorter migration route (Kölzsch et al. 2016). This preference can be expressed as a weighed path length between breeding and wintering sites (Silk et al. 2017). The preference for a short migration route can be simulated by ranking the weighed shortest path lengths. The various path lengths can be used as elements in the decision-making process by analysing their selections on some stopover sites over others (e.g., via patternoriented modelling). This approach can contribute to a better understanding of empirical observed migration pattern, and hence, we can study bird aggregations, the residence time at stopover sites, and the probability and spatial pattern of AIVs dispersal.

\section{Improving field surveillance}

AIVs can travel around the world by hitchhiking on migratory birds. Their wide-range dispersal seems nearly impossible to be prevented from happening. Thereby, a field surveillance plan that captures infection dynamics in wild birds is necessary for monitoring the emerging of HPAIVs outbreaks and mitigating these outbreaks in time.

The goal of gaining better surveillance on infection dynamics of AIVs in wild birds can be achieved by better integration of host and virus sampling efforts (Hill and Runstadler 2016). Traditional field surveillance is mainly relying on passive surveillance that examines samples 
from dead birds, and active surveillance that examines samples from live birds for research purposes. Since some migratory goose species may be 'silent' (i.e., resistant) for HPAIVs infections, traditional field surveillance plans may not be able to capture a representative HPAIVs infection dynamic in wild migratory waterfowl. Furthermore, AIVs can persist in water for a long period of time (Brown et al. 2007, 2009; Shoham et al. 2012), and the amount of AIVs in the environment can be even higher than that in faeces (Leung et al. 2007). These features lead to a potential for AIV outbreaks via environmental transmission. However, traditional field surveillance does not consider the potential contribution from AIVs in the environment.

Therefore, I am advocating more efforts for active surveillance that covers not only the well-known, routinely sampled waterfowl species such as bar-headed goose, but also species which are less often found dead due to HPAIVs infection such as swan goose. This surveillance should take place in both wintering season and spring migration because geese and ducks are likely to be responsible for HPAIVs dispersal in different seasons. Moreover, I am also advocating more efforts for monitoring virus dynamics in the environment, such as water bodies at stopover sites. These efforts can compensate for the knowledge gaps of traditional plan which based on sampling live birds and carcasses.

\section{From geese to butterflies}

My findings broaden our knowledge of the interactions between migratory waterfowl hosts and AIVs, especially of the mechanisms for migration induced AIVs dispersal. Although I studied the interactions between host migration and infectious pathogens in a goose-AIVs system, my findings can be generalized to other host-pathogen systems as well.

Every year, billions of animals migrate over large areas pursuing better foraging opportunities, improved safety, and/or higher reproductive output (Bauer and Hoye 2014). Potentially, migratory animals, not only birds but also insects, fishes, and mammals transport parasites and pathogens from one location to another (Bauer and Hoye 2014; Altizer et al. 2011). For example, songbird migration contributed to the northward dispersal of tick borne Lyme disease and the dispersal of West Nile virus in North America (Leighton et al. 2012; Rappole et al. 2000). Wildebeest Connochaetes taurinus migration contributed to the dispersal of rinderpest, brucellosis and foot-and-mouth disease in the Serengeti (Holdo et al. 2009; Sinclair and Norton-Griffiths 1981; Holdo et al. 2009). And green sea turtles Chelonia mydas disperse tumour-forming herpes virus and spirorchid cardiovascular flukes via their 
seasonal migration (Luschi et al. 2003; Meylanet al. 1990; Ene et al. 2005; Raidal et al. 1998).

My findings can be generally applied to the interaction between monarch butterflies Danaus plexippus and a protozoan parasite Ophryocystis elektroscirrha. The spores of Ophryocystis elektroscirrha can accumulate on milkweed, which is the main food for monarch butterflies. In southern Florida, the milkweed pants are available year-around, and the monarch butterflies are non-migratory (Altizer 2001). A previous study has showed that the infection prevalence of Ophryocystis elektroscirrha in the resident monarch butterfly population is much higher compared with that in a migratory population due to migratory escape and culling (Satterfield et al. 2015). Moreover, the monarch butterflies in eastern North America seasonally migrate to Mexico, generally showing a serial pattern, the monarch butterflies in western North America, on the other hand, seasonally migrate to California, over a broad front with a parallel pattern (Altizer et al. 2011). Since Ophryocystis elektroscirrha can persist in the environment (Satterfield et al. 2015; Altizer et al. 2011), I expect that the eastern North America population that follows a serial migration pattern may have more opportunities to escape from Ophryocystis elektroscirrha compared with the western North America population that follows a parallel pattern, although this expectation needs future empirical studies to examine.

Finally, as Leonardo da Vinci (1452-1519) once said: Realize that everything connects to everything else. The beauty of ecology is built on understanding the complex interactions among biotic and abiotic factors in the world. The study of how goose migration disperses pathogens over long-distances, fundamentally shows that different locations and the organisms that live in these locations are connected. 


\section{Reference}




\section{References}

Alerstam, T., Hedenström, A., Åkesson, S. 2003. Long-distance migration: Evolution and determinants. Oikos, 32:247-260.

Alerstam. T., Lindström, A. 1990. Optimal bird migration: The relative importance of time, energy, and safety. Bird Migration, pp. 331-351.

Alexander, D.J. 2007. An overview of the epidemiology of avian influenza. Vaccine, 25:5637-5644.

Allen, C., Garmestani, A., Havlicek, T., Marquet, P., Peterson, G., Restrepo, C., Stow, C., Weeks, B. 2006. Patterns in body mass distributions: Sifting among alternative hypotheses. Ecology Letters, 9:630-643.

Altizer, S., Bartel, R., Han, B.A. 2011. Animal migration and infectious disease risk. Science, 331:296-302.

Altizer, S.M. 2001. Migratory behaviour and host-parasite co-evolution in natural populations of monarch butterflies infected with a protozoan parasite. Evolutionary Ecology, 3:567-581.

Arriero, E., Muller, I., Juvaste, R., Martinez, F.J., Bertolero, A. 2015. Variation in immune parameters and disease prevalence among lesser black-backed gulls (Larus fuscus sp.) with different migratory strategies. PLoS One, 10:e0118279.

Banks, N.C., Paini, D.R., Bayliss, K.L., Hodda, M. 2015. The role of global trade and transport network topology in the human-mediated dispersal of alien species. Ecology Letters, 18:188-99.

Barabási, A.L., Albert, R. 1999. Emergence of scaling in random networks. Science, 286:509-512.

Barthélemy, M. 2011. Spatial networks. Physics Reports, 499:1-101.

Batbayar, N. 2013. Breeding and migration ecology of bar-headed goose Anser indicus and swan goose Anser cygnoides in Asia. University of Oklahoma, 133 pp.

Batbayar, N., Takekawa, J.Y., Newman, S.H., Prosser, D.J., Natsagdorj, T., Xiao, X. 2011. Migration strategies of swan geese Anser cygnoides from northeast Mongolia. Wildfowl, 61:90-109.

Battley, P.F., Piersma, T. 2005. Body composition and flight ranges of bar-tailed godwits (Limosa lapponica baueri) from New Zealand. Auk, 122:922-937.

Battley, P.F., Warnock, N., Tibbitts, T.L., Gill, R.E., Piersma, T., Hassell, C.J., Douglas, D.C., Mulcahy, D.M., Gartrell, B.D., Schuckard, R., Melville, D.S., Riegen, A.C. 2012. Contrasting extreme long-distance migration patterns in bar-tailed godwits Limosa lapponica. Journal of Avian Biology, 43:21-32.

Bauer, S., Hoye, B.J. 2014. Migratory animals couple biodiversity and ecosystem functioning worldwide. Science, 344:6179.

Bauer, S., Lisovski, S., Eikelenboom-Kil, R.J.F.M., Shariati, M., Nolet, B.A. 2018. Shooting may aggravate rather than alleviate conflicts between migratory geese and agriculture. Journal of Applied Ecology, 2:1-10.

Bengtsson, D., Safi, K., Avril, A., Fiedler, W., Wikelski, M., Gunnarsson, G., Elmberg, J., Tolf, C., Olsen, B., Waldenström, J. 2016. Does influenza A virus infection affect movement behaviour during stopover in its wild reservoir host? Royal Society Open Science, 3:150633.

Berger, J., Young, J.K., Berger, K.M. 2008. Protecting migration corridors: Challenges and optimism for Mongolian saiga. PLoS Biology, 6:1365-1367.

Berthold, P. 1997. Migration: The biology of life on the move. Endeavour, 21:42.

Bigras-Poulin, M., Barfod, K., Mortensen, S., Greiner, M. 2007. Relationship of trade patterns of the Danish swine industry animal movements network to potential disease spread. Preventive Veterinary Medicine, 80:143-165.

BirdLife \& NatureServe. 2014. Bird species distribution maps of the world. 2012. http://maps.iucnredlist.org/map.html?id=22735990.

Black, C.P., Tenney, S.M. 1980. Oxygen transport during progressive hypoxia in high-altitude and 
sea-level waterfowl. Respiration physiology, 39:217-239.

Boulinier, T., Kada, S., Ponchon, A., Dupraz, M., Dietrich, M., Gamble, A., Bourret, V., Duriez, O., Bazire, R., Tornos, J., Tveraa, T., Chambert, T., Garnier, R., McCoy, K.D. 2016. Migration, prospecting, dispersal? What host movement matters for infectious agent circulation? Integrative and Comparative Biology, 56:330-342.

Bowlin, M.S., Bisson, I.A., Shamoun-Baranes, J., Reichard, J.D., Sapir, N., Marra, P.P., Kunz, T.H., Wilcove, D.S., Hedenström, A., Guglielmo, C.G., Åkesson, S., Ramenofsky, M., Wikelski, M. 2010. Grand challenges in migration biology. Integrative and Comparative Biology, 50:261279.

Bradley, C.A., Altizer, S. 2005. Parasites hinder monarch butterfly flight: Implications for disease spread in migratory hosts. Ecology Letters, 8:290-300.

de Rueda, B.C., de Jong, M.C., Eblé, P.L., Dekker, A. 2015. Quantification of transmission of footand-mouth disease virus caused by an environment contaminated with secretions and excretions from infected calves. Veterinary Research, 46:43.

Breban, R., Drake, J.M., Stallknecht, D.E., Rohani, P. 2009. The role of environmental transmission in recurrent avian influenza epidemics. PLoS Computational Biology, 5:4.

Brown, J.D., Goekjian, G., Poulson, R., Valeika, S., Stallknecht, D.E. 2009. Avian influenza virus in water: Infectivity is dependent on $\mathrm{pH}$, salinity and temperature. Veterinary Microbiology, 136:20-26.

Brown, J.D., Stallknecht, D.E., Swayne, D.E. 2008. Experimental infection of swans and geese with highly pathogenic avian influenza virus (H5N1) of Asian lineage. Emerging Infectious Diseases, 14:136-142.

Brown, J.D., Swayne, D.E., Cooper, R.J., Burns, R.E., Stallknecht, D.E. 2007. Persistence of H5 and H7 avian influenza viruses in water. Avian Diseases, 51:285-289.

Brunham, R.C., Plummer, F.A., Stephens, R.S. 1993. Bacterial antigenic variation, host immune response, and pathogen-host coevolution. Infection and Immunity, 61:2273-2276.

Buehler, D.M., Piersma, T. 2008. Travelling on a budget: predictions and ecological evidence for bottlenecks in the annual cycle of long-distance migrants. Philosophical Transactions of the Royal Society B Biological Sciences, 363:247-266.

Burthe, S., Telfer, S., Begon, M., Bennett, M., Smith, A., Lambin, X. 2008. Cowpox virus infection in natural field vole Microtus agrestis populations: Significant negative impacts on survival. Journal of Animal Ecology, 77:110-119.

Cappelle, J., Zhao, D., Gilbert, M., Nelson, M.I., Newman, S.H., Takekawa, J.Y., Gaidet, N., Prosser, D.J., Liu, Y., Li, P., Shu, Y., Xiao, X. 2014. Risks of avian influenza transmission in areas of intensive free-ranging duck production with wild waterfowl. Ecohealth, 11:109-119.

Caton, B.P., Dobbs, T.T., Brodel, C.F. 2006. Arrivals of hitchhiking insect pests on international cargo aircraft at Miami International Airport. Biological Invasions, 8:765-785.

Chen, H., Smith, G.J.D., Li, K.S., Wang, J., Fan, X.H., Rayner, J.M., Vijaykrishna, D., Zhang, J.X., Zhang, L.J., Guo, C.T., Cheung, C.L., Xu, K.M., Duan, L., Huang, K., Qin, K., Leung, Y.H.C., Wu, W.L., Lu, H.R., Chen, Y., Xia, N.S., Naipospos, T.S.P., Yuen, K.Y., Hassan, S.S., Bahri, S., Nguyen, T.D., Webster, R.G., Peiris, J.S.M., Guan, Y. 2006. Establishment of multiple sublineages of H5N1 influenza virus in Asia: Implications for pandemic control. Proceedings of the National Academy of Sciences, 103:2845-2850.

Chen, H., Smith, G.J.D., Zhang, S.Y., Qin, K., Wang, J., Li, K.S., Webster, R.G., Peiris, J.S.M., Guan, Y. 2005. H5N1 virus outbreak in migratory waterfowl. Nature, 436:191-192.

Choi, C.Y., Takekawa, J.Y., Xiong, Y., Liu, Y., Wikelski, M., Heine, G., Prosser, D.J., Newman, S.H., Edwards, J., Guo, F., Xiao, X. 2016. Tracking domestic ducks: A novel approach for documenting poultry market chains in the context of avian influenza transmission. Journal of 
Integrative Agriculture, 15:1584-1594.

Claas, E.C.J., Osterhaus, A.D.M.E., van Beek, R., de Jong, J.C., Rimmelzwaan, G.F., Senne, D.A., Krauss, S., Shortridge, K.F., Webster, R.G. 1998. Human influenza A H5N1 virus related to a highly pathogenic avian influenza virus. Lancet, 351:472-477.

Clausen, K.K., Clausen, P. 2013. Earlier Arctic springs cause phenological mismatch in long-distance migrants. Oecologia, 173:1101-1112.

de Crespigny, F.E.C., Wedell, N. 2006. Wolbachia infection reduces sperm competitive ability in an insect. Proceedings of the National Academy of Sciences, 273:1455-1458.

Darwin, C. 1859. The origin of species by means of natural selection. Murray, London.

van Dijk, J.G.B. 2014. Pathogen dynamics in a partial migrant: Interactions between mallards (Anas platyrhynchos) and avian influenza viruses. Utrecht University, $210 \mathrm{pp}$.

van Dijk, J.G.B., Fouchier, R.A.M., Klaassen, M., Matson, K.D. 2015a. Minor differences in body condition and immune status between avian influenza virus-infected and noninfected mallards: A sign of coevolution? Ecology and Evolution, 5:436-449.

van Dijk, J.G.B., Kleyheeg, E., Soons, M.B., Nolet, B.A., Fouchier, R.A.M., Klaassen, M. 2015 b. Weak negative associations between avian influenza virus infection and movement behaviour in a key host species, the mallard Anas platyrhynchos. Oikos, 124:1293-1303.

van Dijk, J.G.B., Matson, K.D. 2016. Ecological immunology through the lens of exercise immunology: New perspective on the links between physical activity and immune function and disease susceptibility in wild animals. Integrative and Comparative Biology, 56:290-303.

Dingle, H., Drake, V.A. 2007. What is migration? Bioscience, 57:113-121.

Dodds, P.N., Rathjen, J.P. 2010. Plant immunity: Towards an integrated view of plant-pathogen interactions. Nature Reviev Genetics, 11:539-548.

Dubé, C., Ribble, C., Kelton, D., McNab, B. 2011. Introduction to network analysis and its implications for animal disease modelling. Revue Scientifique et Technique, 30:425-36.

Dunning, Jr. J.B. 2008. CRC Handbook of Avian Body Masses. CRC press, 672 pp.

Ebert, D. 2008. Host-parasite coevolution: Insights from the Daphnia-parasite model system. Current Opinion in Microbiology, 11:290-301.

Egevang, C., Stenhouse, I.J., Phillips, R.A., Petersen, A., Fox, J.W., Silk, J.R.D. 2010. Tracking of Arctic terns Sterna paradisaea reveals longest animal migration. Proceedings of the Royal Society B Biological Sciences, 107:2078-2081.

Eichhorn, G., Afanasyev, V., Drent, R.H., van der Jeugd, H.P. 2006. Spring stopover routines in Russian barnacle geese Branta leucopsis tracked by resightings and geolocation. Ardea, 94:667678.

Ellis, T.M., Bousfield, R.B., Bissett, L.A., Dyrting, K.C., Luk, G.S.M., Tsim, S.T., Sturm-Ramirez, K., Webster, R.G., Guan, Y., Peiris, J.S.M. 2004. Investigation of outbreaks of highly pathogenic H5N1 avian influenza in waterfowl and wild birds in Hong Kong in late 2002. Avian Pathology, 33:492-505.

Ely, C.R., Hall, J.S., Schmutz, J.A., Pearce, J.M., Terenzi, J., Sedinger, J.S., Ip, H.S. 2013. Evidence that life history characteristics of wild birds influence infection and exposure to influenza A viruses. PLoS One, 8:e57614.

Ene, A., Su, M., Lemaire, S., Rose, C., Schaff, S., Moretti, R., Lenz, J., Herbst, L.H. 2005. Distribution of chelonid fibropapillomatosis-associated herpesvirus variants in Florida: Molecular genetic evidence for infection of turtles following recruitment to neritic developmental habitats. Journal of Wildlife Diseases, 41:489-497.

Fearnley, L. 2015. Wild goose chase: The displacement of influenza research in the fields of Poyang Lake, China. Cultural Anthropology, 30:12-35.

Fenner, F., Fantini, B. 1999. Biological control of vertebrate pests: The history of myxomatosis, an 
experiment in evolution. CABI publishing.

Folstad, I., Nilssen, A.C., Halvorsen, O., Andersen, J. 1991. Parasite avoidance: the cause of postcalving migrations in Rangifer? Canadian Journal Zoology, 69:2423-2429.

Fox, A.D., Elmberg, J., Tombre, I.M., Hessel, R. 2016. Agriculture and herbivorous waterfowl: A review of the scientific basis for improved management. Biological Reviews, 92:854-877.

Fox, A.D., Walsh, A. 2012. Warming winter effects, fat store accumulation and timing of spring departure of Greenland white-fronted geese Anser albifrons flavirostris from their winter quarters. Hydrobiologia, 697:95-102.

Gaidet, N., Cappelle, J., Takekawa, J.Y., Prosser, D.J., Iverson, S.A., Douglas, D.C., Perry, W.M., Mundkur, T., Newman, S.H. 2010. Potential spread of highly pathogenic avian influenza H5N1 by wildfowl: Dispersal ranges and rates determined from large-scale satellite telemetry. Journal of Applied Ecology, 47:1147-1157.

Gaidet, N., Caron, A., Cappelle, J., Cumming, G.S., Balanca, G., Hammoumi, S., Cattoli, G., Abolnik, C., de Almeida S.R., Gil, P., Fereidouni, S.R., Grosbois, V., Tran, A., Mundava, J., Fofana, B., Ould, E.1., Mamy, A.B., Ndlovu, M., Mondain-Monval, J.Y., Triplet, P., Hagemeijer, W., Karesh, W.B., Newman, S.H., Dodman, T. 2012. Understanding the ecological drivers of avian influenza virus infection in wildfowl: A continental-scale study across Africa. Proceedings of the Royal Society B Biological Sciences, 279:1131-1141.

Galsworthy, S.J., ten Bosch, Q.A., Hoye, B.J., Heesterbeek, J.A.P., Klaassen, M., Klinkenberg, D. 2011. Effects of infection-induced migration delays on the epidemiology of avian influenza in wild mallard populations. PLoS One, 6: e26118.

Garamszegi, L.Z., Møller, A.P. 2007. Prevalence of avian influenza and host ecology. Proceedings of the Royal Society B Biological Sciences, 274:2003-2012.

Gaunt, A., Oring, L., Anderson, D. 1997. Guidelines to the use of wild birds in research. http://www.uprh.edu/olaw/docs/Guidelines/Birds\%20\&\%20Wild\%20Bird\%20Guidelines\%2020 10.pdf

di Giallonardo, F., Geoghegan, J.L., Docherty, D.E., McLean, R.G., Zody, M.C., Qu, J., Yang, X., Birren, B.W., Malboeuf, C.M., Newman, R.M., Ip, H.S., Holmes, E.C. 2016. Fluid spatial dynamics of West Nile virus in the United States: Rapid spread in a permissive host environment. Journal of Virology, 90:862-872.

Gilbert, M., Golding, N., Zhou, H., Wint, G.R.W., Robinson, T.P., Tatem, A.J., Lai, S., Zhou, S., Jiang, H., Guo, D., Huang, Z., Messina, J.P., Xiao, X., Linard, C., van Boeckel, T.P., Martin, V., Bhatt, S., Gething, P.W., Farrar, J.J., Hay, S.I., Yu, H. 2014. Predicting the risk of avian influenza A H7N9 infection in live-poultry markets across Asia. Nature Communications, 5:4116.

Gilbert, M., Jambal, L., Karesh, W.B., Fine, A., Shiilegdamba, E., Dulam, P., Sodnomdarjaa, R., Ganzorig, K., Batchuluun, D., Tseveenmyadag, N., Bolortuya, P., Cardona, C.J., Leung, C.Y.H., Peiris, J.S.M., Spackman, E., Swayne, D.E., Joly, D.O. 2012. Highly pathogenic avian influenza virus among wild birds in Mongolia. PLoS One, 7:e44097.

Gilbert, M., Xiao, X., Chaitaweesub, P., Kalpravidh, W., Premashthira, S., Boles, S., Slingenbergh, J. 2007. Avian influenza, domestic ducks and rice agriculture in Thailand. Agriculture, Ecosystems and Environment, 119:409-415.

Gilbert, M., Xiao, X., Domenech, J., Lubroth, J., Martin, V., Slingenbergh, J. 2006. Anatidae migration in the western Palearctic and spread of highly pathogenic avian influenza H5NI virus. Emerging Infectious Diseases, 12:1650-1656.

van Gils, J.A., Munster, V.J., Radersma, R., Liefhebber, D., Fouchier, R.A.M., Klaassen, M. 2007. Hampered foraging and migratory performance in swans infected with low-pathogenic avian influenza A virus. PLoS One, 2:e184. 
Gong, P., Niu, Z.G., Cheng, X., Zhao, K.Y., Zhou, D.M., Guo, J.H., Liang, L., Wang, X.F., Li, D.D., Huang, H.B., Wang, Y., Wang, K., Li, W.N., Wang, X.W., Ying, Q., Yang, Z.Z., Ye, Y.F., Li, Z., Zhuang, D.F., Chi, Y.B., Zhou, H.Z., Yan, J. 2010. China's wetland change (1990-2000) determined by remote sensing. Science China Earth Science, 53:1036-1042.

Green, M., Alerstam, T., Clausen, P., Drent, R., Ebbinge, B.S. 2002. Dark-bellied brent geese Branta bernicla bernicla, as recorded by satellite telemetry, do not minimize flight distance during spring migration. International Journal of Avian Science, 144:106-121.

Grueber, C.E., Nakagawa, S., Laws, R.J., Jamieson, I.G. 2011. Multimodel inference in ecology and evolution: Challenges and solutions. Journal of Evolutionary Biology, 24:699-711.

Guimerà, R., Amaral, L.A.N. 2004. Modeling the world-wide airport network. European Physical Journal B, 38:381-385.

Gunnarsson, G., Latorre-Margalef, N., Hobson, K.A., van Wilgenburg, S.L., Elmberg, J., Olsen, B., Fouchier, R.A.M., Waldenström, J. 2012. Disease dynamics and bird migration-linking mallards Anas platyrhynchos and subtype diversity of the influenza a virus in time and space, PLoS One, 7:e35679.

Gupta, R.C., Kaushik, T.K., Kumar, S. 2010. An account concerning arrival and departure time of few selected winter migratory birds in Haryana rural ponds. Environment Conservation Journal, 11:1-9.

Hawkes, L.A., Balachandran, S., Batbayar, N., Butler, P.J., Frappell, P.B., Milsom, W.K., Tseveenmyadag, N., Newman, S.H., Scott, G.R., Sathiyaselvam, P., Takekawa, J.Y., Wikelski, M., Bishop, C.M. 2011. The trans-Himalayan flights of bar-headed geese (Anser indicus). Proceedings of the National Academy of Sciences, 108:9516-9519.

Hénaux, V., Samuel, M.D. 2011. Avian influenza shedding patterns in waterfowl: Implication for surveillance, environmental transmission, and disease spread. Journal of Wildlife Diseases, 47:566-578.

Hill, N.J., Runstadler, J.A. 2016. A bird's eye view of influenza A virus transmission: Challenges with characterizing both sides of a co-evolutionary dynamic. Integrative and Comparative Biology, 56:304-316.

Hill, N.J., Takekawa, J.Y., Ackerman, J.T., Hobson, K.A., Herring, G., Cardona, C.J., Runstadler, J.A., Boyce, W.M. 2012. Migration strategy affects avian influenza dynamics in mallards (Anas platyrhynchos). Molecular Ecology, 21:5986-5999.

Holdo, R.M., Holt, R.D., Fryxell, J.M. 2009a. Opposing rainfall and plant nutritional gradients best explain the wildebeest migration in the Serengeti. The American Naturalist, 173:431-445.

Holdo, R.M., Sinclair, A.R.E., Dobson, A.P., Metzger, K.L., Bolker, B.M., Ritchie, M.E., Holt, R.D. 2009b. A disease-mediated trophic cascade in the Serengeti and its implications for ecosystem C. PLoS Biology, 7:e1000210.

Hornman, M., Hustings, F., Koffijberg, K., Klaassen, O., Kleefstra, R., van Winden, E., Sovon Geese and Zwanengroep \& Soldaat L. 2013. Watervogels in Nederland in 2011/2012. https://www.sovon.nl/nl/publicaties/watervogels-nederland-20112012

Hornman, M., Hustings, F., Koffijberg, K., Klaassen, O., Kleefstra, R., van Winden, E., Sovon Geese and Zwanengroep \& Soldaat L. 2015. Watervogels in Nederland in 2012/2013. https://www.sovon.nl/nl/publicaties/watervogels-nederland-20122013

Hoye, B.J., Munster, V.J., Nishiura, H., Fouchier, R.A.M., Madsen, J., Klaassen, M. 2011.

Reconstructing an annual cycle of interaction: Natural infection and antibody dynamics to avian influenza along a migratory flyway. Oikos, 120:748-755.

Hulse-Post, D.J., Sturm-Ramirez, K.M., Humberd, J., Seiler, P., Govorkova, E.A., Krauss, S., Scholtissek, C., Puthavathana, P., Buranathai, C., Nguyen, T.D., Long, H.T., Naipospos, T.S.P, Chen, H., Ellis, T.M., Guan, Y., Peiris, J.S.M., Webster, R.G. 2005. Role of domestic ducks in 
the propagation and biological evolution of highly pathogenic H5N1 influenza viruses in Asia. Proceedings of the National Academy of Sciences, 102:10682-10687.

Iverson, G.C., Warnock, S.E., Butler, R.W., Bishop, M.A., Warnock, N. 1996. Spring migration of western sandpipers along the Pacific coast of North America: A telemetry study. Condor, 98:1021.

Jensen, R.A., Madsen, J., O'connell, M., Wisz, M.S., Tømmervik, H., Mehlum, F. 2008. Prediction of the distribution of Arctic-nesting pink-footed geese under a warmer climate scenario. Global Chang Biology, 14:1-10.

Jeong, J., Kang, H.M., Lee, E.K., Song, B.M., Kwon, Y.K., Kim, H.R., Choi, K.S., Kim, J.Y., Lee, H.J., Moon, O.K., Jeong, W., Choi, J., Baek, J.H., Joo, Y.S., Park, Y.H., Lee, H.S., Lee, Y.J. 2014. Highly pathogenic avian influenza virus (H5N8) in domestic poultry and its relationship with migratory birds in South Korea during 2014. Veterinary Microbiology, 173:249-257.

Johnson, W.P., Schmidt, P.M., Taylor, D.P. 2014. Foraging flight distances of wintering ducks and geese: A review. Avian Conservation and Ecology, 9:2.

Jonassen, C.M., Handeland, K. 2007. Avian influenza virus screening in wild waterfowl in Norway, 2005. Avian Diseases, 51:425-428.

de Jong, M.C.M., Diekmann, O., Heesterbeek, H. 1995. How does transmission of infection depend on population size. Epidemic models: Their structure and relation to data. Mollison D, editors, Cambridge University Press. pp:84-94.

Jousimo, J., Tack, A.J.M., Ovaskainen, O., Mononen, T., Susi, H., Tollenaere, C., Laine, A.L. 2014. Ecological and evolutionary effects of fragmentation on infectious disease dynamics. Science, 344:1289-1293.

Kaluza, P., Kölzsch, A., Gastner, M.T., Blasius, B. 2010. The complex network of global cargo ship movements. Journal of The Royal Society Interface, 7:1093-1103.

Keawcharoen, J., van Riel, D., van Amerongen, G., Bestebroer, T., Beyer, W.E., van Lavieren, R., Osterhaus, A.D.M.E., Fouchier, R.A.M., Kuiken, T. 2008. Wild ducks as long-distance vectors of highly pathogenic avian influenza virus (H5N1). Emerging Infectious Diseases, 14:600-607.

Keeling, M.J., Danon, L., Vernon, M.C., House, T.A. 2010. Individual identity and movement networks for disease metapopulations. Proceedings of the National Academy of Sciences, 107:8866-8870.

van Kerkhove, M.D., Vong, S., Guitian, J., Holl, D., Mangtani, P., San, S., Ghani, A.C. 2009. Poultry movement networks in Cambodia: Implications for surveillance and control of highly pathogenic avian influenza (HPAI/H5N1). Vaccine, 27:6345-6352.

Kerr, P.J. 2012. Myxomatosis in Australia and Europe: A model for emerging infectious diseases. Antiviral Research, 93:387-415.

Khatchikian, C.E., Prusinski, M.A., Stone, M., Backenson, P.B., Wang, I.N., Foley, E., Seifert, S.N., Levy, M.Z., Brisson, D. 2015. Recent and rapid population growth and range expansion of the Lyme disease tick vector, Ixodes scapularis, in North America. Evolution, 69:1678-1689.

Kida, H., Yanagawa, R., Matsuoka, Y. 1980. Duck influenza lacking evidence of disease signs and immune response. Infection and Immunity, 30:547-553.

Kile, J.C., Ren, R., Liu, L., Greene, C.M., Roguski, K., Iuliano, A.D., Jang, Y., Jones, J., Thor, S., Song, Y., Zhou, S., Trock, S.C., Dugan, V., Wentworth, D.E., Levine, M.Z., Uyeki, T.M., Katz, J.M., Jernigan, D.B., Olsen, S.J., Fry, A.M., Azziz-Baumgartner, E., Davis, C.T. 2017. Update: Increase in human infections with novel Asian lineage avian influenza A (H7N9) viruses during the fifth epidemic — China, October 1, 2016-August 7, 2017.

https://www.cdc.gov/mmwr/volumes/66/wr/mm6635a2.htm

Kilpatrick, A.M., Chmura, A.A., Gibbons, D.W., Fleischer, R.C., Marra, P.P., Daszak, P. 2006. Predicting the global spread of H5N1 avian influenza. Proceedings of the National Academy of 
Sciences, 103:19368-19373.

King, S.L., Pierce, A.R., Hersey, K.R., Winstead, N. 2010. Migration patterns and movements of sandhill cranes wintering in central and southwestern Louisiana. Proceedings of the Eleventh North American Crane Workshop, pp:57-61.

Kleijn, D., Munster, V.J., Ebbinge, B.S., Jonkers, D.A., Müskens, G.J.D.M., van Randen, Y., Fouchier, R.A.M. 2010. Dynamics and ecological consequences of avian influenza virus infection in greater white-fronted geese in their winter staging areas. Proceedings of the Royal Society B Biological Sciences, 277:2041-2048.

Kölzsch, A., Müskens, G.J.D.M., Kruckenberg, H., Glazov, P., Weinzierl, R., Nolet, B.A., Wikelski, M. 2016. Towards a new understanding of migration timing: slower spring than autumn migration in geese reflects different decision rules for stopover use and departure. Oikos, 125:1496-1507.

Koskella, B., Brockhurst, M.A. 2014. Bacteria-phage coevolution as a driver of ecological and evolutionary processes in microbial communities. Microbiological Reviews, 38:916-931.

Kou, Z., Lei, F.M., Yu, J., Fan, Z.J., Yin, Z.H., Jia, C.X., Xiong, K.J., Sun, Y.H., Zhang, X.W., Wu, X.M. 2005. New genotype of avian influenza H5N1 viruses isolated from tree sparrows in China. Journal of Virology, 79:15460-15466.

Kranstauber, B., Kays, R., Lapoint, S.D., Wikelski, M., Safi, K. 2012. A dynamic Brownian bridge movement model to estimate utilization distributions for heterogeneous animal movement. Journal of Animal Ecology, 81:738-746.

Krauss, S., Stallknecht, D.E., Negovetich, N.J., Niles, L.J., Webby, R.J., Webster, R.G. 2010. Coincident ruddy turnstone migration and horseshoe crab spawning creates an ecological "hot spot” for influenza viruses. Proceedings of the Royal Society B Biological Sciences, 277:33733379 .

Krauss, S., Walker, D., Pryor, S.P., Niles, L., Chenghong, L., Hinshaw, V.S., Webster, R.G. 2004. Influenza A viruses of migrating wild aquatic birds in north America. Vector-Borne and Zoonotic Diseases, 4:177-189.

Latorre-Margalef, N., Gunnarsson, G., Munster, V.J., Fouchier, R.A.M., Osterhaus, A.D.M.E., Elmberg, J., Olsen, B., Wallensten, A., Fransson, T., Brudin, L., Waldenström, J. 2009. Does influenza A affect body condition of wild mallard ducks, or vice versa? A reply to Flint and Franson. Proceedings of the Royal Society B: Biological Sciences, 276:2347-2349.

Latorre-Margalef, N., Tolf, C., Grosbois, V., Avril, A., Bengtsson, D., Wille, M., Osterhaus, A.D.M.E., Fouchier, R.A.M., Olsen, B., Waldenström, J. 2014. Long-term variation in influenza A virus prevalence and subtype diversity in migratory mallards in northern Europe. Proceedings of the Royal Society B: Biological Sciences, 281:20140098.

Lehikoinen, A., Jaatinen, K. 2012. Delayed autumn migration in northern European waterfowl. Journal of Ornithology, 153:563-570.

Lehikoinen, A., Jaatinen, K., Vähätalo, A.V., Clausen, P., Crowe, O., Deceuninck, B., Hearn, R., Holt, C.A., Hornman, M., Keller, V., Nilsson, L., Langendoen, T., Tománková, I., Wahl, J., Fox, A.D. 2013. Rapid climate driven shifts in wintering distributions of three common waterbird species. Global Change Biology, 19:2071-2081.

Leighton, P.A., Koffi, J.K., Pelcat, Y., Lindsay, L.R., Ogden, N.H. 2012. Predicting the speed of tick invasion: An empirical model of range expansion for the Lyme disease vector Ixodes scapularis in Canada. Journal of Applied Ecology, 49:457-464.

Leung, Y.H.C., Zhang, L.J., Chow, C.K., Tsang, C.L., Ng, C.F., Wong, C.K., Guan, Y., Peiris, J.S.M. 2007. Poultry drinking water used for avian influenza surveillance. Emerging Infectious Diseases, 13:1380-1382.

Lewis, N.S., Javakhishvili, Z., Russell, C.A., Machablishvili, A., Lexmond, P., Verhagen, J.H., 
Vuong, O., Onashvili, T., Donduashvili, M., Smith, D.J. 2013. Avian influenza virus surveillance in wild birds in Georgia: 2009-2011. PLoS One, 8:e58534.

Li, C., Liu, S., Fang, Z., Chen, Y. 2012. Emergence of structural properties in economic networks: A multi-local-world evolving model. Simulation Modelling Practice and Theory, 21:91-102.

Ligon, B.L. 2005. Avian influenza virus H5N1: A review of its history and information regarding its potential to cause the next pandemic. Seminars in Pediatric Infectious Diseases, 16:326-335.

Lisovski, S., van Dijk, J.G.B., Klinkenberg, D., Nolet, B.A., Fouchier, R.A.M., Klaassen, M. 2018. The roles of migratory and resident birds in local avian influenza infection dynamics. Journal of Applied Ecology, 2018:1-13.

Liu, J., Xiao, H., Lei, F., Zhu, Q., Qin, K., Zhang, X.L.W., Zhang, X.L.W., Zhao, D., Wang, G., Feng, Y., Ma, J., Liu, W., Wang, J., Gao, G.F. 2005. Highly pathogenic H5N1 influenza virus infection in migratory birds. Science, 309:1206-1206.

Loehle, C. 1995. Social barriers to pathogen transmission in wild animal populations. Ecology, 76:326-335.

Luschi, P., Hays, G.C., Papi, F. 2003. A review of long-distance movements by marine turtles, and the possible role of ocean currents. Oikos, 103:293-302.

Madsen, J., Cracknell, G. 1999. Goose populations of the Western Palearctic: A review of status and distribution. https://issuu.com/jesper_madsen/docs/goosepopulationswest palearctic

Madsen, J., Klaassen, M. 2006. Assessing body condition and energy budget components by scoring abdominal profiles in free-ranging pink-footed geese Anser brachyrhynchus. Journal of Avian Biology, 37:283-287.

McKay, A.F., Hoye, J.B. 2016. Are migratory animals superspreaders of infection? Integrative and Comparative Biology, 56:260-267.

McKinnon, L., Smith, P.A., Nol, E., Martin, J.L., Doyle, F.I., Abraham, K.F., Gilchrist, H.G., Morrison, R.I.G., Bêty, J. 2010. Lower predation risk for migratory birds at high latitudes. Science, 327:326-327.

Meyers, L.A., Pourbohloul, B., Newman, M.E.J., Skowronski, D.M., Brunham, R.C. 2005. Network theory and SARS: Predicting outbreak diversity. Journal of Theoretical Biology, 232:71-81.

Meylan, A.B., Bowen, B.W., Avise, J.C. 1990. A genetic test of the natal homing versus social facilitation models for green turtle migration. Science, 248:724-727.

Møller, A.P., Erritzøe, J. 1998. Host immune defence and migration in birds. Ecology and Evolution, 12:945-953.

Morbey, Y.E., Ydenberg, R.C. 2001. Protandrous arrival timing to breeding areas: A review. Ecology Letters, 4:663-673.

Moreau, R.E. 1972. Palaearctic-African bird migration systems. New York, Academic Press.

Morran, L.T., Schmidt, O.G., Gelarden, I.A., Parrish, R.C., Lively, C.M. 2011. Running with the Red Queen: Host-parasite coevolution selects for biparental sex. Science, 333:216-218.

Motta, P., Porphyre, T., Handel, I., Hamman, S.M., Ngu, N.V., Tanya, V., Morgan, K., Christley, R., Bronsvoort, B.M.deC. 2017. Implications of the cattle trade network in Cameroon for regional disease prevention and control. Scientific Reports, 7:43932.

Mundkur, T., Langendoen, T., Watkins, D. 2017. The Asian Waterbird Census 2008-2015-Results of Coordinated Counts in Asia and Australasia. https://www.eaaflyway.net/ documents/resources/aewa\%20ref/AWC_2008-2015_Summary_Report_31Mar17.pdf

Munster, V.J., Baas, C., Lexmond, P., Bestebroer, T.M., Guldemeester, J., Beyer, W.E.P., de Wit, E., Schutten, M., Rimmelzwaan, G.F., Osterhaus, A.D.M.E., Fouchier, R.A.M. 2009. Practical considerations for high-throughput influenza A virus surveillance studies of wild birds by use of molecular diagnostic tests. Journal of Clinical Microbiology, 47:666-673. 
Munster, V.J., Baas, C., Lexmond, P., Waldenström, J., Wallensten, A., Fransson, T., Rimmelzwaan, G.F., Beyer, W.E.P., Schutten, M., Olsen, B., Osterhaus, A.D.M.E., Fouchier, R.A.M. 2007. Spatial, temporal, and species variation in prevalence of influenza a viruses in wild migratory birds. PLoS Pathogens, 3:0630-0638.

Muraoka, Y., Schulze, C.H., Pavličev, M., Wichmann, G. 2009. Spring migration dynamics and sexspecific patterns in stopover strategy in the Wood Sandpiper Tringa glareola. Journal of Ornithology, 150:313-319.

Namgail, T., Takekawa, J.Y., Balachandran, S., Mundkur, T., Sathiyaselvam, P., Prosser, D.J., McCracken, T., Newman, S.H. 2017. Migratory ducks and protected wetlands in India. Bird migration across the Himalayas: Wetland functioning amidst mountains and glaciers, Prins, H.H.T. and Namgail, T., editors. Cambridge University Press, Cambridge. pp. 373-379.

Navedo, J.G., Masero, J.A., Overdijk, O., Orizaola, G., Sánchez-Guzmán, J.M. 2010. Assessing the Role of multiple environmental factors on Eurasian spoonbill departure decisions from stopover sites. Ardea, 98:3-12.

Nemeth, N.M., Brown, J.D., Stallknecht, D.E., Howerth, E.W., Newman, S.H., Swayne, D.E. 2013. Experimental infection of bar-headed geese (Anser indicus) and ruddy shelducks (Tadorna ferruginea) with a clade $2.3 .2 \mathrm{H} 5 \mathrm{~N} 1$ highly pathogenic avian influenza virus. Veterinary Pathology, 50:961-970.

Newman, M.E.J. 2003. The structure and function of complex networks. SIAM Review, 45:167-256. Newman, S.H., Hill, N.J., Spragens, K.A., Janies, D., Voronkin, I.O., Prosser, D.J., Yan, B., Lei, F., Batbayar, N., Natsagdorj, T., Bishop, C.M., Butler, P.J., Wikelski, M., Balachandran, S., Mundkur, T., Douglas, D.C., Takekawa, J.Y. 2012. Eco-virological approach for assessing the role of wild birds in the spread of avian influenza H5N1 along the Central Asian Flyway. PLoS One, 7:e30636.

Newman, S.H., Iverson, S.A., Takekawa, J.Y., Gilbert, M., Prosser, D.J., Batbayar, N., Natsagdorj, T., Douglas, D.C. 2009. Migration of whooper swans and outbreaks of highly pathogenic avian influenza H5N1 virus in eastern Asia. PLoS One, 4:e5729.

Newton, I. 2007. The Migration Ecology of Birds. Elsevier, London.

Niu, Y. 2016. Traditional agriculture technique in China. Shantou University Press, China.

O’Reilly, K.M., Wingfield, J.C. 1995. Spring and autumn migration in arctic shorebirds: same distance, different strategies. American Zoologist, 35:222-233.

Olsen, B., Munster, V.J., Wallensten, A., Waldenström, J., Osterhaus, A.D.M.E., Fouchier, R.A.M. 2006. Global patterns of influenza A virus in wild birds. Science, 312:384-388.

World Health Organization. 2017. H5N1 highly pathogenic avian influenza: Timeline of major events. http://www.who.int/influenza/human_animal_interface/avian_influenza/ H5N1_avian_influenza_update.pdf

Ottenburghs, J., van Hooft, P., van Wieren, S.E., Ydenberg, R.C., Prins, H.H.T. 2016. Hybridization in geese: A review. Frontiers in Zoology, 13:20.

Owen, J., Moore, F., Panella, N., Edwards, E., Bru, R., Hughes, M., Komar, N. 2006. Migrating birds as dispersal vehicles for West Nile virus. Ecohealth, 3:79-85.

Owen, J.C., Moore, F.R. 2006. Seasonal differences in immunological condition of three species of thrushes. Condor, 108:389-398.

Palm, E.C., Newman, S.H., Prosser, D.J., Xiao, X., Ze, L., Batbayar, N., Balachandran, S., Takekawa, J.Y. 2015. Mapping migratory flyways in Asia using dynamic Brownian bridge movement models. Movement Ecology, 3:3.

Palmgren, H., Sellin, M., Bergström, S., Olsen, B. 1997. Enteropathogenic bacteria in migrating birds arriving in Sweden. Scandinavian Journal of Infectious Diseases, 29:565-568.

Pasick, J., Berhane, Y., Embury-Hyatt, C., Copps, J., Kehler, H., Handel, K., Babiuk, S., Hooper- 
McGrevy, K., Li, Y., Quynh, M. Le, S.L.P. 2007. Susceptibility of Canada geese (Branta canadensis) to highly pathogenic avian influenza virus (H5N1). Emerging Infectious Diseases, 13:1821-1827.

Paz, S. 2015. Climate change impacts on West Nile virus transmission in a global context. Philosophical Transactions of the Royal Society B Biological Sciences, 370:2013056120130561.

Prins, H.H.T., Namgail, T. Bird migration across the Himalayas and beyond: The need for better conservation and management of a natural wonder. Bird Migration Across the Himalayas, Prins, H.H.T. and Namgail, T., editors. Cambridge University Press, Cambridge. pp. 399-418.

Prosser, D.J., Cui, P., Takekawa, J.Y., Tang, M., Hou, Y., Collins, B.M., Yan, B., Hill, N.J., Li, T., Li, Y., Lei, F., Guo, S., Xing, Z., He, Y., Zhou, Y., Douglas, D.C., Perry, W.M., Newman, S.H. 2011. Wild bird migration across the Qinghai-Tibetan Plateau: A transmission route for highly pathogenic H5N1. PLoS One, 6:e17622.

Prosser, D.J., Hungerford, L.L., Erwin, R.M., Ottinger, M.A., Takekawa, J.Y., Ellis, E.C. 2013. Mapping avian influenza transmission risk at the interface of domestic poultry and wild birds. Frontiers in Public Health, 1:28.

Prosser, D.J., Palm, E.C., Takekawa, J.Y., Zhao, D., Xiao, X., Li, P., Liu, Y., Newman, S.H. 2016. Movement analysis of free-grazing domestic ducks in Poyang Lake, China: A disease connection. International Journal of Geographical Information Science, 30:869-880.

Prosser, D.J., Takekawa, J.Y., Newman, S.H., Yan, B., Douglas, D.C., Hou, Y., Xing, Z., Zhang, D., Li, T., Li, Y., Zhao, D., Perry, W.M., Palm, E.C. 2009. Satellite-marked waterfowl reveal migratory connection between $\mathrm{H} 5 \mathrm{~N} 1$ outbreak areas in China and Mongolia. International Journal of Avian Science, 151:568-576.

QGIS Development Team. 2015. QGIS geographic information system. https://www.qgis.org/ en/docs/index.html

R Development Core Team. 2016. R: A language and environment for statistical computing. $R$ Found Stat Comput Vienna Austria.

Raidal, S.R., Ohara, M., Hobbs, R.P., Prince, R.I.T. 1998. Gram-negative bacterial infections and cardiovascular parasitism in green sea turtles (Chelonia mydas). Australian Veterinary Journal, 76:415-417.

Rappole, J.H. 2013. The avian migrant: the biology of bird migration. Columbia University Press, New York.

Rappole, J.H., Derrickson, S.R., Hubálek, Z., Hubálek, Z. 2000. Migratory birds and spread of West Nile virus in the Western Hemisphere. Emerging Infectious Diseases, 6:319-328.

Reed, K.D., Meece, J.K., Henkel, J.S., Shukla, S.K. 2003. Birds, migration and emerging zoonoses: West Nile virus, lyme disease, influenza A and enteropathogens. Clinical Medicine \& Research, 1:5-12.

Ren, H., Jin, Y., Hu, M., Zhou, J., Song, T., Huang, Z., Li, B., Li, K., Zhou, W., Dai, H., Shi, W., Yue, J., Liang, L. 2016. Ecological dynamics of influenza A viruses: Cross-species transmission and global migration. Scientific Reports, 6:36839.

Reperant, L.A., Fuckar, N.S., Osterhaus, A.D.M.E., Dobson, A.P., Kuiken, T., Fuc, N.S. 2010. Spatial and temporal association of outbreaks of $\mathrm{H} 5 \mathrm{~N} 1$ influenza virus infection in wild birds with the 0 degrees C isotherm. PLoS Pathogens, 6:e1000854.

Rohani, P., Breban, R., Stallknecht, D.E., Drake, J.M. 2009. Environmental transmission of low pathogenicity avian influenza viruses and its implications for pathogen invasion. Proceedings of the National Academy of Sciences, 106:10365-10369.

Samuel, M.D., Hall, J.S., Brown, J.D., Goldberg, D.R., Ip, H., Baranyuk, V.V. 2015. The dynamics of avian influenza in lesser snow geese: Implications for annual and migratory infection patterns. 
Ecological Applications, 25:1851-1859.

Satterfield, D.A., Maerz, J.C., Altizer, S. 2015. Loss of migratory behaviour increases infection risk for a butterfly host. Proceedings of the Royal Society B Biological Sciences, 282:2014173420141734.

Scheper, J., Reemer, M., van Kats, R., Ozinga, W.A., van der Linden, G.T.J., Schaminée, J.H.J., Siepel, H., Kleijn, D. 2014. Museum specimens reveal loss of pollen host plants as key factor driving wild bee decline in The Netherlands. Proceedings of the National Academy of Sciences, 111:17552-17557.

Schneider, D.C., Harrington, B.A. 1981. Timing of shorebird migration in relation to prey depletion. Auk, 98:801-811.

Schulte-Hostedde, A.I., Millar, J.S., Hickling, G.J. 2001. Evaluating body condition in small mammals. Canadian Journal of Zoology, 79:1021-1029.

Schulte-Hostedde, A.I., Zinner, B., Millar, J.S., Hickling, G.J. 2005. Restitution of mass-size residuals: Validating body condition indices. Ecology, 86:155-163.

Scott, G.R., Milsom, W.K. 2007. Control of breathing and adaptation to high altitude in the barheaded goose. American Journal of Physiology. Regulatory, Integrative and Comparative Physiology, 293:R379-R391.

Scott, G.R., Schulte, P.M., Egginton, S., Scott, A.L.M., Richards, J.G., Milsom, W.K. 2011. Molecular evolution of cytochrome c oxidase underlies high-altitude adaptation in the barheaded goose. Molecular Biology and Evolution, 28:351-363.

Seebacher, F., Post, E. 2015. Climate change impacts on animal migration. Climate Change Responses, 2:5.

Sejvar, J.J. 2003. West Nile virus: An historical overview. The Ochsner Journal, 5:6-10.

Seto, K.C., Fragkias, M. 2005. Quantifying spatiotemporal patterns of urban land-use change in four cities of China with time series landscape metrics. Landscape Ecology, 20:871-888.

Shariatinajafabadi, M., Wang, T., Skidmore, A.K., Toxopeus, A.G., Kölzsch, A., Nolet, B.A., Exo, K.M., Griffin, L., Stahl, J., Cabot, D. 2014. Migratory herbivorous waterfowl track satellitederived green wave index. PLoS One, 9:e108331.

Shimada, T., Yamaguchi, N.M., Hijikata, N., Hiraoka, E., Hupp, J.W., Flint, P.L., Tokita, K., Fujita, G., Uchida, K., Sato, F., Kurechi, M., John, M., Ramey, A.M., Higuchi, H. 2014. Satellite tracking of migrating whooper swans Cygnus cygnus wintering in Japan. Ornithological Science, 13:67-75.

Shoham, D., Jahangir, A., Ruenphet, S., Takehara, K. 2012. Persistence of avian influenza viruses in various artificially frozen environmental water types. Influenza Research and Treatment, 2012:1-11.

Si, Y., Skidmore, A.K., Wang, T., de Boer, W.F., Debba, P., Toxopeus, A.G., Li, L., Prins, H.H.T. 2009. Spatio-temporal dynamics of global H5N1 outbreaks match bird migration patterns. Geospatial Health, 4:65-78.

Si, Y., Xin, Q., de Boer, W.F., Gong, P., Ydenberg, R.C., Prins, H.H.T. 2015. Do Arctic breeding geese track or overtake a green wave during spring migration? Scientific Reports, 5:8749.

Si, Y., Xu, Y., Xu, F., Li, X., Zhang, W., Wielstra, B., Wei, J., Liu, G., Luo, H., Takekawa, J., Balachandran, S., Zhang, T., de Boer, W.F., Prins, H.H.T, Gong, P. 2018. Spring migration patterns, habitat use, and stopover site protection status for two declining waterfowl species wintering in China as revealed by satellite tracking. Ecology and Evolution, 2018:1-10.

Silk, M.J., Croft, D.P., Delahay, R.J., Hodgson, D.J., Boots, M., Weber, N., McDonald, R.A. 2017. Using social network measures in wildlife disease ecology, epidemiology, and management. BioScience, 67:245-257.

La Sorte, F.A., Thompson, F.R. 2007. Poleward shifts in winter ranges of North American birds. 


\section{Ecology, 88:1803-1812.}

Stallknecht, D.E., Kearney, M.T., Shane, S.M., Zwank, P.J. 1990. Effects of pH, temperature, and salinity on persistence of avian influenza viruses in water. Avian Diseases, 34:412-418.

Stallknecht, D.E., Shane, S.M., Kearney, M.T., Zwank, P.J. 2015. Persistence of avian influenza viruses in water. Avian Diseases, 34:406-411.

Stephens, P.A., Boyd, I.L., Mcnamara, J.M., Houston, A.I. 2009. Capital breeding and income breeding: Their meaning, measurement, and worth. Ecology, 90:2057-2067.

Takekawa, J.Y., Heath, S.R., Douglas, D.C., Perry, W.M., Javed, S., Newman, S.H., Suwal, R.N., Rahmani, A.R., Choudhury, B.C., Prosser, D.J., Yan, B., Hou, Y., Batbayar, N., Natsagdorj, T., Bishop, C.M., Butler, P.J., Frappell, P.B., Milsom, W.K., Scott, G.R., Hawkes, L.A., Wikelski, M. 2009. Geographic variation in bar-headed geese Anser indicus: Connectivity of wintering areas and breeding grounds across a broad front. Wildfowl, 59:100-123.

Takekawa, J.Y., Newman, S.H., Xiao, X., Prosser, D.J., Spragens, K.A., Palm, E.C., Yan, B., Li, T., Lei, F., Zhao, D., Douglas, D.C., Muzaffar, B.S., Ji, W. 2010a. Migration of waterfowl in the East Asian flyway and spatial relationship to HPAI H5N1 outbreaks. Avian Diseases Digest, 5:e101-e102.

Takekawa, J.Y., Palm, E.C., Prosser, D.J., Hawkes, L.A., Batbayar, N., Balachandran, S., Luo, Z., Xiao, X., Newman, S.H. 2017. Goose migration across the Himalayas: Migratory routes and movement patterns of bar-headed geese. Bird migration across the Himalayas: wetland functioning amidst mountains and glaciers, Prins, H.H.T. and Namgail, T., editors. Cambridge University Press, Cambridge. pp. 15-29.

Takekawa, J.Y., Prosser, D.J., Newman, S.H., Muzaffar, S.B., Hill, N.J., Yan, B., Xiao, X., Lei, F., Li, T., Schwarzbach, S.E., Howell, J.A. 2010b. Victims and vectors: Highly pathogenic avian influenza H5N1 and the ecology of wild birds. Avian Biology Research, 3:51-73.

Taylor, C.M., Laughlin, A.J., Hall, R.J. 2016. The response of migratory populations to phenological change: A migratory flow network modelling approach. Journal of Animal Ecology, 85:648659.

Tian, H., Zhou, S., Dong, L., van Boeckel, T.P., Cui, Y., Newman, S.H., Takekawa, J.Y., Prosser, D.J., Xiao, X., Wu, Y., Cazelles, B., Huang, S., Yang, R., Grenfell, B.T., Xu, B. 2015. Avian influenza H5N1 viral and bird migration networks in Asia. Proceedings of the National Academy of Sciences, 112:172-177.

Tombre, I.M., Høgda, K.A., Madsen, J., Griffin, L.R., Kuijken, E., Shimmings, P., Rees, E., Verscheure, C. 2008. The onset of spring and timing of migration in two arctic nesting goose populations: The pink-footed goose Anser bachyrhynchus and the barnacle goose Branta leucopsis. Journal of Avian Biology, 39:691-703.

Tong, S., Zhu, X., Li, Y., Shi, M., Zhang, J., Bourgeois, M., Yang, H., Chen, X., Recuenco, S., Gomez, J., Chen, L.M., Johnson, A., Tao, Y., Dreyfus, C., Yu, W., McBride, R., Carney, P.J., Gilbert, A.T., Chang, J., Guo, Z., Davis, C.T., Paulson, J.C., Stevens, J., Rupprecht, C.E., Holmes, E.C., Wilson, I.A., Donis, R.O. 2013. New world bats harbor diverse influenza A viruses. PLoS Pathogens, 9:e1003657.

Underhill, L.G., Kirby, J.S., West, R.B., Scott, D.A., Davidson, N.C., Haanstra, L., Piersma, T., Hotker, H., Stroud, D.A. 2001. An atlas of wader populations in Africa and western Eurasia. Ostrich, 72:176-177.

Verhagen, J.H., van Dijk, J.G.B., Vuong, O., Bestebroer, T., Lexmond, P., Klaassen, M., Fouchier, R.A.M. 2014. Migratory birds reinforce local circulation of avian influenza viruses. PLoS One, 9:e112366.

Verhagen, J.H., Herfst, S., Fouchier, R.A. 2015a. How a virus travels the world. Science, 347:616617. 
Verhagen, J.H., van der Jeugd, H.P., Nolet, B.A., Slaterus, R., Kharitonov, S.P., de Vries, P.P., Vuong, O., Majoor, F., Kuiken, T., Fouchier, R.A. 2015b. Wild bird surveillance around outbreaks of highly pathogenic avian influenza A (H5N8) virus in the Netherlands, 2014, within the context of global flyways. Eurosurveillance, 20:21-32.

Viana, D.S., Gangoso, L., Bouten, W., Figuerola, J. 2016. Overseas seed dispersal by migratory birds. Proceedings of the Royal Society B Biological Sciences, 283:20152406.

Wallensten, A., Munster, V.J., Latorre-Margalef, N., Brytting, M., Elmberg, J., Fouchier, R.A.M., Fransson, T., Haemig, P.D., Karlsson, M., Lundkvist, Å., Osterhaus, A.D.M.E., Stervander, M., Waldenström, J., Olsen, B. 2007. Surveillance of influenza A virus in migratory waterfowl in northern Europe. Emerging Infectious Diseases, 13:404-411.

Wang, R.H., Jin, Z., Liu, Q.X., van de Koppel, J., Alonso, D. 2012. A simple stochastic model with environmental transmission explains multi-year periodicity in outbreaks of avian flu. PLoS One, 7:e28873.

Wang, Y., Jiang, Z., Jin, Z., Tan, H., Xu, B. 2013. Risk factors for infectious diseases in backyard poultry farms in the Poyang Lake area, China. PLoS One, 8:e67366.

Watts, D.J., Strogatz, S.H. 1998. Collective dynamics of "small-world" networks. Nature, 393:440442.

Webster, R.G., Bean, W.J., Gorman, O.T., Chambers, T.M., Kawaoka, Y. 1992. Evolution and ecology of influenza A viruses. Microbiological Reviews, 56:152-179.

Webster, R.G., Yakhno, M., Hinshaw, V.S., Bean, W.J., Copal, M.K. 1978. Intestinal influenza: Replication and characterization of influenza viruses in ducks. Virology, 84:268-278.

Weitz, J.S., Hartman, H., Levin, S.A. 2005. Coevolutionary arms races between bacteria and bacteriophage. Proceedings of the National Academy of Sciences, 102:9535-9540.

Welte, V.R., Terán, M.V. 2004. Emergency prevention system (EMPRES) for transboundary animal and plant pests and diseases - The EMPRES-Livestock: An FAO initiative. Annals of the New York Academy of Sciences, pp. 19-31.

Sinclair, A.R.E., Norton-Griffiths, M., editors. 1981. Serengeti: Dynamics of an ecosystem. The University of Chicago Press, Chicago.

WHO. 2018. Cumulative number of confirmed human cases of avian influenza A(H5N1) reported to WHO. http://www.who.int/influenza/human_animal_interface/en/

Wilcove, D.S. 2008. No way home: The decline of the world's great animal migrations. Island Press, Washington, DC.

Wilensky, U. 1999. NetLogo. https://ccl.northwestern.edu/netlogo/docs/

World Organization for Animal Health. 2017. Update on highly pathogenic avian influenza in animals (Type H5 and H7). http://www.oie.int/animal-health-in-the-world/update-on-avian-influenza

Xu, C., Havers, F., Wang, L., Chen, T., Shi, J., Wang, D., Yang, J., Yang, L., Widdowson, M.A., Shu, Y. 2013. Monitoring avian influenza a (H7N9) virus through national influenzalike illness surveillance, China. Emerging Infectious Diseases, 19:1289-1292.

Xu, Y., Gong, P., Wielstra, B., Si, Y. 2016. Southward autumn migration of waterfowl facilitates cross-continental transmission of the highly pathogenic avian influenza H5N1 virus. Scientific Reports, 6:30262.

Xu, Y., Si, Y., Yin, S., Zhang, W., Grishchenko, M., Prins, H.H.T., Gong, P., de Boer, W.F. 2018. Mismatch between habitat degradation and seasonal distributions of migratory waterfowl. In Prep.

Yamaguchi, N., Hiraoka, E., Fujita, M., Hijikata, N., Ueta, M., Takagi, K., Konno, S., Okuyama, M., Watanabe, Y., Osa, Y., Morishita, E., Tokita, K., Umada, K., Fujita. G., Higuchi, H. 2008. Spring migration routes of mallards (Anas platyrhynchos) that winter in Japan, determined from satellite telemetry. Zoological Science, 25:875-881. 
Yin, S., Kleijn, D., Müskens, G.J.D.M., Fouchier, R.A.M., Verhagen, J.H., Glazov, P.M., Si, Y., Prins, H.H.T., de Boer, W.F. 2017. No evidence that migratory geese disperse avian influenza viruses from breeding to wintering ground. PLoS One, 12:e177790.

Yong, D.L., Liu, Y., Low, B.W., Espanola, C.P., Choi, C.Y., Kawakami, K. 2015. Migratory songbirds in the East Asian-Australasian flyway: A review from a conservation perspective. Bird Conservation International, 25:1-37.

Zhang, Y., Jia, Q., Prins, H.H.T., Cao, L., de Boer, W.F. 2015. Effect of conservation efforts and ecological variables on waterbird population sizes in wetlands of the Yangtze River. Scientific Reports, 5:17136.

Zhao, M., Christie, M., Coleman, J., Hassell, C., Gosbell, K., Lisovski, S., Minton, C., Klaassen, M. 2017. Time versus energy minimization migration strategy varies with body size and season in long-distance migratory shorebirds. Movement Ecology, 5:23.

Zhou, L., Ren, R., Yang, L., Bao, C., Wu, J., Wang, D., Li, C., Xiang, N., Wang, Y., Li, D., Sui, H., Shu, Y., Feng, Z., Li, Q., Ni, D. 2017. Sudden increase in human infection with avian influenza A (H7N9) virus in China, September-December 2016. Western Pacific Surveillance and Response Journal, 8:6-14. 


\section{Summary}




\section{Summary}

Millions of birds undertake seasonal migration between breeding and wintering sites. Bird migration causes various ecological effects such as affecting local predator-prey relationships and transporting pathogens, seeds and energy. Among these effects, pathogen dispersal has caused a large debate, including how migratory birds disperse pathogens, and how migratory birds interact with pathogens during their migration. A better understanding of pathogen dispersal is urgently needed because it is relevant to both wildlife and human health. Therefore, empirical studies such as spatial-temporal correlations between infection outbreaks and migration trajectories, genetic studies between outbreaks and infection dynamics in migratory populations, and theoretical modelling have been carried out.

Although previous studies suggested that bird migration can disperse pathogens along migration route of birds, however, bird migration may also reduce infection prevalence and limit pathogen dispersal by so-called 'migratory escape' and 'migratory culling'. Therefore, migration can affect pathogen dispersal and infection prevalence in a population, but its effects may vary among host-pathogen systems.

Most migratory bird species use stopover sites where they refuel and rest during their migration. The movement of birds connects these stopover sites, together with their breeding and wintering sites, in a migration network. Some stopover sites are selected over others, and this selection varies between species, and over time and space within a certain species, so configurations of migration network change, and can be characterised by 'serial stopover sites' (when the birds are migrating over a narrow front) or 'parallel stopover sites' (when migration occurs over a broad front). These patterns have been clearly observed by previous studies through satellite telemetry tracking.

Apart from various spatial configurations, migratory birds vary their timing of departure as well, and this synchrony in departure can vary from weeks to months. The combinations of the various patterns in network configuration and departure synchrony influence aggregation size, resting duration at stopover sites, and contact probabilities among individuals. However, the effects of network configuration and migration synchrony on pathogen dispersal and infection dynamic has not been fully examined yet.

Furthermore, although stopover sites are crucial for migratory birds to complete their migration, the availability of suitable stopover sites in the East Asian-Australasian Flyway 
decreased, especially in China, where $30 \%$ of natural wetlands were lost over the last two decades. In reaction to this wetland loss, the migration network becomes restricted to fewer remaining sites, and bird abundance on the remaining sites correspondingly increases. This intensive use of remaining sites may increase the probability of site infection and infection prevalence in the population. However, the impact of wetland loss on infection dynamics has not been investigated before.

Network analysis is a promising tool to analyse pathogen dispersal by migratory birds. For example, it was used to study the dispersal of severe acute respiratory syndrome, and foot and mouth disease. Real world networks such as trade networks and transport networks, are often recognized as scale-free networks. Such networks are very efficient in dispersing pathogens over the network. When extensive habitat loss occurs, however, the scale-free topology could disappear, which can make pathogen dispersal among sites less effective. Alternatively, the infection prevalence in migratory birds might be increased due to larger aggregations at remaining sites. However, the topologies of bird migration networks have rarely been examined in empirical studies or in theoretical work, although it could provide a better understanding of the variables that influence pathogen dispersal.

In this study, I focused on avian influenza viruses (AIVs), an influenza virus that is adapted to infect birds, especially waterfowl, such as many duck, goose and swan species. It infects mainly birds, but in some cases, it can also infect mammals such as swine, horses, whales, bats and humans. Avian influenza viruses can be classified into two groups: low pathogenic avian influenza viruses (LPAIVs) and highly pathogenic avian influenza viruses (HPAIVs), based on the severity of the illness that they cause in chickens. Infection of LPAIVs in wild birds only causes mild symptoms, however, subtypes H5 and H7 can mutate to HPAIV when multiple low pathogenic avian influenza subtypes co-infect one host, especially in poultry farms with low bio-security and large numbers of domestic birds.

HPAIV attracted a lot of attention due to their rapid dispersal and large impacts. For example, the highly pathogenic avian influenza H5N1 was for the first time detected in a domestic goose in 1996 in Guangdong, China, and then detected in wild birds in 2002 in Hong Kong, China. It suggested that migratory wild birds were infected with avian influenza virus from domestic birds. Furthermore, a H5N1 outbreak was detected in wild birds in 2005 at Qinghai Lake, China, killing more than 6000 birds. Within a few months, the H5N1 was detected in Europe, Middle East and Africa. Although intensive studies have focused on 
dispersal of avian influenza virus, most of these were carried out in duck species such as mallard. Few studies have examined the role of other migratory waterfowl, such as goose species. Since HPAIV can spill-over to humans and could cause high mortality rates, it is urgent to understand the mechanism of avian influenza virus dispersal.

Overall, the aim of this study is to obtain a better understanding of the impact of migration on dispersing avian influenza virus by combining modelling and spatial-temporal statistical approaches.

In chapter 2, I examined the infection dynamic of LPAIV in migratory goose species. I analysed throat and cloaca samples that were collected from three species from their breeding sites, stopover sites and wintering sites. I examined the infection prevalence on these sites, and analysed the temporal patterns in infection prevalence. My results showed that migratory geese were probably not infected with LPAIVs before arrival on their wintering sites, as they had a relatively low infection prevalence just after the arrival, but the prevalence increased over the winter period. My results suggest that migratory geese were exposed to the LPAIV shortly after their arrival, indicating that they might not disperse the virus during autumn migration, but more likely disperse it during spring migration.

In chapter 3, I examined the effects of spatial and temporal migration patterns on the dynamics of low pathogenic avian influenza infection prevalence. I applied a discrete-time SIR (Susceptible-Infected-Recovered) model, with environmental transmission and migration, to various migration strategies, including networks with serial, and/or parallel stopover sites, and with various levels of migration synchrony. My results showed that both an increase in the number of serial stopover sites and an increase in the synchrony of departure timing reduces the infection prevalence due to 'migratory escape'. Whereas increasing the number of parallel stopover sites increases the infection prevalence, because the migratory population is exposed to a larger total amount of virus in the environment, speeding-up the accumulation of infections. Furthermore, my simulations suggest that if migratory species adopt a migration pattern with multiple serial stopover sites and with high migration synchrony, the AIV transmission becomes less efficient in the population, and thereby lead to a low infection prevalence.

In chapter 4, I tested whether habitat loss facilitates pathogen dispersal and infection prevalence in a migratory population. I identified all potential stopover sites of greater whitefronted geese in the East Asian-Australasian Flyway, and constructed migration networks 
with various habitat loss scenarios. I used Agent-based models to simulate bird migration over various migration networks, and integrated these with SIR-type infection dynamics to simulate epidemiological processes. I studied the dynamic of infection prevalence in migratory populations and the infection probability at stopover sites under various habitat loss scenarios. Consistent with my previous findings, I found that migration can reduce infection prevalence in a population due to migratory escape. However, the population cannot lose infection completely due to a relay effect that resting birds can be infected with avian influenza viruses that were shed by previous resting birds. Moreover, under severe levels of habitat loss, i.e., removing all sites with area decrease, geese start aggregating earlier in the fewer remaining sites, and thereby facilitate infection. In addition, habitat loss increases the infection probability for the remaining sites due to a larger amount of visiting birds, which potentially carry the virus. These results thus suggest that habitat loss facilitates outbreak of avian influenza virus infection in a migratory population and increases the probability for pathogen dispersal.

In chapter 5, I summarized the historical HPAIV outbreaks in swan goose and bar-headed goose and compared their contact opportunities with avian influenza outbreaks areas and with the distribution areas of domestic birds in their migration corridors. Their migration corridors were estimated from GPS tracking data, using a dynamic Brownian Bridge Movement Models (dBBMMs). I found that swan geese were more likely to come into contact with outbreak areas, but fewer outbreaks occurred in their population. In contrast to swan geese, bar-headed geese were less likely to come into contact with outbreak areas, but more outbreaks occurred in their population. Moreover, I found that the densities of domestic ducks in the migratory corridor of swan geese were higher compared with those of barheaded geese. On the basis of these findings, I proposed two possible explanations for these contrast infection patterns. First, frequent contact and a long contact history with domestic ducks may have caused higher levels of innate immunity in swan goose. Second, the migration strategy of bar-headed goose may compromise immunity, so that bar-headed geese are more vulnerable to HPAIV.

These studies broaden the knowledge of bird species' roles in affecting avian influenza virus infection dynamic and the virus dispersing during seasonal migration. The environmental transmission plays an important role in keeping the virus circulating in a migratory population, and I therefore recommend increasing the efforts for monitoring virus concentrations in water bodies used during migration. Moreover, since swan goose may have 
higher levels of innate immunity and be more resistant to infection by HPAIVs, I also recommend increasing active surveillance that covers not only the well-known affected goose species such as bar-headed goose, but also goose species which are less often found dead due to infection with HPAIVs.

Although this study focused on the interactions between host migration and infectious pathogens in the goose-AIVs system, the findings can be generalized to other migratory hostpathogen systems such as butterflies-parasite systems, if the pathogen can persist in the environment. 
Samenvatting 


\section{Samenvatting}

Miljoenen vogels ondernemen seizoengebonden migratie tussen broed- en overwinteringsplaatsen. Vogelmigratie veroorzaakt verschillende ecologische effecten, zoals het beïnvloeden van lokale predator-prooi relaties, en het verspreiden van pathogenen, zaden en energie. Van deze effecten heeft de verspreiding van pathogenen tot een groot debat geleid. Een belangrijke vraag is hoe trekvogels pathogenen verspreiden en hoe trekvogels tijdens hun migratie interacteren met ziekteverwekkers. Een beter begrip van de verspreiding van pathogenen is dringend nodig omdat het relevant is voor zowel dieren in het wild als de menselijke gezondheid. Daarom zijn empirische studies uitgevoerd die correlaties in tijd en ruimte onderzochten tussen infectie-uitbraken en migratieroutes. Ook zijn er genetische studies gedaan omtrent uitbraken en de infectiedynamica in migrerende populaties, alsmede theoretische modellering.

Eerdere studies suggereerden dat pathogenen verspreid kunnen worden via de migratieroute van trekvogels. Vogelmigratie kan echter ook de prevalentie van infecties verminderen en de verspreiding van pathogenen beperken via zogenaamde 'migratoire ontsnapping' en 'migratoire ruiming'. Daarom kan migratie van invloed zijn op de verspreiding van pathogenen en de prevalentie van infecties in een populatie, maar de effecten ervan kunnen per systeem verschillen.

De meeste trekvogelsoorten gebruiken stopplaatsen waar ze bijtanken en rusten tijdens hun migratie. De migratie van vogels verbindt deze stopplaatsen, samen met hun broed- en overwinteringslocaties, in een migratienetwerk. Sommige stopplaatsen worden bij voorkeur gekozen boven andere, en deze voorkeur varieert tussen soorten en in tijd en ruimte binnen een bepaalde soort. Dus, de configuratie van migratienetwerken verandert en wordt gekenmerkt door 'seriële stopplaatsen' (wanneer de vogels migreren over een breed front) of 'parallelle stopplaatsen' (wanneer migratie over een smal front plaatsvindt). Deze patronen zijn duidelijk waargenomen in eerdere studies dankzij satelliettelemetrie.

Afgezien van verschillende ruimtelijke configuraties, varieert ook de vertrektijd van trekvogels en deze synchronie in het vertrekmoment kan variëren van weken tot maanden. De combinaties van de verschillende patronen in netwerkconfiguratie en synchronie in het vertrekmoment beïnvloeden de aggregatiegrootte, de rustduur op stopplaatsen, en de kans op contact tussen individuen. De effecten van netwerkconfiguratie en migratiesynchronie op de verspreiding van pathogenen en infectiedynamiek zijn echter nog niet volledig onderzocht. 
Hoewel stopplaatsen cruciaal zijn voor trekvogels om hun migratie te voltooien, is de beschikbaarheid van geschikte plaatsen in de Oost-Aziatische Australazische trekroute afgenomen, vooral in China, waar 30\% van de natuurlijke wetlands in de afgelopen twee decennia verloren zijn gegaan. Als reactie op dit verlies aan wetlands wordt het migratienetwerk beperkt tot minder stopplaatsen en neemt het aantal vogels op die locaties aanzienlijk toe. Dit intensieve gebruik van de resterende stopplaatsen kan de kans op infectie in zo'n stopplaats en de prevalentie van infecties in de populatie vergroten. De impact van het verlies van wetlands op de infectiedynamiek is echter nog niet eerder onderzocht.

Netwerkanalyse is een veelbelovend hulpmiddel om de verspreiding van pathogenen door trekvogels te analyseren. Het werd bijvoorbeeld gebruikt om de verspreiding van het 'ernstig acuut respiratoir syndroom' (SARS) en mond- en klauwzeer te bestuderen. Netwerken zoals handelsnetwerken en transportnetwerken worden vaak erkend als schaalvrije netwerken. Dergelijke netwerken zijn zeer efficiënt in het verspreiden van pathogenen binnen het netwerk. Wanneer echter ernstig habitatverlies optreedt, kan de schaalvrije topologie verdwijnen, waardoor de verspreiding van pathogenen tussen locaties minder effectief wordt. Aan de andere kant kan de infectieprevalentie bij trekvogels juist toenemen als gevolg van een grotere aggregatie van individuen op de resterende locaties. De topologieën van vogelmigratienetwerken zijn echter zelden onderzocht in empirische studies of in theoretisch werk, hoewel ze kunnen bijdragen aan een beter begrip van de variabelen die van invloed zijn op de verspreiding van pathogenen.

In deze studie heb ik gefocust op vogelgriepvirussen (AIV's), een groep van virussen die zijn aangepast om vogels te infecteren, vooral watervogels zoals eenden, ganzen en zwanen. Vogelgriep infecteert voornamelijk vogels, maar in sommige gevallen infecteert het ook zoogdieren zoals varkens, paarden, walvissen, vleermuizen en mensen. Vogelgriepvirussen kunnen worden ingedeeld in twee groepen: laag-pathogene vogelgriepvirussen (LPAIV's) en hoog-pathogene vogelgriepvirussen (HPAIV's), een indeling die is gebaseerd op de ernst van de ziekte die zij bij kippen veroorzaken. Infectie van LPAIV's bij wilde vogels veroorzaakt slechts milde symptomen, maar subtypes H5 en H7 kunnen muteren naar HPAIV wanneer meerdere laag-pathogene AIV-subtypen één gastheer co-infecteren, met name in pluimveebedrijven met geringe biologische veiligheid en grote aantallen vogels.

HPAIV heeft veel aandacht getrokken vanwege de snelle verspreiding en grote impact. Zo werd het hoog-pathogene vogelgriepvirus $\mathrm{H} 5 \mathrm{~N} 1$ voor het eerst waargenomen in een gans in 
Guangdong, China in 1996, en vervolgens weer in 2002 in wilde vogels in Hongkong, China. Dit suggereerde dat trekvogels besmet waren met het vogelgriepvirus van tamme vogels. In 2005 werd een H5N1-uitbraak geconstateerd bij wilde vogels in Qinghai Lake, China, waarbij meer dan 6000 vogels werden gedood. Binnen een paar maanden werd H5N1 gedetecteerd in Europa, het Midden-Oosten en Afrika. Hoewel intensieve studies zich hebben toegespitst op de verspreiding van het vogelgriepvirus, werden de meeste daarvan uitgevoerd bij verschillende soorten eenden zoals de wilde eend. Weinig studies hebben de rol van andere migrerende watervogels onderzocht, zoals die van ganzen. Omdat HPAIV kan overslaan naar mensen en hoge sterftecijfers kan veroorzaken, is er urgentie bij het beter begrijpen van de variabelen die de verspreiding van vogelgriepvirussen beïnvloeden.

Het doel van deze studie is om een beter inzicht te krijgen in de impact van migratie bij trekvogels op het verspreiden van het vogelgriepvirus door modellering en ruimtelijktemporele statistische benaderingen te combineren.

In hoofdstuk 2 onderzocht ik de infectiedynamiek van LPAIV in migrerende ganzen. Ik analyseerde keel- en cloacamonsters die werden verzameld van drie soorten ganzen uit hun broedplaatsen, stopplaatsen en overwinteringsplaatsen. Ik onderzocht de infectieprevalentie in deze locaties en analyseerde de temporele patronen in de infectieprevalentie. Mijn resultaten tonen aan dat migrerende ganzen waarschijnlijk niet besmet waren met LPAIV's vóór hun aankomst op hun overwinteringsplaatsen, omdat ze een relatief lage infectieprevalentie hadden net na hun aankomst, maar de prevalentie steeg tijdens de winterperiode. Mijn resultaten suggereren dat migrerende ganzen kort na hun aankomst werden blootgesteld aan LPAIV, wat er op kan duiden dat ze het virus niet verspreiden tijdens de herfstmigratie, maar waarschijnlijk tijdens de voorjaarstrek.

In hoofdstuk 3 onderzocht ik de effecten van migratiepatronen in tijd en ruimte op de dynamiek van de infectieprevalentie van LPAIV. Ik heb een SIR (Susceptible-InfectedRecovered)-model met discrete tijd toegepast, met indirecte transmissie en migratie via de omgeving, en verschillende migratiestrategieën, inclusief netwerken met seriële en / of parallelle stopplaatsen en met verschillende niveaus van migratiesynchronisatie. Mijn resultaten toonden aan dat zowel een toename van het aantal locaties met seriële stopplaatsen als een toename in de synchronie van de timing van vertrek de infectieprevalentie vermindert als gevolg van 'migratoire ontsnapping'. Een toename in het aantal parallelle stopplaatsen verhoogt de infectieprevalentie echter, omdat de migrerende populatie wordt blootgesteld aan 
een grotere totale hoeveelheid virus in het milieu, waardoor de accumulatie van infecties wordt versneld. Verder suggereren mijn simulaties dat als migrerende soorten een migratiepatroon aannemen met meerdere seriële stopplaatsen en met een hoge migratiesynchronie, de AIV-transmissie minder efficiënt wordt in de populatie en daardoor leidt tot een lage infectieprevalentie.

In hoofdstuk 4 heb ik getest of habitatverlies de verspreiding en infectieprevalentie van pathogenen in een migrerende populatie bevordert. Ik identificeerde alle potentiële stopplaatsen van kolganzen in de Oost-Aziatische Australazische trekroute en modelleerde migratienetwerken met verschillende scenario's voor habitatverlies. Ik gebruikte 'agentbased' modellen om vogelmigratie over verschillende migratienetwerken te simuleren, en integreerde deze met infectiedynamica van het SIR-type om epidemiologische processen te simuleren. Ik bestudeerde de dynamiek van de infectieprevalentie in migrerende populaties en de infectiekans op stopplaatsen onder verschillende scenario's van habitatverlies. In overeenstemming met mijn eerdere bevindingen, ontdekte ik dat migratie de infectieprevalentie in een populatie kan verlagen als gevolg van 'migratoire ontsnapping'. De populatie kan de infectie echter niet volledig verliezen als gevolg van een relaiseffect, waarbij rustende vogels kunnen worden besmet met het vogelgriepvirus dat werd achtergelaten door eerdere rustende vogels. Bovendien zullen ganzen onder ernstige niveaus van habitatverlies, d.w.z. het verwijderen van alle plaatsen met oppervlakteafname, eerder aggregeren in de paar plaatsen die over blijven, waardoor infectie kan toenemen. Bovendien verhoogt het verlies van habitat de infectiekans voor de resterende locaties vanwege een groter aantal vogels in die locaties, die mogelijk het virus bij zich dragen. Deze resultaten suggereren dus dat habitatverlies de uitbraak van vogelgriepvirus in trekvogels vergemakkelijkt en de kans op verspreiding ervan vergroot.

In hoofdstuk 5 vat ik de historische HPAIV-uitbarstingen in zwaanganzen en Indische ganzen samen en vergelijk hun contactmogelijkheden met gebieden waar vogelgriepvirussen zijn uitgebroken en met het verspreidingsgebied van gedomesticeerde vogels in hun trekroute. De trekroutes werden geschat op basis van GPS-trackinggegevens, met behulp van dynamische Brownian Bridge Movement Models (dBBMM's). Ik vond dat zwaanganzen eerder in contact kwamen met uitbraakgebieden, maar dat er minder uitbraken voorkwamen in hun populatie. In tegenstelling tot zwaanganzen, hadden de Indische ganzen minder kans om in contact te komen met de uitbraakgebieden, maar er deden zich meer uitbraken voor in hun populatie. Bovendien vond ik dat de dichtheden van gedomesticeerde eenden in de 
trekroute van zwaanganzen hoger waren in vergelijking met die van de Indische ganzen. Op basis van deze bevindingen, kwam ik met twee mogelijke verklaringen voor deze contrasterende infectiepatronen. Ten eerste kan frequent contact en een lange contactgeschiedenis met eenden een hogere mate van aangeboren immuniteit bij zwaanganzen hebben veroorzaakt. Ten tweede kan de migratiestrategie van de Indische gans hun immuniteit verminderen, zodat Indische ganzen kwetsbaarder zijn voor HPAIV.

Deze studies verbreden de kennis van de rol van verschillende soorten vogels bij het verspreiden van vogelgriepvirussen tijdens seizoensgebonden migratie. De overdracht van vogelgriepvirussen via de omgeving speelt een belangrijke rol bij het in stand houden van de circulatie van deze virussen in migrerende populaties, en daarom pleit ik voor meer inspanning voor het monitoren van virusconcentraties in waterlichamen die tijdens de vogeltrek worden gebruikt. Aangezien zwaanganzen mogelijk een hogere mate van aangeboren immuniteit hebben en daardoor meer resistent zijn tegen infectie met HPAIV's, raad ik ook aan om actieve surveillance te verhogen die niet alleen betrekking heeft op de bekende ganzensoorten, zoals Indische ganzen, maar ook soorten die minder vaak dood worden aangetroffen als gevolg van infectie met HPAIV's.

Hoewel deze studie zich richtte op de interacties tussen migratie van ganzen en vogelgriepvirussen, kunnen mijn bevindingen worden gegeneraliseerd naar andere systemen van migrerende gastheren en hun pathogenen, zoals vlinders en hun parasieten, als het pathogeen ook in het milieu kan blijven bestaan. 
摘要

摘 要 


\section{摘要}

每年約有數以百万計的鳥類在其繁殖地與越冬地之間遷徙。鳥類遷徙會帶來諸多 生態影響，例如改變䝓物-捕食者關系，傳播病原體、种子等等。在這些生態影響之 中，病原體傳播引起了大量的關注與討論。鍳于鳥類遷徙所引發的病原體傳播與動物 和人類的健康息息相關，深入理解其傳播機理是十分緊迫與必要的。蝙此，疾病爆發 與鳥類遷徙路徑之間的時空相關性研究、疾病爆發間的基因相關性分析、遷徙种群內 病原體感染動態以及相關理論模型研究被廣泛應用以了解其傳播機理。

前人研究發現，鳥類在遷徙過程中可以携帶病原體，并在其遷徙過程中進行長距 離傳播。然而，鳥類遷徙也可以通過 “遷徙逃離 ( migratory escape )” 和 “遷徙清除 （ migratory culling）”等過程，使种群內感染率的下降，并降低病原體的空間傳播距 離。由此可見, 鳥類遷徙能够影響病原體的傳播及种群內感染率的動態變化, 但其影 響却可能因宿主-病原體關系而异。

在鳥類遷徙過程中，大多數鳥類會利用停歇地來休息并補給能量以維持遷徙。鳥 類在不同停歇地之間的移動，將停歇地連接成遷徙網絡。同時，遷徙鳥類可能更傾向 于利用某些滿足特定條件的停歇地，而這种傾向性受到物种、時間及空間的影響。因 此，由鳥類遷徙所形成的遷徙綱絡的綱絡結構也隨之不同。野外衛星追踪數据表明， 鳥類遷徙過程會采取 “寬鋒型”和 “窄鋒型”兩种策略。因此，我們簡單將遷徙網絡

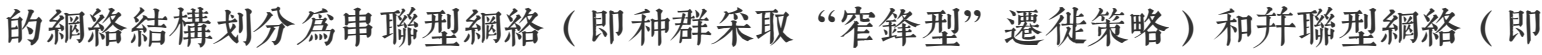
种群采取 “寬鋒型”遷徙策略）。

除空間策略的不同以外，遷徙個體在其遷徙起始時間上也存在個體間差异 ( 即遷 徙同步性差异)，而這种差异可能長達數周甚至數月。雖然遷徙過程中的時空差异 （網絡結構差异及遷徙同步性差异）影響遷徙鳥類的時空聚集、停歇時間以及個體間 
接觸㯕率，但前人的研究倘未分析網絡結構以及遷徙同步性對病原體傳播以及种群內 感染率的影響。

此外, 雖然遷徙途中的停歇地對遷徙鳥類完成其遷徙生活史十分重要, 但東亞澳大利亞遷徙路綫上的適宜停歇地數量却在逐漸下降，這一趨勢在中國境内尤其明 顯。在過去的二十年中, 約有 $30 \%$ 的濕地喪失, 而這一趨勢將導致候鳥遷徙網絡由更 少數量的適宜停歇地構成。同時，遷徙個體將不得不聚集在更少的停歇地上，導致停 歇地中遷徙個體數量上升，進而可能導致疾病爆發風險以及病原體傳入停歇地的風險 上升。然而，適宜停歇地的喪失對于种群內疾病感染率以及病原體空間傳播的影響劣 未得到充分的研究。

網絡分析非常適合被用于研究由宿主移動所導致的病原體傳播過程。例如, 網絡 分析已經被應用于研究嚴重急性呼吸綜合症 ( SARS) 及口蹄疫 ( foot and mouth disease ）的傳播。大多數現實網絡的網絡結構鳻無尺度網絡（scale-free network），如 貿易網絡、運輸網絡等，而無尺度網絡可以高效地傳播病原體。但當大量停歇地喪失 (即大量網絡節點消失) 時, 綱絡可能喪失其無尺度綱絡結構特征, 并導致病原體傳 播效率下降。綜上所述, 停歇地喪失可能會增加疾病爆發以及病原體傳入停歇地的概 率，但同時也可能降低病原體在遷徙路綫上的傳播效率。雖然梁入了解停歇地喪失對 病原體傳播及其影響因子有深遠影響，但前人對此方面的研究十分有限。

禽流感 ( Avian Influenza ) 是一种全球流行的人畜共患病，其主要宿主是鳥類， 尤其是水禽類，包括鴨類、雁類及我類，但也會感染哺乳動物，如猪、馬、鯨魚、蝙 蝠，甚至人類。根据對䌖的不同致病性，禽流感病毒可以被分爫高致病性禽流感 (HPAIVs) 和低致病性禽流感(LPAIVs)。其中, 低致病性禽流感一般不會引起宿主的 臨床症狀，但當 $\mathrm{H} 5$ 和 $\mathrm{H} 7$ 兩個亞型同時感染同一個宿主個體，它們可能會通過基因重 
組或基因突變產生高致病性禽流感, 這在低衛生保障及高飼養密度的家禽農場中易發 生。

高致病性禽流感可以在短時間內大范圍傳播, 并對動物及人類的健康產生重大影 響。例如，1996 年，高致病性禽流感 H5N1 首次在中國廣東省的家飬大雁中被檢測出 來，隨后又于 2002 年在中國香港的野生鳥中被檢測到。這可能也意味著野生鳥類所携 帶的高致病性禽流感 H5N1 是由家禽傳染。2005 年, 高致病性禽流感 H5N1 在青海湖 的遷徙鳥中大爆發, 導致超過 6000 祇鳥類死亡。緊接著在之后的几個月中, 高致病性 禽流感 H5N1 接連在歐洲、中東以及非洲爆發。雖然前人已經針對禽流感病毒的傳播 機制開展了大量研究, 但大部分研究關注在鴨類, 如綠頭鴨（Anas platyrhynchos）。 前人的研究很少關注其他遷徙鳥類對禽流感病毒傳播過程的影響，如遷徙大雁等。由 于高致病性禽流感能够感染人類, 并引起較高死亡率, 因此, 對于禽流感病毒傳播及 其相關影響因子的研究十分迫切。

綜上所述，本研究結合模型模擬及時空分析等手段，旨在研究鳥類遷徙行爲對禽 流感病傳播的影響。

在第二章中, 我分析了不同遷徙大雁物种种群内低致病性禽流感感染率的時空動 態。我們針對 3 個不同大雁物种种群（豆雁 Anser fabalis、白䝷黑雁 Branta leucopsis 以 及白額雁 Anser albifrons），分別在其繁殖地、停歇地以及越冬地內采集了個體口腔及 泄殖腔樣本, 并檢測這些個體是否感染禽流感病毒。研究結果表明, 遷徙大雁在抵達 其越冬地時, 种群内禽流感感染率非常低。這說明遷徙大雁在其繁殖地、停歇地中感 染禽流感的可能性非常小。此外, 在越冬期間, 禽流感感染率逐漸上升, 這可能說 明, 遷徙大雁所感染的禽流感病毒主要源自于越冬地, 這也意味著, 遷徙大雁可能并 不會在其秋季遷徙過程中傳播禽流感病毒, 相反, 遷徙大雁可能在春季遷徙過程中導 致禽流感病毒的北向傳播。 
在第三章中，我通過模型模擬測試了遷徙時空策略對大雁种群內低致病性禽流感 感染動態的影響。我結合離散時間 SIR（Susceptible-Infected-Recovered）模型、環境傳

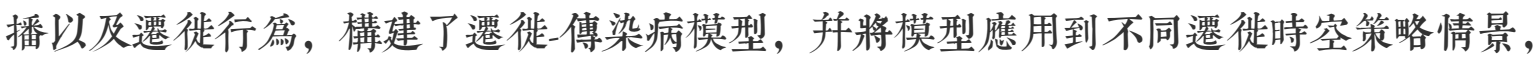
包括串聯綱絡、并連網絡、串并連綱絡以及不同遷徙同步性。結果表明，由于 “遷徙 逃離” 現象的存在，串聯遷徙網絡中停歇地個數的增加以及遷徙同步性的增加會導致 种群內感染率的下降。此外, 并連網絡中停歇地個數的增加會導致感染率的上升, 這 是因雼，同時使用多個停歇地，導致种群在遷徙過程中與更多存留在環境中的禽流感 病毒接觸, 進而增加感染風險。研究還表明, 當遷徙种群利用多個串聯停歇地, 同時 采取高同步性遷徙時, 禽流感在种群內的傳播效率會降低, 從而使种群內感染率相應 下降。

在第四章中, 我研究了停歇地喪失是否會促進禽流感病毒的空間傳播以及遷徙种 群內感染率的上升。首先, 我笁選了由額雁在東亞一澳大利亞遷徙路綫上的所有潜在適 宜停歇地, 并利用這些停歇地構建了遷徙網絡。同時, 我根据停歇地面積的喪失程 度, 分別構建了不同栖息地喪失情景下的遷徙網絡。此外, 我采用“個體窟本模型 (Agent-Based Models) ” 模擬种群在不同綱絡情景中的遷徙過程。我采用了 SIR 模型 模擬种群在不同遷徙綱絡情境下的感染動態, 并分析了禽流感病毒被携帶進入停歇地 的概率。結果表明, 由于 “遷徙逃離” 過程的存在, 遷徙可以導致种群內感染率下 降。然而，遷徙种群并不能通過 “遷徙逃離” 來完全擺脫禽流感病毒，這主要因雹， 更早到達的受感染個體所釋放的病毒在環境中會存留較長時間, 而后續到達的健康個 體在停歇時, 依然會通過環境傳播而受到感染 (滯后效應)。此外, 在最嚴重的停歇 地喪失情景下（即移除所有面積下降的停歇地），遷徙個體不得不更早停止其遷徙， 并聚集在存留的少數停歇地上，而這种高密度的聚集會促進病毒在遷徙個體間傳播。 此外, 由于大量個體集中在少數存留的停歇地上, 進而導致禽流感病毒被携帶進入存 
留停歇地的概率更大。因此, 停歇地的喪失可能會促進禽流感爆發, 并可能提高禽流 感病毒進入現存停歇地的概率。

在第五章中, 我總結了高致病性禽流感在鴻雁（ swan goose）、斑頭雁（barheaded goose ）中的歷史爆發數据，并比較了兩個物种在其遷徙路徑上與高致病性禽流 感爆發、家禽接觸的風險大小。遷徙路徑的估算基于衛星追踪數据，并結合了動態布 朗橋運動模型（dynamic Brownian Bridge Movement Models）。結果表明，鴻雁在其遷 徙路豩中更易與高致病性禽流感爆發接觸，但高致病性禽流感極少在鴻雁种群中爆 發。相反, 斑頭雁在其遷徙路徑中不易與高致病性禽流感爆發接觸，但其种群中却經 常爆發高致病性禽流感。同時, 在鴻雁遷徙路徑中, 家禽的密度遠高于斑頭雁遷徙路 豩中的家禽密度。基于以上發現, 我針對鴻雁與斑頭雁在高致病性禽流感歷史爆發數 据上的差异, 提出兩條假設。首先, 鴻雁與家禽之間的高頻度、長期地接觸歷史可能 導致鴻雁對于高致病性禽流感產生較强的先天免疫。其次, 斑頭雁長距離、高海拔的 遷徙策略，可能會導致免疫力下降，進而導致斑頭雁在高致病性禽流感病毒感染下十 分脆弱。

以上䃑究拓展了我們對于遷徙鳥類在禽流感傳播過程中作用的理解。由于環境傳 播在維持禽流感病毒在遷徙种群內個體間傳播中起到重要作用。因此, 我建議加强對 遷徙季節間停歇地水體禽流感病毒濃度的野外監測。此外, 因爲鴻雁對于高致病性禽 流感可能有較高的免疫力, 建議今后野外監測不僅僅關注在易感物种种群 ( 如斑頭 雁 ），同時監測對于高致病性禽流感具有較好抗性的物种种群（如鴻雁）。

雖然本研究集中討論了遷徙大雁與禽流感病毒之間的相互作用關系，但在其他宿 主-病原體模型中, 如果病原體可以在宿主體外存活, 那本研究結論也同樣適用, 例如 蝴蝶與寄生蟲模型。 


\section{Affiliations of co-authors}




\section{Affiliations of co-authors}

\section{W.F. de Boer, H.H.T. Prins, H.J. de Knegt, Y. Xu}

Resource Ecology Group, Wageningen University and Research, Wageningen, the Netherlands

\section{Kleijn}

Plant Ecology and Nature Conservation Group, Wageningen University and Research, Wageningen, the Netherlands

\section{G.J.D.M. Müskens}

Animal Science Group, Wageningen University and Research, Wageningen, the Netherlands

\section{R.A.M. Fouchier}

Department of Viroscience, Erasmus MC, Rotterdam, the Netherlands

\section{J.H. Verhagen}

Centre for Ecology and Evolution in Microbial Model Systems, Linnaeus University, Växjö, Sweden

\section{P.M. Glazov}

Laboratory of Biogeography, Institute of Geography Russian Academy of Sciences, Moscow, Russia

\section{Y.Si}

Ministry of Education Key Laboratory for Earth System Modelling and Centre for Earth System Science, Tsinghua University, Beijing, China

\section{M.C.M. de Jong}

Quantitative Veterinary Epidemiology Group, Wageningen University \& Research, Wageningen, the Netherlands

\section{N. Batbayar}

Wildlife Science and Conservation Center of Mongolia, Ulaanbaatar, Mongolia

\section{J.Y. Takekawa}

Suisun Resource Conservation District, Suisun City, California, USA

\section{D.J. Prosser}

Patuxent Wildlife Research Center, U.S. Geological Survey, Maryland, USA 


\section{Acknowledgments}




\section{Acknowledgments}

After years of hard work, I successively accomplished this PhD thesis. It is not easy, and it would not be possible without the help and support from my family, supervisors, colleagues and friends. Hereby, I would like to express my appreciation to some of them at the end of this thesis.

Mom and dad, you cannot read this acknowledgment, but I still want to express my gratitude and appreciation to you. Thank you for your understanding and nearly nonconditional support. I must have luckily inherited some of your precious qualities such as diligence and perseverance, otherwise, I should not be able to finish this thesis on time.

Fred, I still remember how nervous I was when we had the Skype interview four years ago. Thank you for giving me this opportunity to work with you. During my $\mathrm{PhD}$ study in Wageningen, I doubted myself from time to time because my knowledge background did not fit to this project very well. However, you are always supportive and encouraging. The production of this thesis could not be so smoothly without your help. You are also very inspiring for finding knowledge gaps in the current research context, which is a very necessary quality for working in academia. Without your unique perspectives, this thesis would have been completely different. I was also inspired by your way of communicating with students. I am still learning it, and it is becoming a very valuable character in me as well. Moreover, thank you for inviting me to assist in your courses, during which I practiced the communication skills that I learned from you, and also had chances to help students.

Herbert, you are the most unique teacher I ever met in my 20+ years' study. You compare me (and all your other students) to a dog. As you explained so many times, your obligation is training a puppy (me) becoming a good hunting dog (independent scientist). I appreciate your logic, especially because in some academic cultures where the teacher-student relationship could be a sort of boss-employee or, even worse, master-slave relationship. I also appreciated what you said that $\mathrm{PhD}$ project is not only about answering scientific questions, but also training persons for being good at finding and solving problems. Thank you for this advice so that I stop looking at myself just as a scientist candidate but started looking at myself as a young person with lots of career possibilities. Another remark that deeply imprinted in my mind is that, as scientist, I should be responsible for what I say and write, and exaggeration should be avoided in academia, especially in the present time when people are reaching out for attention. I love our philosophical discussions, although my expression fluency was often 
impeded by my English. I wonder how our discussions could be developed if the language doesn't stand in our way. You care about my happiness, which is often omitted even by myself. Your care makes me think about why and how I would pursue my career. Thank you for all your inspirations, and hopefully, I can bear them as long as possible.

Yali, thank you for your sharp advice for improving my studies. Your advice always leads me to think from other perspectives. Apart from giving advice, you also listened to me when I was expressing my concerns and worries for my future career, and gave back good suggestions. I appreciate that you would like to be a collaborator and a friend at the same time.

David, thank you for inspiring me in doing scientific research, although we only collaborated for the Chapter 2. I remember that we had so many discussions about the research question in the Chapter 2. You were encouraging me to formulate the question specifically, but I was confused. So, I asked 'How specifically does it need to be?' You answered 'As specific as yes or no.' It was ringing in my head even when I was doing the later Chapters. It was reminding me to focus on one question a time since a board one can easily lead to out-of-focus.

Jente, I am so grateful for your kindness. There were so many moments that I drag you away from your desk and forced you to have a discussion with me. You never said "No". You are always willing to help me with my manuscript even after you moved to Sweden.

Yanjie, you never tired of having a discussion, and you are always willing to share your insights, knowledge and skills with me. Every time when I got stuck, I know I can get immediate help from you, and I don't need to be shy to ask for your help. You made a good example of collaborating and showed why collaboration is important.

The list can go on and on, it is not easy to list all the persons who helped or inspired me for my $\mathrm{PhD}$ study, and it is also not easy to stop list these names either. I also thank Mart,Henjo, Helen, Audrie, Sintayehu, Ntuthuko, Josanne, John and all the co-authors for their contribution to this thesis.

$\mathrm{PhD}$ is not only about doing research but also about growth, development, and maturity. Some of my friends and colleagues know that, apart from the $\mathrm{PhD}$ project, I did lots of volunteer works in the past four years. I met lots of excellent people who helped me 
Acknowledgments

developing. I especially want to express gratitude to Yuanxi Shi, Jing Luo, Yanqiu Jiang, Hui Tan, Chenxinhui Xu and Huihua Zhou for making a good example of taking responsibilities. 
Short biography 


\section{Short biography}

Shenglai Yin was born on $29^{\text {th }}$ October 1987 in Tianjin,

China. He spent most of his childhood in a small village where he had daily contact with rivers, frogs, insects and vegetation. In 2006, he enrolled in the Nanjing University of Information Science and Technology to study ecology.

During his undergraduate study, he was fascinated by ecology, and also by Chinese and Indian traditional philosophy. In 2009, he participated in research projects, entitled 'Numerical simulation for effects of enhanced

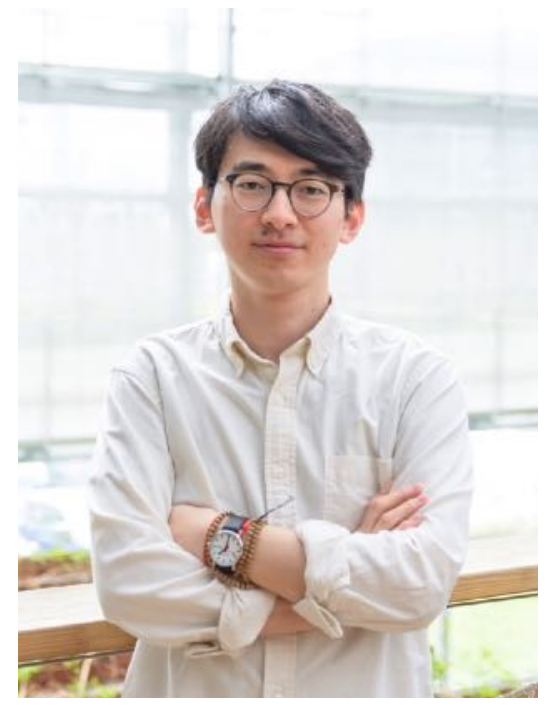
surface UV-B and $\mathrm{O}_{3}$ on crops' and 'Effects of land-use type on soil carbon flux'. With the first project, he wrote his BSc thesis and awarded as an excellent graduate.

In 2006, he enrolled in Nanjing University to pursue his MSc degree in ecology. During 2006-2010, he participated in the research project, entitled 'Assessing coastal wetlands under global climate changes', for measuring greenhouse gases emission in a costal wetland where was dominated by invasive plant Spartina alterniflora. He also part-timely joined in other research projects such as waste water treatment and water quality monitoring.

In 2010, he obtained a PhD scholarship from Chinese Scholarship Council (CSC). In the same year, he enrolled in Wageningen University \& Research to pursue his $\mathrm{PhD}$ degree in Resource Ecology Group under the supervision of Dr. Fred de Boer and Prof. Dr. Herbert Prins. He mainly studied the impacts of goose migration on infection dynamic of avian influenza virus and the virus dispersal. 


\section{Publications}




\section{Publications}

Published

S. Yin, D. Kleijn, G.J.D.M. Müskens, R.A.M. Fouchier, J.H.Verhagen, P.M. Glazov, Y. Si, H.H.T. Prins, W.F.de Boer. No evidence that migratory geese disperse avian influenza viruses from breeding to wintering ground. PLoS ONE 12(5): e0177790. https://doi.org/10.1371/journal.pone.0177790.

In preparation

S. Yin, H.J. de Knegt, M.C.M. de Jong, Y. Si, H.H.T. Prins, W.F. de Boer. Migration pattern influences pathogen prevalence: modelling the effects of migration network configuration and migration synchrony on infection prevalence in a migratory population. PLoS Computational Biology. In revision.

Y. Xu, Y. Si, S. Yin, W. Zhang, M. Grishchenko, H.H.T. Prins, P. Gong, W.F. de Boer. Species-dependent exposure to habitat degradation in relation to seasonal distributions of migratory waterfowl. Landscape Ecology. In revision.

S. Yin, M.C.M. de Jong, Y. Xu, H.H.T. Prins, W.F. de Boer. Habitat loss facilitates infection outbreak and pathogen dispersal: An agent-based model of infected migratory waterfowl. Submitted.

S. Yin, Y. Xu, N. Batbayar, J.Y. Takekawa, Y. Si, D.J. Prosser, H.H.T. Prins, W.F. de Boer. Comparing outbreak patterns of highly pathogenic avian influenza viruses between Barheaded goose and Swan goose. 


\section{PE\&RC training and education statement}




\section{PE\&RC training and education statement}

With the training and education activities listed below the $\mathrm{PhD}$ candidate has complied with the requirements set by the C.T. de Wit Graduate School for Production Ecology and Resource Conservation (PE\&RC) which comprises of a minimum total of 32 ECTS $(=22$ weeks of activities)

\section{Review of literature (6 ECTS)}

- Migration network and avian influenza virus; Delft University

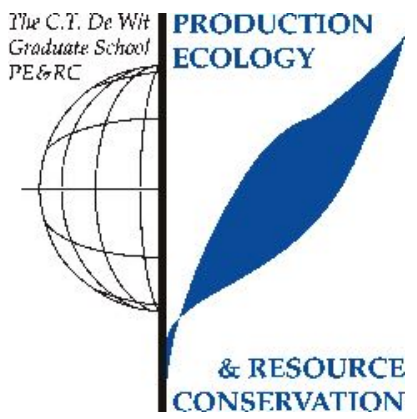
of Technology

\section{Writing of project proposal (4.5 ECTS)}

- Impacts of migration on prevalence of avian influenza infection in a migratory population

\section{Post-graduate courses (9.4 ECTS)}

- Introduction to R for statistical analysis; SENSE

- Art of modelling; PE\&RC

- Learning and gaining from your model: a course in analysis, application, and publication of individual/agent-based models; Technische Universität, Dresden

- Machine learning for spatial data; PE\&RC

- Towards a global one health: an interdisciplinary lens to explore synergies, trade-offs and pathways for food systems transitions; WIAS (2018)

Deficiency, refresh, brush-up courses (8 ECTS)

- Ecological methods; PE\&RC (2014)

- Disease ecology: new frontiers; a capita Selecta series; PE\&RC (2014)

\section{Competence strengthening / skills courses (4.5 ECTS)}

- Project and time management; WGS (2014)

- Techniques for writing and presenting a scientific paper; WGS (2015)

- $\quad$ Scientific writing; WGS (2015)

\section{PE\&RC Annual meetings, seminars and the PE\&RC weekend (2.4 ECTS)}

- PE\&RC Introduction weekend (2014)

- PE\&RC Mid-term weekend (2015)

- PhD Symposium (2016)

- PE\&RC Last year weekend (2017)

Discussion groups / local seminars / other scientific meetings (4.1 ECTS)

- Ecological theory and application (2015)

- Wageningen Evolution and Ecology Seminars (WEES) seminar (2015-2017)

- R Users meeting (2015-2018)

- Masterclass: one health approach to infectious diseases (2017)

International symposia, workshops and conferences (3.1 ECTS)

- Netherlands Annual Ecology Meeting (2014, 2018)

- Impact of environmental changes on infectious diseases (2017)

\section{Lecturing / Supervision of practicals / tutorials (9.3 ECTS):}

- Animal ecology (2015-2017)

- Ecological method (2016)

- Disease ecology (2017) 
Colophon

\section{Colophon}

Cover designed by Ling Yang.

The research described in this thesis was financially supported by Chinese Scholarship Council and LEB fund (Fonds Landbouw Export Bureau 1916-1918).

Financial support from Wageningen University for printing this thesis is gratefully acknowledged.

Lay-out and print by: Digiforce B.V. || Uitgeverij Boxpress 